\title{
WestVirginiaUniversity
}

THE RESEARCH REPOSITORY @ WVU

Graduate Theses, Dissertations, and Problem Reports

2016

\section{The Effect of Chemotherapy on Stromal Components of the Bone}

Marrow

lan Woodrow Hare

Follow this and additional works at: https://researchrepository.wvu.edu/etd

\section{Recommended Citation}

Hare, lan Woodrow, "The Effect of Chemotherapy on Stromal Components of the Bone Marrow" (2016). Graduate Theses, Dissertations, and Problem Reports. 5764.

https://researchrepository.wvu.edu/etd/5764

This Dissertation is protected by copyright and/or related rights. It has been brought to you by the The Research Repository @ WVU with permission from the rights-holder(s). You are free to use this Dissertation in any way that is permitted by the copyright and related rights legislation that applies to your use. For other uses you must obtain permission from the rights-holder(s) directly, unless additional rights are indicated by a Creative Commons license in the record and/ or on the work itself. This Dissertation has been accepted for inclusion in WVU Graduate Theses, Dissertations, and Problem Reports collection by an authorized administrator of The Research Repository @ WVU.

For more information, please contact researchrepository@mail.wvu.edu. 


\title{
The Effect of Chemotherapy on Stromal Components of the Bone Marrow
}

\author{
lan Woodrow Hare
}

\author{
Dissertation Submitted \\ to the College of Medicine \\ at West Virginia University
}

in partial fulfillment of the requirements for the degree of

Doctor of Philosophy in

Immunology and Microbial Pathogenesis

\author{
Laura F Gibson, Ph.D., Chair, Mentor \\ John Barnett, Ph.D. \\ William Petros, Pharm.D., FCCP \\ John Ruppert, M.D., Ph.D. \\ James Sheil, Ph.D.
}

Department of Microbiology, Immunology and Cell Biology

Morgantown, West Virginia

2016

Keywords: Mesenchymal Stem Cell, Osteoblast, Bone Marrow, Chemotherapy

Copyright 2016 lan Hare 


\title{
ABSTRACT
}

\section{The Effect of Chemotherapy on Stromal Components of the Bone Marrow}

\author{
lan Woodrow Hare
}

The cells comprising the stromal compartment of the bone marrow microenvironment are critical to the maintenance of several homeostatic processes of the body. For example, mesenchymal stem cells (MSCs) and osteoblasts are vital to the regulation of differentiation and quiescence of hematopoietic cells, maintaining the skeletal system, and regulating tumor microenvironments. In addition to contributing to these processes, MSCs display several properties that make them favorable for the use in transplantation therapies. The work described herein summarizes the means by which chemotherapy damages these cells, and potential consequences of such damage with regard to their function.

Previously, our laboratory has investigated chemotherapy induced damage of osteoblast potential to support hematopoiesis, describing an increased presence of tumor growth factor beta (TGF- $\beta$ ) and interleukin- 6 as contributing factors. We have expanded upon these observations to describe damage elicited by etoposide (VP16) and melphalan on the expression of extracellular matrix and hematopoietic support proteins in the murine pre-osteoblast cell lines MC3T3E1 and 7F2. We showed that chemotherapy dysregulates extracellular matrix (ECM), resulting in reduced type I collagen expression in cell lines, as well as altered morphology of the endosteum in VP16 treated mice. In addition, chemotherapy reduced the abundance of hematopoietic support proteins CXCL12 and osteopontin. Chemotherapy exposure also reduced the expression of osteogenic differentiation associated transcription factors, coincident with reduced differentiation potential of pre-osteoblast cells. These observations highlight the vulnerability of osteoblasts to dysregulation of both hematopoietic support and osteogenic functions following chemotherapy exposure.

In the second study, we expanded our evaluation of stromal cell vulnerability to chemotherapy to mesenchymal stem cells (MSCs). MSCs are beginning to be utilized clinically for transplantation therapies, a process which requires in vitro expansion of cells prior to patient administration. To determine whether in vitro expansion affects the susceptibility of MSCs to chemotherapy stress, we evaluated the cellular response to etoposide (VP16) at various passages in vitro. Although passaging did not influence the susceptibility of MSCs to VP16, we found the repair of VP16 induced DNA damage was altered with extended passage. Exposure of MSCs to VP16 reduced homologous recombination (HR) associated transcripts, a phenomenon that was augmented with passage in vitro. Using plasmid based reporter assays, we found that HR mediated repair was reduced in untreated cells, and MSCs were less able to increase non-homologous end joining (NHEJ) following VP16 after extended passage. These results indicated an alteration of the ability of passaged MSCs to perform DNA repair following VP16 stress, indicating that MSCs should not be passaged too extensively prior to utilization for transplantation.

In contrast to the beneficial aspects of MSC function during MSC transplantation, MSCs can display pathogenic interactions with their surrounding environments, such as during cancer progression. In the case of the tumor microenvironment, MSCs have been shown to regulate tumor phenotype through the secretion of various signaling molecules. For example, the Wnt signaling 
pathway has been shown to regulate the phenotype of certain tumors. We investigated the expression of Wnt signaling molecules by MSCs after chemotherapy exposure and found that Dkk-1, a secreted inhibitor of Wnt signaling, was increased following exposure to VP16, melphalan, and 5-fluorouracil. Through the use of chemical inhibitors and activators of p53, as well as siRNA silencing, we showed that Dkk-1 elevations in MSCs after chemotherapy were mediated by p53, consistent with the published presence of a p53 promoter element within the DKK1 promoter. These results suggested the potential for MSC derived Dkk-1 to elicit negative effects on patients harboring Dkk-1 responsive tumors, and the possible approach of targeting Dkk-1 pharmacologically in these patients.

Collectively, these findings highlight the dynamic nature of bone marrow derived stromal cells, and illustrate that they are responsive to stress in ways that could negatively impact the health of patients receiving chemotherapy treatment. Given the numerous processes that are regulated by these cells, it is important to identify mechanisms by which chemotherapy elicits damage, providing a conceptual framework for developing means of reducing toxicities associated with chemotherapy treatment by maintaining the ability of bone marrow derived stromal cells to perform critical functions. 


\section{ACKNOWLEDGEMENTS}

I could not have done any of this without the love and support of my family and friends. Thanks to all of you for everything.

I am fortunate to have had the chance to meet Dr. Laura Gibson, and to learn so much from her. She has been instrumental to my successes through good example; I am grateful for her guidance and support over the years. I am thankful for the opportunity to train in her laboratory and benefit from her mentorship both personally and professionally. In addition to my Mentor, I would like to thank my committee members for their efforts and support during my training, Dr. John Barnett, Dr. William Petros, Dr. Michael Ruppert, and Dr. James Sheil.

Thanks also to my parents, Kelly, and Jesse, for making this possible and always being there for me. I want to acknowledge my family members who have passed away before this date, but are always in my thoughts, Grandpa Hare (Odie), Grandpa Bolton (Kenneth), Grandma Bolton (Irene), and Oma (Irmengard Lewis). A big thanks to Grandma (Marie Hare) for her wisdom and consistent encouragement. To the Lewis clan, Bill, Kim, Chad, Janice, Wendy, Travis, and Micki, thanks to all of you for your love and support. This goes for my adorable niece and nephew (Allie and Bryant) as well. I would also like to thank my current and previous lab members for their companionship and for everything they have taught me, Will, Blake, Beckie, Deb, Patrick, Audrey, Jim, and Marieta.

Finally, I would like to acknowledge my wife, Jessi. Had it not been for her love and inspiration, I would have not attempted, let alone accomplished these goals. I am incredibly lucky to be with her, and look forward to what lies ahead of us. 


\section{TABLE OF CONTENTS}

The Effect of Chemotherapy on Stromal Components of the Bone Marrow................ i

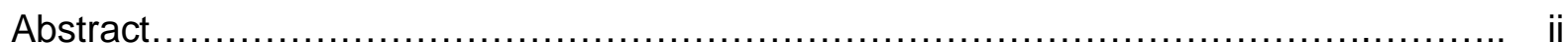

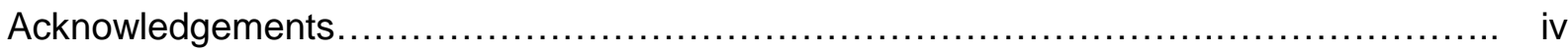

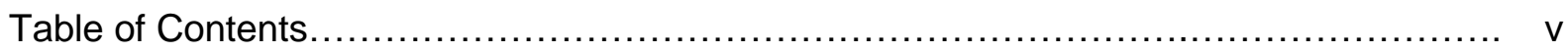

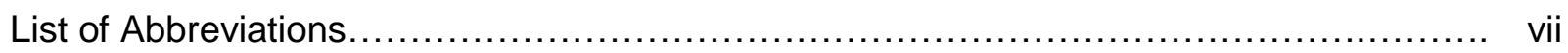

Chapter I - The Effect of Chemotherapy on Stromal Components of the Bone Marrow:

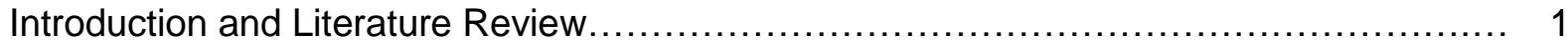

Stromal Components of the Bone Marrow.................................. 2

Bone Marrow Stromal Cell Function and Clinical Application.................... 8

Effects of Chemotherapy on Stromal Cell Function.............................. 17

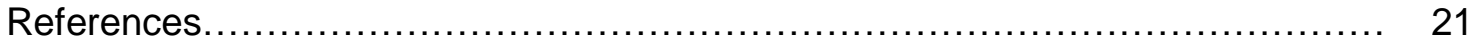

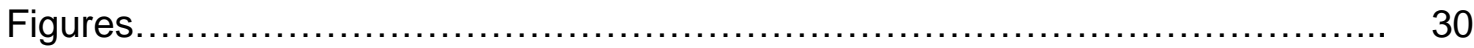

Chapter II - Bone Marrow Osteoblast Vulnerability to Chemotherapy.................. 32

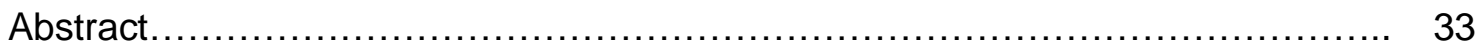

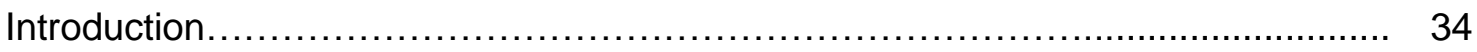

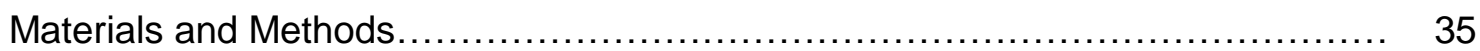

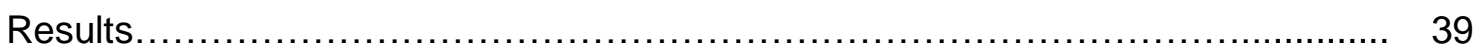

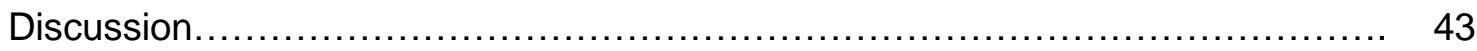

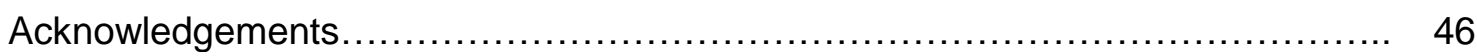

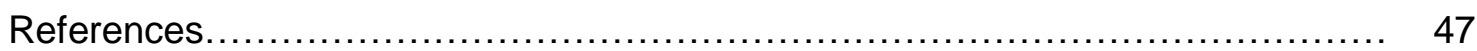

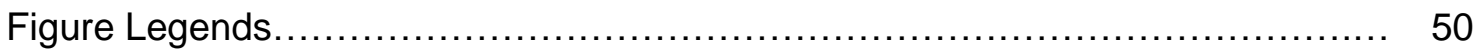

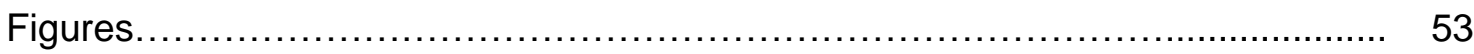


Chapter III - In Vitro Expansion of Bone Marrow Derived Mesenchymal Stem Cells Alters DNA Double Strand Break Repair of Etoposide Induced DNA Damage....

Abstract.

Introduction

Materials and Methods

Results.

Discussion.

Conclusions.

Acknowledgements

76

References.

77

Figure Legends.

81

Figures

Chapter IV - Chemotherapy Induced Dkk-1 Expression by Primary Human Mesenchymal Stem Cells is p53 Dependent.

Abstract.

Materials and Methods

Introduction

Results

Discussion.

Acknowledgements.

References.

Figure Legends.

Figures.

Chapter V - General Discussion

References. 


\section{LIST OF ABBREVIATIONS}

\begin{tabular}{|c|c|}
\hline ALP & Alkaline Phosphatase \\
\hline BMP-2 & Bone Morphogenic Protein-2 \\
\hline BMSC & Bone Marrow Stromal Cell \\
\hline BSP & Bone Sialoprotein \\
\hline CAF & Cancer Associated Fibroblast \\
\hline CFU-F & Colony Forming Unit Fibroblast \\
\hline CLP & Common Lymphoid Progenitor \\
\hline Col1A1 & Collagen Type $1 \alpha 1$ \\
\hline Col2A1 & Collagen Type $2 \alpha 1$ \\
\hline CXCL12 & C-X-C motif Chemokine 12 \\
\hline Dkk-1 & Dickkopf-related Protein 1 \\
\hline DMP1 & Dentin Matrix Acidic Phosphoprotein 1 \\
\hline ECM & Extra Cellular Matrix \\
\hline Flt-3 & Fms-like Tyrosine Kinase 3 \\
\hline FSP-1 & Fibroblast Specific Protein-1 \\
\hline G-CSF & Granulocyte Colony Stimulating Factor \\
\hline GM-CSF & Granulocyte Macrophage Colony Stimulating Factor \\
\hline GVHD & Graft versus Host Disease \\
\hline HA & Hyaluronic Acid \\
\hline HSC & Hematopoietic Stem Cell \\
\hline HSPC & Hematopoietic Stem and Progenitor Cell \\
\hline ICAM-1 & Intercellular Adhesion Molecule-1 \\
\hline IDO & Indoleamine-pyrrole 2,3-dioxygenase \\
\hline IL-3 & Interleukin-3 \\
\hline Lin- & Lineage Negative \\
\hline LRP5/6 & Low-density lipoprotein receptor-related protein 5/6 \\
\hline M-CSF & Macrophage Colony Stimulating Factor \\
\hline MMP & Matrix Metalloproteinase \\
\hline MSC & Mesenchymal Stem Cell \\
\hline MyoD1 & Myogenic Differentiation 1 \\
\hline OCN & Osteocalcin \\
\hline Ol & Osteogenesis Imperfecta \\
\hline OPN & Osteopontin \\
\hline OSE2 & Osteocalcin-Specific Element 2 \\
\hline OSM & Oncostatin M \\
\hline OSX & Osterix \\
\hline PDGFR $\beta$ & Platelet-Derived Growth Factor Receptor $\beta$ \\
\hline$P d x 1$ & Pancreatic Duodenal Homeobox 1 \\
\hline PGE2 & Prostaglandin E2 \\
\hline RunX2 & Runt-related Transcription Factor 2 \\
\hline
\end{tabular}


SCF

SOX9

Thy-1

TNF- $\alpha$

VCAM-1

a-SMA
Stem Cell Factor

SRY (Sex Determining Region Y)-Box 9

Thymocyte Antigen-1

Tumor Necrosis Factor- $\alpha$

Vascular Cell Adhesion Molecule 1

a-Smooth Muscle Actin 
Chapter I

The Effect of Chemotherapy on Stromal Components of the Bone Marrow

Literature Review 
The bone marrow is a complex environment that supports several homeostatic processes within the body. Although hematopoietic cells that arise from the bone marrow have been extensively studied, the stromal cells that share the bone marrow niche are less understood. The following addresses literature related to the stromal cells which comprise the bone marrow, outlines their functions, and addresses what is known regarding how these functions are hampered by chemotherapy treatment.

\section{i. Stromal Components of the Bone Marrow}

The bone marrow is an environment that fosters several critical homeostatic functions in mammals. Serving as a primary lymphoid organ for immune cell development, the bone marrow provides an environment permissive for the generation immune cells in the human body ${ }^{1}$. In addition, the marrow plays a critical role in the generation of cells necessary for bone development, a constitutively active process which assembles and maintains the skeletal system $^{2}$. The regulation of hematopoietic and skeletal activities within the bone marrow is reliant on the presence of a multipotent population of mesenchymal derived stromal cells, termed mesenchymal stem cells (MSCs), and their progeny. The following provides a partial summary of what is currently understood regarding these stromal populations of the bone marrow, and how their plasticity is regulated within the bone marrow microenvironment.

\section{General Architecture of the Bone Marrow}

Bone marrow is a tissue comprised of hematopoietic, mesenchymal, endothelial, and neural derived cells encased by cortical bone (Figure 1). The marrow can be defined as the contents of this ring of cortical bone, and is heavily vascularized. The center of the marrow contains a medullary artery and central sinus, with branching vasculature that travels throughout the marrow and bone regions ${ }^{3}$. Gaps between the cortical bone and vasculature are filled by 
various populations of bone marrow stromal cells, providing a cellular framework which secretes extracellular matrix consisting of, but not limited to, collagen, laminin, and fibronectin ${ }^{4}$ which provides a structural framework. Hematopoietic cells comprise the majority of the cellularity of the bone marrow, and are almost always within proximity of a stromal or endothelial cell ${ }^{1}$. Sympathetic nerve fibers are also present within the marrow space, and are known to regulate hematopoietic functions such as cell egress from the marrow during stem cell mobilization ${ }^{5}$.

\section{Mesenchymal Stem Cells}

Stromal cells of the bone marrow are derived from a multipotent precursor population, termed mesenchymal stem cells (MSCs) ${ }^{6}$. MSCs are fibroblastic cells that are defined functionally by their ability to differentiate into osteoblasts, adipocytes, and chondrocytes in vivo, and have been documented to form other cell types in vitro, including neurons, muscle cells, and beta cells ${ }^{7}$. While present in adipose, perivascular, dermal, heart, and muscle tissues ${ }^{8}$, MSCs were first discovered in the bone marrow. In 1976, Friedenstein et al. were the first to describe stromal cells of the bone marrow when they observed colonies of adherent cells displaying a fibroblast morphology following in vitro culture of murine bone marrow ${ }^{9}$. These cells displayed clonal growth characteristics, and displayed the ability to differentiate into osteoblasts following transplantation into mice ${ }^{10}$. In 1999, Pittenger et al. were the first to comprehensively identify MSCs within human bone marrow which were capable of osteogenic, adipogenic, and chondrogenic differentiation in vitro, setting the current standard by which MSCs are recognized and functionally described ${ }^{6}$.

Although much has been learned recently regarding the biology of MSCs, they are less understood and characterized than their hematopoietic counterparts. Many MSC surface molecules have been described including CD44, CD90, CD105, c-Kit, and PDGFRa. However, these molecules are not specific to MSCs, and share expression with closely associated 
hematopoietic cell populations of the bone marrow. Combinations of surface markers have been useful in isolating stromal cells that have an MSC phenotype. PDGFRa ${ }^{+}$Sca- $1^{+}$CD $45^{-}$TER $119^{-}$ cells isolated from murine bone marrow (termed PaS cells) ${ }^{11}$,

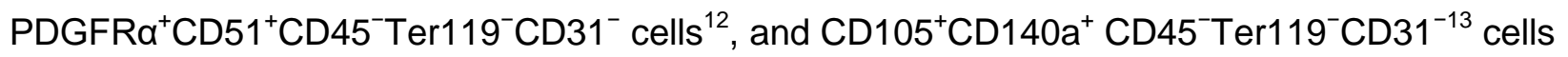
have been shown to have the ability to differentiate into osteoblasts, adipocytes, and chondrocytes in vitro. However, only PDGFRa ${ }^{+} \mathrm{CD} 51^{+} \mathrm{CD} 45^{-} \mathrm{Ter} 119^{-} \mathrm{CD} 31^{-}$cells have been described in human marrow, and CD105+CD140a+ CD45-Ter119-CD31- cells can only differentiate into osteoblasts when observed in vivo. These observations highlight the functional heterogeneity displayed by MSCs, and the necessity for better characterization at a surface marker and functional level.

Given the challenges inherent to identifying MSCs by surface phenotype, recent advances have been made using genetic labeling strategies. Nestin is an intermediate filament protein which was first discovered in neural stem cell populations of the brain ${ }^{14}$. While investigating mechanisms of neural crest development, Mendez-Ferrer et al. observed a small percentage of stromal cells $(<1 \%)$ in the bone marrow of Nestin-GFP mice which were green fluorescent protein (GFP) positive. Further evaluation of these cells showed that they displayed an MSC phenotype, and were necessary for support of hematopoietic stem cells ${ }^{15}$. Further evaluation of Nestin ${ }^{+}$stromal cells has shown that although MSC populations generally are enriched for Nestin, this is not unique to MSCs and osteogenic subsets are Nestin ${ }^{+}$as well. Wong et al. has shown that in vitro osteogenic differentiation of MSCs retains Nestin expression, suggesting that the marker is not MSC specific ${ }^{16}$. In an attempt to find a novel mesoderm expressed gene for MSC enumeration, Greenbaum et al. utilized Prx1, a transcription factor which is activated during limb bud development ${ }^{17}$. Prx1-ROSA26 mice displayed fluorescence in bone marrow stromal cells with an MSC phenotype. However, ROSA26 ${ }^{+}$osteoblasts and adipocytes were observed as well, showing that Prx1 was a marker 
of MSCs as well as more differentiated MSC derived stromal subsets within the marrow ${ }^{17}$. Although genetic markers have been found to evaluate MSCs in vivo, there is a great interest in identifying genes which are expressed specifically by MSCs, and do not display expression in more differentiated MSC derived stromal cells.

\section{Osteoblasts}

Osteoblasts are derived from MSCs, and generate bone by the formation and mineralization of extracellular matrix (ECM). Osteoblasts are located primarily at bone surfaces and arise from MSC precursors that often occupy a similar niche ${ }^{6}$. Early evaluations of CFU-F (Colony Forming Unit - Fibroblast) cells from cultured bone marrow, later understood to contain MSCs, showed that the presence of bone morphogenic protein (BMP) could induce cells to mineralize $\mathrm{ECM}^{18}$. The heterogeneity of CFU-F was later appreciated when a population of CFU-F shown to express bone associated proteins (osteocalcin and osteonectin) was observed to differ in size, response to osteogenic stimuli, and proliferative capacity, corresponding to osteoprogenitor cells of varying degrees of differentiation ${ }^{19}$. The genetic regulation of osteogenic differentiation was poorly understood until Komori et al. showed that mice deficient in Cbfa1, the gene that encodes Runt-related transcription factor (RunX2), died shortly after birth and displayed reduced skeletal development. Stromal cells isolated from $\mathrm{Cbfa}^{+/+}$bone marrow displayed elevated alkaline phosphatase (ALP) activity and increased osteocalcin expression relative to $\mathrm{Cbfa}^{+/-}$marrow, indicative of reduced osteogenic potential in stromal cells with decreased $\mathrm{Cbfa}^{20}{ }^{20}$. RunX2 is therefore necessary for osteogenic differentiation of MSCs, defining the step from an MSC to pre-osteoblast phenotype by initiating the expression of proteins containing an osteoblast-specific cis-acting element (OSE2) in their promoter regions. The promoter or many proteins vital to osteogenesis contain an OSE2, such as type 1 collagen alpha 1 (Col1A1), osteopontin (OPN), osteocalcin (OCN), and osterix (OSX) ${ }^{21}$. Col1A1, OPN, and $\mathrm{OCN}$ are necessary for the formation and mineralization of ECM during osteogenesis 
(described in section ii of this literature review). OSX is a zinc finger transcription factor that has been shown to be expressed following RunX2 in the progression towards a mature osteoblast phenotype ${ }^{22} . \mathrm{OSX}^{-/-}$mice have similar skeletal deformities observed in Cbfa1 ${ }^{-/-}$mice. RunX2 can still be detected in mesenchymal tissues of $\mathrm{OSX}^{-/-}$mice, however, OSX cannot be detected in $\mathrm{Cbfa}^{-/-}$mice, indicating that OSX is regulated downstream of RunX2 and is required for differentiation to a mature osteoblast phenotype ${ }^{23}$.

Mature osteoblasts differentiate into osteocytes, terminally differentiated stromal cells that reside deeper within bone tissue than osteoblasts and $\mathrm{MSCs}^{24}$. Osteocytes are encased by bone matrix, a process thought be a result of osteoblasts immobilizing the osteocyte within layers of $\mathrm{ECM}^{25}$. However, others have postulated that osteocyte burrowing is a more active process, involving the cleavage of bone matrix by osteocyte matrix metalloproteinase-14 (MMP14) and migration deep within bone tissue ${ }^{26}$. The progression from an osteoblast to osteocyte phenotype is less understood than the mechanisms by which less-differentiated osteoprogenitors mature, however, osteocyte gene expression has been described and is distinct from mature osteoblasts ${ }^{24}$. Although osteocytes express osteocalcin similarly to mature osteoblasts, RunX2, OSX, OPN, Col1A1, and ALP expression is reduced relative to osteoblasts $^{22}$

\section{Adipocytes}

Adipocytes are the primary cellular component of adipose tissue, storing glucose as triglycerides for release into the bloodstream in the form of fatty acids when the body is in need of energy ${ }^{27}$. The cellular morphology of adipocytes is different from MSCs, appearing slightly larger, round in shape, and containing cytosolic lipid droplets which are visible under brightfield microscopy. Ulf Smith was the first to document the presence of stromal cells in adipose tissue, capable of differentiating into adipocytes in vitro in the presence of human serum ${ }^{28}$. 
Adipogenic differentiation is dependent on the expression of peroxisome proliferatoractivated receptor y (PPARY) and CCAAT/enhancer binding protein $\alpha(C / E B P \alpha)^{29}$. PPARy and $\mathrm{C} / \mathrm{EBP} \alpha$ are transcription factors that activate the expression of genes necessary for adipocyte function, such as glucose transporter 4, lipoprotein lipase, and fatty acid synthase ${ }^{30}$. Insulin and glucocorticoids have been shown to induce PPARy and C/EBPa expression in human MSCs ${ }^{31}$. Embryonic stem cells from PPARY ${ }^{-/-}$mice are unable to differentiate into adipocytes ${ }^{32}$, and although $\mathrm{C} / \mathrm{EBPa}^{-/-}$stromal cells are capable of differentiating into adipocytes, they are not as robust as wild type cells ${ }^{33}$. These results indicate that both transcription factors are necessary for normal adipocyte function; however, it is PPARy that predominantly drives adipogenic differentiation of MSCs.

\section{Chondrocytes}

Similar to bone, cartilage serves as an organic matrix with supportive properties that are conducive to loading and bearing weight; however, the ECM components that comprise cartilage are more flexible than bone, and are generally less mineralized. Chondrocytes are responsible for the generation of cartilage, forming ECM in a similar manner as osteoblasts, only secreting different molecules which are ultimately less rigid ${ }^{34}$. Chondrocyte ECM is primarily composed of collagen type $2 \mathrm{~A}(\mathrm{Col} 2 \mathrm{~A} 1)$ and aggrecan, a proteoglycan that has a high affinity for hyaluronic acid $(\mathrm{HA})^{35}$. High density culture of MSCs with dexamethasone and transforming growth factor $\beta$ (TGF- $\beta$ ) has been shown to induce chondrogenic differentiation in vitro $^{36}$. SRY-type high mobility group box 9 (SOX9), which has been shown to be expressed in MSCs following TGF- $\beta$ exposure, has been described as an early transcription factor driving chondrogenic differentiation, promoting the expression of Col2 $\mathrm{A} 1^{37}$.

\section{Other Mesenchymal Stem Cell Derived Cell Types}


Although not as well described in the literature as osteoblasts, adipocytes, and chondrocytes, MSCs have been observed to differentiate into other cell types as well. Toma et al. presented evidence of MSC differentiation into cardiomyocytes in vivo, following transplantation of human $\mathrm{LacZ}^{+} \mathrm{MSCs}$ into immunodeficient mice ${ }^{38}$. In vitro culture of MSCs with 5-azacytidine has been shown to alter cellular morphology and induce the expression of Myogenic Differentiation 1 (MyoD1), a myogenic differentiation marker ${ }^{39}$. In addition, retroviral expression of pancreatic duodenal homeobox $1(\mathrm{Pdx} 1)$ in human MSCs was shown to activate the expression of insulin following glucose exposure, similar to the function of pancreatic beta cells ${ }^{40}$. These findings indicate that MSCs are a multipotent population of cells, potentially capable of differentiating into numerous clinically beneficial cell types (described in more detail in part ii of this literature review).

\section{ii. Bone Marrow Stromal Cell Function and Clinical Application}

\section{Hematopoiesis}

Hematopoiesis is the process by which stem and progenitor cells of the immune system differentiate into the cellular constituents of blood. The hematopoietic stem cell (HSC) is the most immature of hematopoietic cells, and is capable of differentiation into all hematopoietic cell types and performing asymmetric division (Figure 2). Vertebrates harbor a deeply quiescent pool of HSCs that are capable of differentiating into myeloid and lymphoid progenitor cell populations that lose the ability to self-renew, but are more proliferative than the primitive $\mathrm{HSC}^{41}$. There is a finite number of HSCs in the bone marrow of vertebrates. When proliferation of this stem cell pool is not properly regulated, the pool can be depleted, a phenomenon known as exhaustion ${ }^{42}$. 
The differentiation and proliferation of HSC and other hematopoietic progenitor cells are regulated in part by the bone marrow microenvironment. The concept of a niche that regulates the function of stem cells was first hypothesized by Schofield ${ }^{43}$, built upon the observations that hematopoietic cells occupy distinct regions of the bone marrow ${ }^{44}$ and the requirement of bone marrow stromal cells for ex vivo maintenance of hematopoietic cells ${ }^{45}$. In 2004, Visnjic et al. suggested that osteoblasts were the stromal population responsible for supporting HSC when they observed a great reduction in HSCs as well as more differentiated lymphoid and myeloid cells following in vivo ablation of osteoblasts ${ }^{46}$. This notion was revisited by Greenbaum and Ding et al., performing similar studies that involved evaluating the abundance of hematopoietic cell populations in mice where C-X-C motif chemokine 12 (CXCL12) was ablated from various stromal populations in vivo. CXCL12 is a chemokine that is expressed by bone marrow stromal cells and plays a critical role in the recruitment and retention of HSCs and progenitor cells to the bone marrow niche ${ }^{47}$. Ablation of CXCL12 from MSC populations resulted in a release of HSCs from the bone marrow niche ${ }^{17}$, while ablation of CXCL12 from osteoblasts only dispersed common lymphoid progenitor (CLP) cells ${ }^{48}$, suggesting that MSCs contribute to the maintenance of HSC support while osteoblasts are only responsible for supporting CLPS.

Stromal cells of the bone marrow secrete many factors that regulate the quiescence and differentiation of HSCs. TGF- $\beta$ and OPN have both been shown to reduce the proliferation of $\mathrm{HSCs}^{49,50}$. When there is a necessity for blood cell generation, MSC and osteoblast derived stem cell factor (SCF), interleukin-3 (IL-3) and Fms-like tyrosine kinase 3 (Flt-3) are some of the factors that support the proliferation and survival of HSCs and committed progenitor cells ${ }^{51}$. In addition, granulocyte, granulocyte-macrophage, and macrophage colony stimulating factors (GCSF, GM-CSF, and M-CSF) have been shown to promote the differentiation of HSCs into neutrophils, neutrophils and macrophages, or macrophages (respectively) ${ }^{52}$. The balance between proliferation and differentiation is absolutely critical to steady state hematopoiesis and 
highlights the potential of any dysfunction of elements of the supportive marrow microenvironment to contribute to dysregulated immune system function.

The ECM that is secreted by MSCs and osteoblasts plays an indirect role in influencing the bioavailability of cytokines to (such as TGF- $\beta^{53}$ and $O P N^{50}$ ) to HSCs in the bone marrow microenvironment ${ }^{54}$. MSCs and osteoblasts also secrete proteoglycans into ECM which can modulate the stability of cytokine gradients. For example, stromal derived heparin sulfate has been shown to be necessary for the stabilization of GM-CSF ${ }^{55}, \mathrm{IL}-3^{56}$, and $\mathrm{CXCL} 12^{57}$ in the bone marrow. Saez et al. recently utilized the CXCL12 modulating potential of heparin sulfate to mobilize HSCs by inhibiting the biosynthesis of heparin sulfate specifically in osteoprogenitor cells ${ }^{58}$. HA is another proteoglycan expressed by MSCs and osteoblasts, and facilitates binding of hematopoietic cells to the bone marrow niche via CD44 expressed on the surface of hematopoietic cells ${ }^{59}$. Other MSC and osteoblast expressed surface proteins that mediate direct binding to hematopoietic cells include vascular cell adhesion protein 1 (VCAM-1), intracellular adhesion molecule 1 (ICAM-1), and thymocyte antigen 1 (Thy-1) ${ }^{59}$, and are necessary for the anchoring of hematopoietic cells to supportive stromal cells within the bone marrow niche. Many studies have indicated that this physical interaction is absolutely essential for hematopoietic cell development, and cannot be substituted for by any combination of cytokines or growth factors ${ }^{1}$.

\section{Osteogenesis}

Prior to the understanding that bone marrow osteoblasts and osteoprogenitor cells contribute to hematopoietic support, their primary described function was osteogenesis. Osteogenesis is a process that involves the differentiation of MSCs (described in section i of this literature review) to osteoblasts, secreting an abundance of ECM which is subsequently mineralized, resulting in the dense bone tissue which comprises our skeletal system². 
The organic component of bone is referred to as osteoid, and consists of osteoblast secreted ECM and ECM binding proteins. Osteoid accounts for fifty percent of bone volume ${ }^{60}$. The predominant component of osteoblast ECM is Col1A1, contributing to ninety percent of osteoid $^{2}$. The high tensile strength of collagen confers strength to bone tissue, while remaining permissive to a small degree of flexibility ${ }^{61}$. Although less abundant than Col1A1 in bone, osteoblast secreted ECM proteins are essential for several components of bone function. OCN is a non-collagenous protein produced by mature osteoblasts and osteocytes, and has been shown to play a structural role by binding tightly to Col1A1 and hydroxyapatite $\left(\mathrm{Ca}_{10}\left(\mathrm{PO}_{4}\right)_{6}(\mathrm{OH})_{2}\right)$, a crystalized from of calcium and phosphate that comprises the majority of bone mineral density ${ }^{62}$. OPN is a highly negatively charged ECM protein that has also been described as playing a structural role in osteoblast ECM through interactions with $\mathrm{OCN}^{63}$. OCN has also been shown to sequester calcium, serving as a negative regulator of bone mineralization $^{64}$.

Following the formation of osteoid, osteoblasts regulate the process by which osteoid is mineralized. The mineralization of osteoid provides compression strength and the hardness that is characteristic of bone tissue ${ }^{65}$. The majority of the inorganic portion of bone is hydroxyapatite ${ }^{62}$. The formation of hydroxyapatite is regulated by various secreted osteoblast proteins which can promote its formation or generate the calcium and inorganic phosphate necessary for its synthesis. Dentin matrix protein 1 (DMP1) and bone sialoprotein (BSP) are nucleating factors, structurally ideal for initiating the crystallization process that forms hydroxyapatite in bone ${ }^{66}$. Alkaline phosphatase (ALP) is abundantly expressed by osteoblasts, and cleaves phosphate from various molecular sources such that it can be incorporated into hydroxyapatite ${ }^{67}$. Dietary ascorbic acid also plays a role in maintaining the presence of minerals that comprise hydroxyapatite by stabilizing levels of calcium and phosphorus in the blood ${ }^{68}$. 
The formation of bone is tightly regulated by various signaling pathways that influence the differentiation of MSCs to an osteoblast phenotype and induce the expression of osteoblast specific genes. Wnt signaling is known to be a critical regulator of bone development through the regulation of $\beta$-catenin mediated gene expression activated by various Wnt activating ligands binding to Frizzled and low-density lipoprotein receptor-related proteins (LRPs) at the surface of the osteoblast ${ }^{69}$. The first evidence of Wnt signaling regulating bone development was described by Gong et al., showing that mutations in the LRP5 gene correlated with patient diagnosis of osteoporosis-pseudoglioma syndrome, a genetically acquired disease that is associated with very low bone mass and frequent fractures ${ }^{70}$. This finding was later confirmed by Kato et al. in a LRP5 $5^{-/}$mouse mode ${ }^{71}$. Of the $19 \mathrm{Wnt}$ activating ligands expressed by humans $^{72}$, several positively regulate osteogenic differentiation, including $\mathrm{Wnt}^{3} \mathrm{a}^{73}$ and Wnt $10 b^{74}$. Secreted inhibitors of Wnt signaling also play a role in regulating this response, such as dickkopf 1 (Dkk-1), a steric inhibitor of LRP5/6 which is expressed by osteoblasts and prevents Wnt induced osteogenic differentiation in vivo ${ }^{75}$. Soluble frizzled receptor 1 (SFRP1), a soluble form of the Frizzled Wnt receptor, quenches Wnt activating ligands in the extracellular environment. Bodine et al. observed increased bone mass and osteoblast differentiation in $\mathrm{SFRP}^{-/-}$mice, highlighting the importance of SFRP1 in the regulation of osteogenesis in vivo ${ }^{76}$.

\section{Tumor Microenvironment Regulation}

MSCs were initially discovered in the bone marrow, but are now appreciated to be more widely distributed ${ }^{8}$. Although generally beneficial, the activities of MSCs and MSC derived stromal populations can contribute to disease states, such as in the setting of diverse tumor microenvironments. The tumor microenvironment can be defined broadly as the cellular environment surrounding a tumor. This environment is comprised of tumor cells surrounded by normal tissue which often contains MSCs, as well as fibroblasts, vasculature, and immune cells $^{77}$. Similar to the ways that MSCs regulate the hematopoietic niche, MSCs play a role in 
regulating the characteristics of a tumor through the expression of cytokines or other signaling molecules. For example, co-culture of breast cancer cell lines with MSCs was shown to increase the expression of miR-199a, which decreased FOXOP2 and increased metastasis when tumor cells were implanted subcutaneously into nude mice ${ }^{78}$. Conversely, Wang et al. showed that MSC derived Oncostatin M (OSM) inhibited tumor growth and metastasis in a murine model of lung adenocarcinoma ${ }^{79}$. These observations highlight the ability of MSCs to both positively and negatively regulate the tumor microenvironment.

Literature describing the tumor microenvironment often focuses on the activity of cancer associated fibroblasts (CAFs), a population of fibroblasts that is considered quite heterogeneous, similar to $\mathrm{MSCs}^{80}$. It is believed that CAFs are derived from tissue resident MSCs or fibroblasts ${ }^{77}$, however, some consider MSCs and CAFs as similar cell types that are defined by their proximity and their propensity to regulate tumor activity ${ }^{81}$. Defined qualitatively by fibroblast morphology and adjacency to a tumor, CAFs have also been described as expressing $\alpha$-smooth muscle actin ( $\alpha$-SMA), platelet-derived growth factor $\beta$ (PDGFR $\beta$ ), and fibroblast-specific protein 1 (FSP-1 $)^{82}$. However, these surface markers are expressed on MSCs, as well as other cell types within the tumor microenvironment ${ }^{83-85}$. These observations show that MSCs and CAFs are both heterogeneous populations of stromal cells which often contribute to the regulation of the tumor microenvironment in similar ways. In addition to MSCs and CAFs, osteoblasts have been reported to regulate tumor activity in cancers that originate in the bone or marrow (such as acute lymphoblastic leukemia, multiple myeloma, and osteosarcoma), or commonly metastasize to them (breast and prostate) $)^{79}$.

Although MSCs are distributed in tissues surrounding tumors, it is often observed that MSCs actively home from distant anatomical sites to the tumor. This phenomenon has been attributed, in part, to the expression of chemotactic cytokines by the tumor, such as CXCL12 ${ }^{86}$ and interleukin- $6^{87}$. Quante et al. showed that some CAFs surrounding tumors in a murine 
model of gastric cancer were derived from bone marrow MSCs. Mice were administered GFP ${ }^{+}$ MSCs that efficiently engrafted the bone marrow prior to developing gastric cancer. Once gastric tumors developed, over $20 \%$ of the cells were $\alpha-\mathrm{SMA}^{+} \mathrm{GFP}^{+}$indicating that MSCs home to the marrow to distant tumors, even though tissue resident MSCs were already present ${ }^{88}$. Once attracted to the site of a tumor, MSCs can change gene expression in ways that anchor them to the tumor site. For example, Uchibori et al. observed that high concentrations of tumor necrosis factor- $\alpha$ (TNF- $\alpha$ ) within the tumor microenvironment induced VCAM-1 expression by MSCs, anchoring them around nearby endothelial cells ${ }^{89}$.

Once present within the tumor microenvironment, MSCs can promote tumor growth by various mechanisms. MSCs have been shown to secrete cytokines that create a generally immune suppressive environment. For example, Patel et al. showed that MSC derived TGF- $\beta$ increased the presence of regulatory $T$ cells that resulted in the inhibition of immune mediated tumor clearance of breast cancer cells ${ }^{89}$. MSCs have also been shown to suppress the proliferation of activated $\mathrm{CD} 8^{+} \mathrm{T}$ cells through the expression of prostaglandin E2 (PGE2), indoleamine 2, 3-dioxygenase (IDO) and TGF- $\beta^{90}$. In addition, MSCs have been described as promoting an anti-inflammatory alternatively activated macrophage (M2) phenotype in a model of myocardial infarction ${ }^{91}$. In addition to suppressing the ability of the immune system to target cancerous cells, MSCs can promote angiogenesis. Suzuki reported increased expression of angiogenic cytokines in B16 melanoma cells co-cultured with MSCs, as well as increased tumor vessel area when B16 cells were co-injected into mice with MSCs (relative to B16 cells alone) ${ }^{92}$.

In vivo work investigating the role of osteoblasts in regulating hematological cancers has provided insight into ways osteoblasts can prevent malignancy, and how the initiation of disease can be influenced by niche cues. Raaijmakers et al. have shown that deletion of dicer in osteoblasts results in the generation of myelodysplastic syndrome ${ }^{93}$. In addition, the constitutive activation of $\beta$-catenin in osteoblasts has been shown to initiate acute myeloid leukemia in 
mice $^{94}$. These observations serve as evidence for the importance of stromal cells in the maintenance of stem cell niches, and the necessity of understanding how perturbations within the niche can influence malignancy.

\section{Mesenchymal Stem Cell Transplantation}

MSCs display several attributes that have drawn attention to their clinical potential for transplantation. MSCs represent a population of cells that can be obtained from bone marrow, adipose, and placental specimens ${ }^{6}$, then expanded in vitro to generate cells for transplantation into humans or animals experiencing diseases caused by dysfunctional mesenchymal tissues or inflammation. The well described ability of MSCs to differentiate into osteoblasts, chondrocytes, and other stromal cells of the body (discussed earlier in this literature review) led researchers and clinicians to investigate the potential utilization of MSCs to treat diseases that involve deficiencies of these cell types. Orilc et al. was the first to show that transplanted bone marrow depleted of committed hematopoietic lineage marker positive cells $\left(\mathrm{Lin}^{+}\right)$homed to murine necrotic tissue following myocardial infarction, subsequently repairing the affected ventricle and forming almost 70 percent of the tissue after recovery ${ }^{95}$. Dysfunctional pancreatic beta cells in a murine model of diabetes myelitis were rescued by intravenous infusion of MSCs, resulting in increased insulin production by pancreatic cells and glucose homeostasis ${ }^{96}$.

These findings inspired the first attempt to utilize MSC transplantation in humans. Osteogenesis imperfecta $(\mathrm{OI})$ is a severe congenital disease that results in brittle and undeveloped bone due to various mutations in the COL1A1 gene. In 2002, Horwitz et al. administered allogenic MSCs to six children with OI in an attempt to repopulate their bone marrows with MSCs capable of differentiating into functional osteoblasts. The authors found evidence of MSC homing to bone and skin, and reported 60-94 percent increases in bone growth velocity (relative to age matched controls) six months following transplantation ${ }^{97}$. 
Although all of these studies documented the dissemination of transplanted MSCs throughout the body, the abundance of MSCs and their progeny were generally limited, indicating a technical difficulty regarding the use of this technique clinically. For example, Dominici et al. observed $30 \%$ of murine bone consisting of $\mathrm{GFP}^{+} \mathrm{MSC}$ s shortly after transplantation, decreasing to $10 \%$ by 52 weeks of age and undetectable at subsequent time points ${ }^{98}$. This observation suggests that multiple transplants of MSCs may be necessary to provide lasting treatment effects. Consistent with this notion, Götherström et al. found that prenatal administration of allogenic MSCs for the treatment of OI followed by re-transplantation at 19 months and 8 years of age prolonged the positive effects of treatment in two patients ${ }^{99}$. These results highlight the clinical potential of MSC transplantation, and the necessity of efficient ex vivo expansion of cells that maintain critical functions to acquire adequate cell numbers for long term clinical benefits.

As discussed previously in this literature review, MSCs have been documented to have immune suppressive properties. MSCs were shown to reduce the proliferative potential of activated T-cells and delay the rejection of grafted skin tissue in baboons ${ }^{100}$. Zappia et al. were the first to show that the anti-inflammatory properties of MSCs were capable of reducing the severity of disease in a murine model of experimental autoimmune encephalitis when administered at the onset of disease ${ }^{101}$. Transplanted MSCs have also benefited the motor function of rats 14 days following stroke, believed in part to be a consequence of reduced neuroinflammation by MSCs ${ }^{102}$. The immune suppressive capabilities of MSCs have been utilized to prevent graft vs. host disease (GVHD) in human patients; a Sweedish patient experiencing severe treatment-resistant grade IV GVHD from an allogenic bone marrow transplant for the treatment of acute lymphoblastic leukemia was administered MSCs twice intravenously, resulting in a full recovery one year out from a disease that has a median survival of two months ${ }^{103}$. These results were corroborated by a larger study showing a $77.7 \%$ two year 
survival-rate for patients with refractory GVHD treated with two administrations of donor $\operatorname{MSCs}^{104}$

Although favorable results have been observed in animal models and some clinical trials of MSC transplantation, no MSC based therapy has currently been approved by the United States Food and Drug Administration. Prochymal®, a MSC based stem cell therapy developed by Osiris Therapeutics has currently been approved as a first line treatment of acute GVHD in Canada, and is currently under Phase III clinical trials for GVHD in the United States (clinicaltrials.gov identifier NCT00562497). Clinical trials are also currently active for the treatment of Crohn's disease, type-1 diabetes, and myocardial infarction (clinicaltrials.gov identifiers NCT00543374, NCT00690066, and NCT00877903). The technically involved process of acquiring MSCs from autologous or allogenic donors, expansion ex vivo, and multiple administrations to a patient has hampered the progression of MSC transplantation towards first line clinical use ${ }^{105}$. However, the lack of cures (and often treatments) for the diseases that benefit from MSC transplantation have maintained interest in the process since the early 2000's. This unique necessity for ex vivo expansion of MSCs prior to use in stem cell therapies highlights the need for a better understanding of how to optimally expand MSCs without altering phenotype; it also illustrates the necessity of better understanding this process to ensure the optimization of good manufacturing practice during MSC expansion.

\section{iii. Effects of Chemotherapy on Stromal Cell Function}

\section{Regulation of Immune Regeneration}

Cytotoxic chemotherapy regimens preferentially target proliferative cells, a characteristic that enables the killing of tumor cells, but at the expense of healthy proliferative tissues. The bone marrow is an example of such a tissue, displaying rapid cellular proliferation to supply the 
high cellular demand of continuous blood generation. In the context of hematopoietic malignancies, this immune cell toxicity can be the intent of therapy, such as during myeloablative chemotherapy regimens. Myeloablation serves to eliminate as many of the hematopoietic cells of the marrow as possible, providing space for marrow repopulation by transplanted hematopoietic cells from an autologous or allogenic source. Although hematopoietic donor cells are capable of repopulating the marrow, the process is often slow. Following myeloablative chemotherapy and transplantation, deficiencies in immune cell counts often persist for more than a year after transplantation ${ }^{106}$, leaving patients susceptible to anemia and infection for an extended period of time. Immune deficiencies can persist in patients for years following treatment. For example, women treated for breast cancer have displayed deficiencies in vaccine efficacy years after the treatment of their cancers ${ }^{107}$.

Although it is possible that these deficits are due to a shortcoming of the transplanted hematopoietic cells, it is also possible that the phenomenon is regulated by dysfunction of the bone marrow niche. Unlike the transplanted hematopoietic cells, stromal cells of the bone marrow experience chemotherapy damage that negatively influences their ability to support hematopoietic function. Kemp et al. showed that MSCs isolated from patients treated with high dose chemotherapy for hematological malignancies displayed reduced abilities to expand in vitro, as well as reduced CD44 expression ${ }^{108}$. Dominici et al. observed osteoblasts in the endosteal niche becoming highly proliferative shortly after chemotherapy treatment to repair damage inflicted upon the anatomical architecture of the bone marrow ${ }^{109}$. Although damaged stromal cells of the bone marrow are quickly replenished, their function has been shown to be reduced for a long period of time. For example, Galotto et al. have shown that CFU-F frequencies are diminished in patients who have received bone marrow transplantation relative to normal controls for up to 12 years following transplantation, and cultured stromal cells from these patients are less able to support the long term persistence of HSCs in vitro ${ }^{110}$. These 
observations highlight the susceptibility of bone marrow stromal cells to damage that impedes their hematopoietic support functions and reminds us of the fact that this population of cells is not simply a stable support system but a dynamic, responsive population.

Evidence for stromal dysregulation is also present in the context of myelosuppressive chemotherapy regimens. When less intensive chemotherapy treatment is needed for the treatment of a malignancy, peripheral blood cell counts will drop following therapy, followed by a recovery which lasts on the order weeks to months. This phenomenon is referred to as myelosuppression, and is more clinically prevalent than myeloablative therapies ${ }^{111}$. Myelosuppressive chemotherapy has been associated with damage of sympathetic nerves of the bone marrow, resulting in attenuated hematopoietic recovery ${ }^{112}$. In addition, Brenet et al. showed that 5-fluorouracil treatment of mice resulted in an increase in TGF- $\beta$ signaling in the bone marrow. By inhibiting TGF- $\beta$ with neutralizing antibodies, the authors were able to promote the rate of granulocyte and erythrocyte recovery after chemotherapy treatment ${ }^{113}$. This observation is consistent with several lines of evidence from our laboratory and others outlining the suppressive activity of TGF- $\beta$ on HSCs, as well as the fact that chemotherapy exposure increases the expression of active TGF- $\beta$ by bone marrow stromal cells and osteoblasts ${ }^{114-116}$. Our observations show the likelihood that the increased TGF- $\beta$ observed by Brenet et al. after chemotherapy treatment was in part derived from stromal cells of the bone marrow. This observation indicates the potential of pharmacologically targeting niche factors that regulate HSCs for chemotherapy associated leukopenia, as opposed to HSCs themselves.

The prospect of modulating bone marrow stromal cell derived molecules following chemotherapy exposure is a new but developing field. Acceleron has developed Sotatercept®, a peptide drug consisting of an activin receptor type IIA domain fused to the Fc portion of human IgG1, serving to broadly inhibit TGF- $\beta$ family extracellular signaling molecules ${ }^{117}$. Sotatercept has shown clinical efficacy for the treatment of chemotherapy induced anemia in 
Phase II clinical trials ${ }^{118}$. A better understanding of the signaling pathways that modulate hematopoietic regeneration following bone marrow stress is required to determine other potential ways to promote immune regeneration in patients who have undergone chemotherapy treatment.

\section{Bone Development}

Impaired osteogenesis is often overlooked as a toxicity associated with chemotherapy treatment. However, deficits in bone formation have been documented across a spectrum of cancers treated with various chemotherapeutic agents. Observations in Chapter II of this dissertation provide evidence for the alteration of osteoblast function in vitro. Consistent with these observations, Georgiou and Davies et al. have shown deficits in the function of osteoblasts isolated from rats and humans, respectively, following chemotherapy treatment $^{119,120}$.

Attenuated osteogenesis following chemotherapy has been documented in vivo as well. Tillmann et al. evaluated bone mineral density in children who have been treated with high dose chemotherapy for acute lymphoblastic leukemia, showing that chemotherapy treated children displayed a decrease in bone mineral density relative to age matched controls, correlating with an increased incidence in fractures ${ }^{121}$. Women treated with carboplatin, paclitaxel, or cisplatin for various gynecological cancers have experienced reduced lumbar bone mineral density one year after treatment ${ }^{122}$. Similar results were observed in men treated for Hodgkin's lymphoma, displaying attenuated bone mineral density in the lumbar spine and forearms as long as 6.8 years following treatment ${ }^{123}$. Little is known regarding the mechanism behind chemotherapy induced osteogenic deficiencies; more studies are required to understand this phenomenon well enough to design therapies that prevent chemotherapy induced toxicities of the skeletal system.

\section{Summary}


The findings described in this literature review illustrate the dynamic nature of stromal cells of the bone marrow microenvironment. Playing a role in several homeostatic processes within the body, this clinically significant group of cells displays several characteristics that justify the need to better understand their biology. For example, the necessity of MSCs to regulate the characteristics of other cell populations (such as hematopoietic and tumor populations, described earlier in this literature review) underlies the importance in understanding how they operate in both normal and stressed conditions. Chapters II, III and IV of this dissertation outline distinct changes in MSC and osteoblast cells that are a consequence of chemotherapy exposure, a clinically relevant example of systemic stress in vivo. Furthermore, Chapter III describes the effects of ex vivo expansion of MSCs, and how this could potentially affect MSC function following transplantation into a host for stem cell therapy. Collectively, the following will contribute to better understanding mechanisms regarding the response of MSCs to chemotherapy stress, providing insight into means by which these responses can be modulated to better manage sequelae experienced by patients as a consequence of damaged stromal components of the bone marrow microenvironment.

\section{References}

1. Eaves CJ. Hematopoietic stem cells: concepts, definitions, and the new reality. Blood. 2015;125(17):2605-2613.

2. James AW. Review of Signaling Pathways Governing MSC Osteogenic and Adipogenic Differentiation. Scientifica. 2013;2013:684736.

3. Nagasawa T. Microenvironmental niches in the bone marrow required for B-cell development. Nat. Rev. Immunol. 2006;6(2):107-116.

4. Chen X-D, Dusevich V, Feng JQ, Manolagas SC, Jilka RL. Extracellular matrix made by bone marrow cells facilitates expansion of marrow-derived mesenchymal progenitor cells and prevents their differentiation into osteoblasts. J. Bone Miner. Res. Off. J. Am. Soc. Bone Miner. Res. 2007;22(12):1943-1956.

5. Katayama Y, Battista M, Kao W-M, et al. Signals from the sympathetic nervous system regulate hematopoietic stem cell egress from bone marrow. Cell. 2006;124(2):407-421. 
6. Pittenger MF, Mackay AM, Beck SC, et al. Multilineage Potential of Adult Human Mesenchymal Stem Cells. Science. 1999;284(5411):143-147.

7. Kurpinski K, Lam H, Chu J, et al. Transforming growth factor-beta and notch signaling mediate stem cell differentiation into smooth muscle cells. Stem Cells Dayt. Ohio. 2010;28(4):734-742.

8. Li M, Ikehara S. Bone-marrow-derived mesenchymal stem cells for organ repair. Stem Cells Int. 2013;2013:132642.

9. Friedenstein AJ, Gorskaja JF, Kulagina NN. Fibroblast precursors in normal and irradiated mouse hematopoietic organs. Exp. Hematol. 1976;4(5):267-274.

10. Friedenstein AJ, Chailakhyan RK, Gerasimov UV. Bone marrow osteogenic stem cells: in vitro cultivation and transplantation in diffusion chambers. Cell Tissue Kinet. 1987;20(3):263-272.

11. Morikawa S, Mabuchi $Y$, Kubota $Y$, et al. Prospective identification, isolation, and systemic transplantation of multipotent mesenchymal stem cells in murine bone marrow. J. Exp. Med. 2009;206(11):2483-2496.

12. Pinho S, Lacombe J, Hanoun M, et al. PDGFRa and CD51 mark human Nestin+ sphereforming mesenchymal stem cells capable of hematopoietic progenitor cell expansion. $J$. Exp. Med. 2013;210(7):1351-1367.

13. Park D, Spencer JA, Koh BI, et al. Endogenous bone marrow MSCs are dynamic, faterestricted participants in bone maintenance and regeneration. Cell Stem Cell. 2012;10(3):259-272.

14. Lendahl U, Zimmerman LB, McKay RD. CNS stem cells express a new class of intermediate filament protein. Cell. 1990;60(4):585-595.

15. Méndez-Ferrer S, Michurina TV, Ferraro F, et al. Mesenchymal and haematopoietic stem cells form a unique bone marrow niche. Nature. 2010;466(7308):829-834.

16. Wong A, Ghassemi E, Yellowley CE. Nestin expression in mesenchymal stromal cells: regulation by hypoxia and osteogenesis. BMC Vet. Res. 2014;10:173.

17. Greenbaum A, Hsu Y-MS, Day RB, et al. CXCL12 in early mesenchymal progenitors is required for haematopoietic stem-cell maintenance. Nature. 2013;495(7440):227-230.

18. Urist MR, DeLange RJ, Finerman GA. Bone cell differentiation and growth factors. Science. 1983;220(4598):680-686.

19. Long MW, Robinson JA, Ashcraft EA, Mann KG. Regulation of human bone marrowderived osteoprogenitor cells by osteogenic growth factors. J. Clin. Invest. 1995;95(2):881887.

20. Komori T, Yagi H, Nomura S, et al. Targeted disruption of Cbfa1 results in a complete lack of bone formation owing to maturational arrest of osteoblasts. Cell. 1997;89(5):755-764.

21. Ducy P, Zhang R, Geoffroy V, Ridall AL, Karsenty G. Osf2/Cbfa1: a transcriptional activator of osteoblast differentiation. Cell. 1997;89(5):747-754. 
22. Liu TM, Lee EH. Transcriptional regulatory cascades in Runx2-dependent bone development. Tissue Eng. Part B Rev. 2013;19(3):254-263.

23. Nakashima K, Zhou X, Kunkel G, et al. The novel zinc finger-containing transcription factor osterix is required for osteoblast differentiation and bone formation. Cell. 2002;108(1):1729.

24. Dallas SL, Bonewald LF. Dynamics of the transition from osteoblast to osteocyte. Ann. N. Y. Acad. Sci. 2010;1192:437-443.

25. Franz-Odendaal TA, Hall BK, Witten PE. Buried alive: how osteoblasts become osteocytes. Dev. Dyn. Off. Publ. Am. Assoc. Anat. 2006;235(1):176-190.

26. Holmbeck K, Bianco P, Pidoux I, et al. The metalloproteinase MT1-MMP is required for normal development and maintenance of osteocyte processes in bone. J. Cell Sci. 2005;118(Pt 1):147-156.

27. Rosen ED, MacDougald OA. Adipocyte differentiation from the inside out. Nat. Rev. Mol. Cell Biol. 2006;7(12):885-896.

28. Smith U. Morphologic studies of human subcutaneous adipose tissue in vitro. Anat. Rec. 1971;169(1):97-104.

29. Moseti D, Regassa A, Kim W-K. Molecular Regulation of Adipogenesis and Potential AntiAdipogenic Bioactive Molecules. Int. J. Mol. Sci. 2016;17(1.):

30. Rodríguez A, Ezquerro S, Méndez-Giménez L, Becerril S, Frühbeck G. Revisiting the adipocyte: a model for integration of cytokine signaling in the regulation of energy metabolism. Am. J. Physiol. Endocrinol. Metab. 2015;309(8):E691-714.

31. Vidal-Puig AJ, Considine RV, Jimenez-Liñan M, et al. Peroxisome proliferator-activated receptor gene expression in human tissues. Effects of obesity, weight loss, and regulation by insulin and glucocorticoids. J. Clin. Invest. 1997;99(10):2416-2422.

32. Rosen ED, Sarraf P, Troy AE, et al. PPAR gamma is required for the differentiation of adipose tissue in vivo and in vitro. Mol. Cell. 1999;4(4):611-617.

33. Rosen ED, Hsu C-H, Wang X, et al. C/EBPalpha induces adipogenesis through PPARgamma: a unified pathway. Genes Dev. 2002;16(1):22-26.

34. Caldwell KL, Wang J. Cell-based articular cartilage repair: the link between development and regeneration. Osteoarthr. Cartil. OARS Osteoarthr. Res. Soc. 2015;23(3):351-362.

35. Richardson SM, Kalamegam G, Pushparaj PN, et al. Mesenchymal stem cells in regenerative medicine: Focus on articular cartilage and intervertebral disc regeneration. Methods San Diego Calif. 2015;

36. Mackay AM, Beck SC, Murphy JM, et al. Chondrogenic differentiation of cultured human mesenchymal stem cells from marrow. Tissue Eng. 1998;4(4):415-428.

37. Furumatsu T, Tsuda M, Taniguchi N, Tajima Y, Asahara H. Smad3 induces chondrogenesis through the activation of SOX9 via CREB-binding protein/p300 recruitment. J. Biol. Chem. 2005;280(9):8343-8350. 
38. Toma C, Pittenger MF, Cahill KS, Byrne BJ, Kessler PD. Human mesenchymal stem cells differentiate to a cardiomyocyte phenotype in the adult murine heart. Circulation. 2002;105(1):93-98.

39. Drost AC, Weng S, Feil G, et al. In vitro myogenic differentiation of human bone marrowderived mesenchymal stem cells as a potential treatment for urethral sphincter muscle repair. Ann. N. Y. Acad. Sci. 2009;1176:135-143.

40. Karnieli O, Izhar-Prato Y, Bulvik S, Efrat S. Generation of insulin-producing cells from human bone marrow mesenchymal stem cells by genetic manipulation. Stem Cells Dayt. Ohio. 2007;25(11):2837-2844.

41. Schroeder T. Asymmetric cell division in normal and malignant hematopoietic precursor cells. Cell Stem Cell. 2007;1(5):479-481.

42. Nakamura-Ishizu A, Takizawa $H$, Suda $T$. The analysis, roles and regulation of quiescence in hematopoietic stem cells. Dev. Camb. Engl. 2014;141(24):4656-4666.

43. Schofield $\mathrm{R}$. The relationship between the spleen colony-forming cell and the haemopoietic stem cell. Blood Cells. 1978;4(1-2):7-25.

44. Lord BI, Testa NG, Hendry JH. The relative spatial distributions of CFUs and CFUc in the normal mouse femur. Blood. 1975;46(1):65-72.

45. Dexter TM, Allen TD, Lajtha LG. Conditions controlling the proliferation of haemopoietic stem cells in vitro. J. Cell. Physiol. 1977;91(3):335-344.

46. Visnjic D, Kalajzic Z, Rowe DW, et al. Hematopoiesis Is Severely Altered in Mice with an Induced Osteoblast Deficiency. Blood. 2004;103(9):3258-3264.

47. Nagasawa T. CXC chemokine ligand 12 (CXCL12) and its receptor CXCR4. J. Mol. Med. Berl. Ger. 2014;92(5):433-439.

48. Ding L, Morrison SJ. Haematopoietic stem cells and early lymphoid progenitors occupy distinct bone marrow niches. Nature. 2013;495(7440):231-235.

49. Fortunel NO, Hatzfeld A, Hatzfeld JA. Transforming growth factor-beta: pleiotropic role in the regulation of hematopoiesis. Blood. 2000;96(6):2022-2036.

50. Liu L, Qin C, Butler WT, Ratner BD, Jiang S. Controlling the orientation of bone osteopontin via its specific binding with collagen I to modulate osteoblast adhesion. $J$. Biomed. Mater. Res. A. 2007;80(1):102-110.

51. Wodnar-Filipowicz A. Flt3 ligand: role in control of hematopoietic and immune functions of the bone marrow. News Physiol. Sci. Int. J. Physiol. Prod. Jointly Int. Union Physiol. Sci. Am. Physiol. Soc. 2003;18:247-251.

52. Hamilton JA. Colony-stimulating factors in inflammation and autoimmunity. Nat. Rev. Immunol. 2008;8(7):533-544.

53. Hyytiäinen M, Penttinen C, Keski-Oja J. Latent TGF-beta binding proteins: extracellular matrix association and roles in TGF-beta activation. Crit. Rev. Clin. Lab. Sci. 2004;41(3):233-264. 
54. Gattazzo F, Urciuolo A, Bonaldo P. Extracellular matrix: a dynamic microenvironment for stem cell niche. Biochim. Biophys. Acta. 2014;1840(8):2506-2519.

55. Gordon MY, Riley GP, Watt SM, Greaves MF. Compartmentalization of a haematopoietic growth factor (GM-CSF) by glycosaminoglycans in the bone marrow microenvironment. Nature. 1987;326(6111):403-405.

56. Roberts R, Gallagher J, Spooncer E, et al. Heparan sulphate bound growth factors: a mechanism for stromal cell mediated haemopoiesis. Nature. 1988;332(6162):376-378.

57. Sweeney EA, Lortat-Jacob H, Priestley GV, Nakamoto B, Papayannopoulou T. Sulfated polysaccharides increase plasma levels of SDF-1 in monkeys and mice: involvement in mobilization of stem/progenitor cells. Blood. 2002;99(1):44-51.

58. Saez B, Ferraro F, Yusuf RZ, et al. Inhibiting stromal cell heparan sulfate synthesis improves stem cell mobilization and enables engraftment without cytotoxic conditioning. Blood. 2014;124(19):2937-2947.

59. Solis MA, Chen $\mathrm{Y}-\mathrm{H}$, Wong TY, et al. Hyaluronan regulates cell behavior: a potential niche matrix for stem cells. Biochem. Res. Int. 2012;2012:346972.

60. Hoemann CD, Lafantaisie-Favreau C-H, Lascau-Coman V, Chen G, Guzmán-Morales J. The cartilage-bone interface. J. Knee Surg. 2012;25(2):85-97.

61. Pavlin D, Gluhak-Heinrich J. Effect of mechanical loading on periodontal cells. Crit. Rev. Oral Biol. Med. Off. Publ. Am. Assoc. Oral Biol. 2001;12(5):414-424.

62. Hoang QQ, Sicheri F, Howard AJ, Yang DSC. Bone recognition mechanism of porcine osteocalcin from crystal structure. Nature. 2003;425(6961):977-980.

63. Ritter NM, Farach-Carson MC, Butler WT. Evidence for the formation of a complex between osteopontin and osteocalcin. J. Bone Miner. Res. Off. J. Am. Soc. Bone Miner. Res. 1992;7(8):877-885.

64. Addison WN, Masica DL, Gray JJ, McKee MD. Phosphorylation-dependent inhibition of mineralization by osteopontin ASARM peptides is regulated by PHEX cleavage. J. Bone Miner. Res. Off. J. Am. Soc. Bone Miner. Res. 2010;25(4):695-705.

65. Tomoaia G, Pasca R-D. On the Collagen Mineralization. A Review. Clujul Med. 1957. 2015;88(1):15-22.

66. Clarke B. Normal bone anatomy and physiology. Clin. J. Am. Soc. Nephrol. CJASN. 2008;3 Suppl 3:S131-139.

67. Millán JL. Alkaline Phosphatases : Structure, substrate specificity and functional relatedness to other members of a large superfamily of enzymes. Purinergic Signal. 2006;2(2):335-341.

68. Hart A, Cota A, Makhdom A, Harvey EJ. The Role of Vitamin C in Orthopedic Trauma and Bone Health. Am. J. Orthop. Belle Mead NJ. 2015;44(7):306-311.

69. Herr P, Hausmann G, Basler K. WNT secretion and signalling in human disease. Trends Mol. Med. 2012;18(8):483-493. 
70. Gong Y, Slee RB, Fukai N, et al. LDL receptor-related protein 5 (LRP5) affects bone accrual and eye development. Cell. 2001;107(4):513-523.

71. Kato M, Patel MS, Levasseur R, et al. Cbfa1-independent decrease in osteoblast proliferation, osteopenia, and persistent embryonic eye vascularization in mice deficient in Lrp5, a Wnt coreceptor. J. Cell Biol. 2002;157(2):303-314.

72. Cruciat C-M, Niehrs C. Secreted and Transmembrane Wnt Inhibitors and Activators. Cold Spring Harb. Perspect. Biol. 2013;5(3):a015081.

73. Gaur T, Lengner CJ, Hovhannisyan $\mathrm{H}$, et al. Canonical WNT signaling promotes osteogenesis by directly stimulating Runx2 gene expression. J. Biol. Chem. 2005;280(39):33132-33140.

74. Stevens JR, Miranda-Carboni GA, Singer MA, et al. Wnt10b deficiency results in agedependent loss of bone mass and progressive reduction of mesenchymal progenitor cells. J. Bone Miner. Res. Off. J. Am. Soc. Bone Miner. Res. 2010;25(10):2138-2147.

75. Li J, Sarosi I, Cattley RC, et al. Dkk1-mediated inhibition of Wnt signaling in bone results in osteopenia. Bone. 2006;39(4):754-766.

76. Bodine PVN, Zhao W, Kharode YP, et al. The Wnt antagonist secreted frizzled-related protein-1 is a negative regulator of trabecular bone formation in adult mice. Mol. Endocrinol. Baltim. Md. 2004;18(5):1222-1237.

77. Mishra PJ, Mishra PJ, Humeniuk R, et al. Carcinoma-associated fibroblast-like differentiation of human mesenchymal stem cells. Cancer Res. 2008;68(11):4331-4339.

78. Cuiffo BG, Campagne A, Bell GW, et al. MSC-regulated microRNAs converge on the transcription factor FOXP2 and promote breast cancer metastasis. Cell Stem Cell. 2014;15(6):762-774.

79. Wang M-L, Pan C-M, Chiou S-H, et al. Oncostatin m modulates the mesenchymalepithelial transition of lung adenocarcinoma cells by a mesenchymal stem cell-mediated paracrine effect. Cancer Res. 2012;72(22):6051-6064.

80. Paunescu V, Bojin FM, Tatu CA, et al. Tumour-associated fibroblasts and mesenchymal stem cells: more similarities than differences. J. Cell. Mol. Med. 2011;15(3):635-646.

81. De Veirman K, Rao L, De Bruyne E, et al. Cancer associated fibroblasts and tumor growth: focus on multiple myeloma. Cancers. 2014;6(3):1363-1381.

82. Augsten M. Cancer-associated fibroblasts as another polarized cell type of the tumor microenvironment. Front. Oncol. 2014;4:62.

83. Liu Y, Deng B, Zhao Y, Xie S, Nie R. Differentiated markers in undifferentiated cells: expression of smooth muscle contractile proteins in multipotent bone marrow mesenchymal stem cells. Dev. Growth Differ. 2013;55(5):591-605.

84. Foronjy RF, Majka SM. The potential for resident lung mesenchymal stem cells to promote functional tissue regeneration: understanding microenvironmental cues. Cells. 2012;1(4):874. 
85. Chang Y, Li H, Guo Z. Mesenchymal stem cell-like properties in fibroblasts. Cell. Physiol. Biochem. Int. J. Exp. Cell. Physiol. Biochem. Pharmacol. 2014;34(3):703-714.

86. Gao H, Priebe W, Glod J, Banerjee D. Activation of signal transducers and activators of transcription 3 and focal adhesion kinase by stromal cell-derived factor 1 is required for migration of human mesenchymal stem cells in response to tumor cell-conditioned medium. Stem Cells Dayt. Ohio. 2009;27(4):857-865.

87. Rattigan Y, Hsu J-M, Mishra PJ, Glod J, Banerjee D. Interleukin 6 mediated recruitment of mesenchymal stem cells to the hypoxic tumor milieu. Exp. Cell Res. 2010;316(20):34173424.

88. Quante M, Tu SP, Tomita $\mathrm{H}$, et al. Bone marrow-derived myofibroblasts contribute to the mesenchymal stem cell niche and promote tumor growth. Cancer Cell. 2011;19(2):257272.

89. Patel SA, Meyer JR, Greco SJ, et al. Mesenchymal stem cells protect breast cancer cells through regulatory T cells: role of mesenchymal stem cell-derived TGF-beta. J. Immunol. Baltim. Md 1950. 2010;184(10):5885-5894.

90. Li M, Sun X, Kuang X, et al. Mesenchymal stem cells suppress CD8+ T cell-mediated activation by suppressing natural killer group 2 , member $D$ protein receptor expression and secretion of prostaglandin E2, indoleamine 2, 3-dioxygenase and transforming growth factor- $\beta$. Clin. Exp. Immunol. 2014;178(3):516-524.

91. Cho D-I, Kim MR, Jeong $\mathrm{H}$, et al. Mesenchymal stem cells reciprocally regulate the M1/M2 balance in mouse bone marrow-derived macrophages. Exp. Mol. Med. 2014;46:e70.

92. Suzuki K, Sun R, Origuchi M, et al. Mesenchymal stromal cells promote tumor growth through the enhancement of neovascularization. Mol. Med. Camb. Mass. 2011;17(78):579-587.

93. Raaijmakers MHGP, Mukherjee S, Guo S, et al. Bone progenitor dysfunction induces myelodysplasia and secondary leukaemia. Nature. 2010;464(7290):852-857.

94. Kode A, Manavalan JS, Mosialou I, et al. Leukaemogenesis induced by an activating $\beta$ catenin mutation in osteoblasts. Nature. 2014;506(7487):240-244.

95. Orlic D, Kajstura J, Chimenti S, et al. Bone marrow stem cells regenerate infarcted myocardium. Pediatr. Transplant. 2003;7 Suppl 3:86-88.

96. Lee $\mathrm{RH}$, Seo MJ, Reger RL, et al. Multipotent stromal cells from human marrow home to and promote repair of pancreatic islets and renal glomeruli in diabetic NOD/scid mice. Proc. Natl. Acad. Sci. U. S. A. 2006;103(46):17438-17443.

97. Horwitz EM, Gordon PL, Koo WKK, et al. Isolated allogeneic bone marrow-derived mesenchymal cells engraft and stimulate growth in children with osteogenesis imperfecta: Implications for cell therapy of bone. Proc. Natl. Acad. Sci. U. S. A. 2002;99(13):89328937. 
98. Dominici M, Marino R, Rasini V, et al. Donor cell-derived osteopoiesis originates from a self-renewing stem cell with a limited regenerative contribution after transplantation. Blood. 2008;111(8):4386-4391.

99. Götherström C, Westgren M, Shaw SWS, et al. Pre- and postnatal transplantation of fetal mesenchymal stem cells in osteogenesis imperfecta: a two-center experience. Stem Cells Transl. Med. 2014;3(2):255-264.

100. Bartholomew A, Sturgeon C, Siatskas M, et al. Mesenchymal stem cells suppress lymphocyte proliferation in vitro and prolong skin graft survival in vivo. Exp. Hematol. 2002;30(1):42-48.

101. Zappia E, Casazza S, Pedemonte E, et al. Mesenchymal stem cells ameliorate experimental autoimmune encephalomyelitis inducing T-cell anergy. Blood. 2005;106(5):1755-1761.

102. Li Y, Chen J, Chen XG, et al. Human marrow stromal cell therapy for stroke in rat: neurotrophins and functional recovery. Neurology. 2002;59(4):514-523.

103. Le Blanc K, Rasmusson I, Sundberg B, et al. Treatment of severe acute graft-versus-host disease with third party haploidentical mesenchymal stem cells. Lancet Lond. Engl. 2004;363(9419):1439-1441.

104. Weng JY, Du X, Geng SX, et al. Mesenchymal stem cell as salvage treatment for refractory chronic GVHD. Bone Marrow Transplant. 2010;45(12):1732-1740.

105. Uccelli A, Moretta L, Pistoia V. Mesenchymal stem cells in health and disease. Nat. Rev. Immunol. 2008;8(9):726-736.

106. Nieboer $\mathrm{P}$, de Vries $\mathrm{EG}$, Mulder $\mathrm{NH}$, et al. Long-term haematological recovery following high-dose chemotherapy with autologous bone marrow transplantation or peripheral stem cell transplantation in patients with solid tumours. Bone Marrow Transplant. 2001;27(9):959-966.

107. Wiser I, Orr N, Kaufman B, et al. Immunosuppressive Treatments Reduce Long-Term Immunity to Smallpox among Patients with Breast Cancer. J. Infect. Dis. 2010;201(10):1527-1534.

108. Kemp K, Morse R, Wexler S, et al. Chemotherapy-induced mesenchymal stem cell damage in patients with hematological malignancy. Ann. Hematol. 2010;89(7):701-713.

109. Dominici M, Rasini V, Bussolari R, et al. Restoration and reversible expansion of the osteoblastic hematopoietic stem cell niche after marrow radioablation. Blood. 2009;114(11):2333-2343.

110. Galotto M, Berisso G, Delfino L, et al. Stromal damage as consequence of high-dose chemo/radiotherapy in bone marrow transplant recipients. Exp. Hematol. 1999;27(9):14601466.

111. Pasquini MC, Zhu X. Current uses and outcomes of hematopoietic stem cell transplantation: CIBMTR Summary Slides, 2015. Available at: http://www.cibmtr.org 
112. Lucas $D$, Scheiermann $C$, Chow $A$, et al. Chemotherapy-induced bone marrow nerve injury impairs hematopoietic regeneration. Nat. Med. 2013;19(6):695-703.

113. Brenet F, Kermani P, Spektor R, Rafii S, Scandura JM. TGF $\beta$ restores hematopoietic homeostasis after myelosuppressive chemotherapy. J. Exp. Med. 2013;210(3):623-639.

114. Wang L, Clutter S, Benincosa J, Fortney J, Gibson LF. Activation of Transforming Growth Factor- $\beta 1 / p 38 /$ Smad3 Signaling in Stromal Cells Requires Reactive Oxygen SpeciesMediated MMP-2 Activity During Bone Marrow Damage. STEM CELLS. 2005;23(8):11221134.

115. Rellick SL, O'Leary H, Piktel D, et al. Bone marrow osteoblast damage by chemotherapeutic agents. PloS One. 2012;7(2):e30758.

116. Corazza F, Hermans C, Ferster A, et al. Bone marrow stroma damage induced by chemotherapy for acute lymphoblastic leukemia in children. Pediatr. Res. 2004;55(1):152158.

117. Ruckle J, Jacobs M, Kramer W, et al. Single-dose, randomized, double-blind, placebocontrolled study of ACE-011 (ActRIIA-IgG1) in postmenopausal women. J. Bone Miner. Res. Off. J. Am. Soc. Bone Miner. Res. 2009;24(4):744-752.

118. Raftopoulos H, Laadem A, Hesketh PJ, et al. Sotatercept (ACE-011) for the treatment of chemotherapy-induced anemia in patients with metastatic breast cancer or advanced or metastatic solid tumors treated with platinum-based chemotherapeutic regimens: results from two phase 2 studies. Support. Care Cancer Off. J. Multinatl. Assoc. Support. Care Cancer. 2016;24(4):1517-1525.

119. Georgiou KR, Scherer MA, Fan C-M, et al. Methotrexate chemotherapy reduces osteogenesis but increases adipogenic potential in the bone marrow. J. Cell. Physiol. 2012;227(3):909-918.

120. Davies JH, Evans BAJ, Jenney MEM, Gregory JW. Effects of chemotherapeutic agents on the function of primary human osteoblast-like cells derived from children. J. Clin. Endocrinol. Metab. 2003;88(12):6088-6097.

121. Tillmann V, Darlington ASE, Eiser C, Bishop NJ, Davies HA. Male sex and low physical activity are associated with reduced spine bone mineral density in survivors of childhood acute lymphoblastic leukemia. J. Bone Miner. Res. Off. J. Am. Soc. Bone Miner. Res. 2002;17(6):1073-1080.

122. Hui SK, Khalil A, Zhang Y, et al. Longitudinal assessment of bone loss from diagnostic computed tomography scans in gynecologic cancer patients treated with chemotherapy and radiation. Am. J. Obstet. Gynecol. 2010;203(4):353.e1-7.

123. Holmes SJ, Whitehouse RW, Clark ST, et al. Reduced bone mineral density in men following chemotherapy for Hodgkin's disease. Br. J. Cancer. 1994;70(2):371-375. 


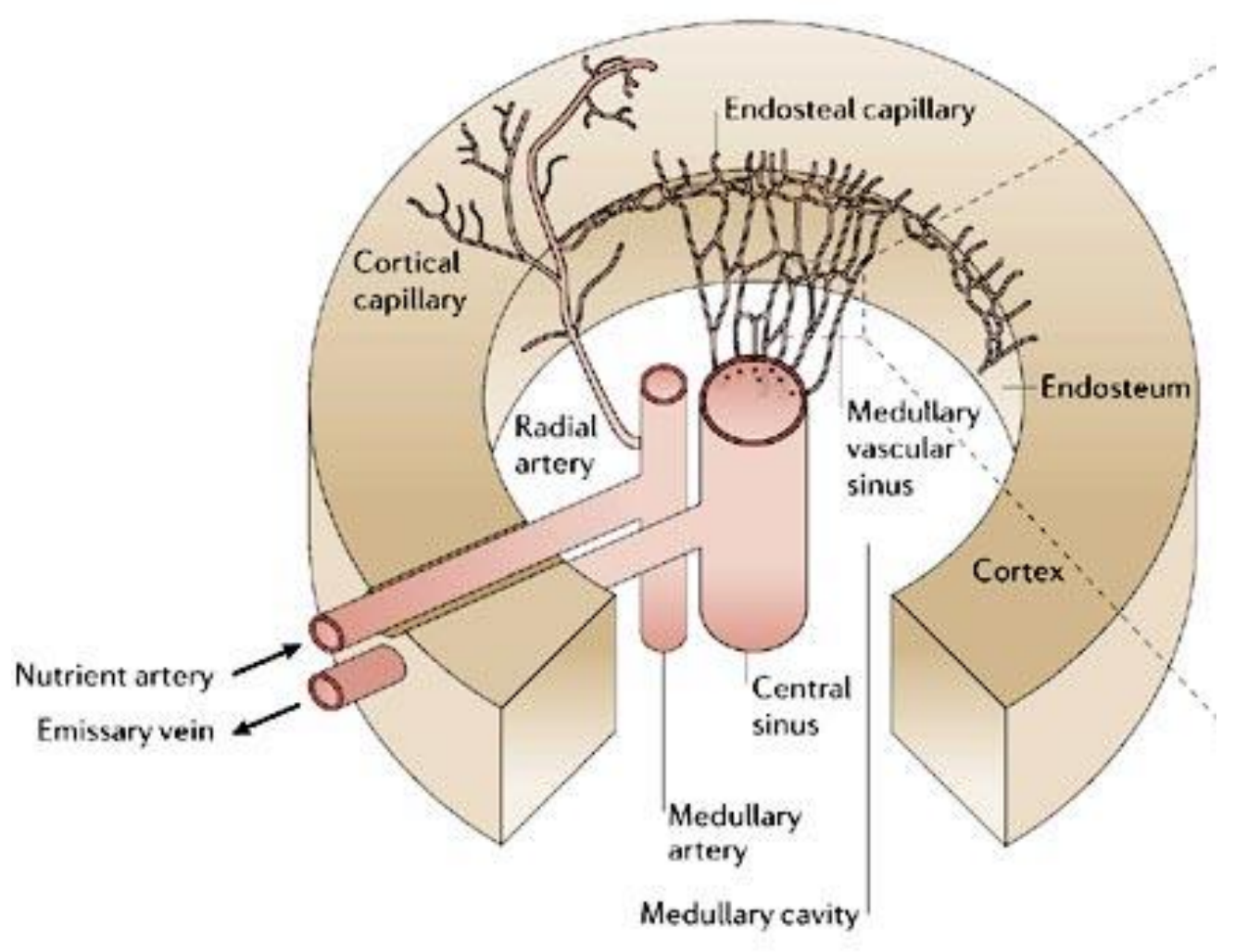

Figure 1. Structure of the mammalian femur.

Image adapted from Nagasawa T. 2006. Microenvironmental niches in the bone marrow required for B-cell development. Nature Reviews Immunology. Permission Number: 3835720017612. 


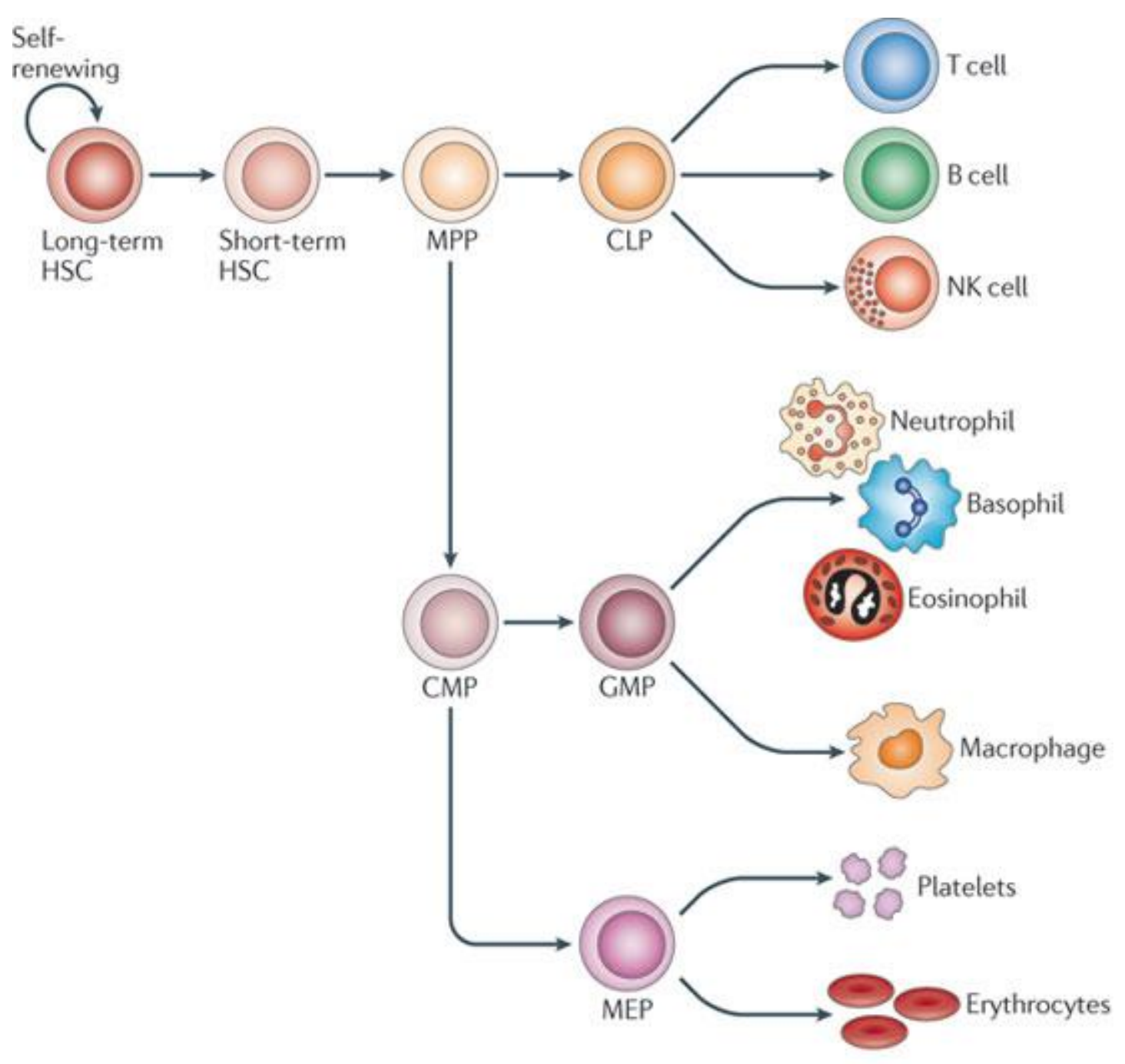

Nature Reviews | Immunology

Figure 2. Differentiation schema of hematopoietic cells.

King K and Goodall M. 2010. Inflammatory modulation of HSCs: viewing the HSC as a foundation for the immune response. Nature Reviews Immunology. Permission Number: 3835730219427. 


\title{
Chapter II
}

\section{Bone Marrow Osteoblast Vulnerability to Chemotherapy}

\author{
Marieta Gencheva ${ }^{1,5}$, Ian Hare ${ }^{1,2,5}$, Susan Kurian ${ }^{3}$, Jim Fortney ${ }^{1}$, Debbie Piktel ${ }^{1}$, Robert \\ Wysolmerski $^{1,4}$, Laura F. Gibson ${ }^{1,2^{\star}}$
}

${ }^{1}$ Alexander B. Osborn Hematopoietic Malignancy and Transplantation Program of the Mary Babb Randolph Cancer Center, Robert C. Byrd Health Sciences Center, West Virginia University School of Medicine, Morgantown, WV, USA

${ }^{2}$ Department of Microbiology, Immunology and Cell Biology, Robert C. Byrd Health Sciences Center, West Virginia University School of Medicine, Morgantown, WV, USA

${ }^{3}$ MBRCC summer fellowship program, Robert C. Byrd Health Sciences Center, West Virginia University School of Medicine, Morgantown, WV, USA

${ }^{4}$ Department of Neurobiology and Anatomy, Robert C. Byrd Health Sciences Center, West Virginia University School of Medicine, Morgantown, WV, USA

${ }^{5}$ The authors contributed equally to this work

This work is published in the European Journal of Haematology, 16 March, 2013 


\section{Abstract}

Osteoblasts are a major component of the bone marrow microenvironment which provide support for hematopoietic cell development. Functional disruption of any element of the bone marrow niche, including osteoblasts, can potentially impair hematopoiesis. We have studied the effect of two widely used drugs with different mechanisms of action, etoposide (VP16) and melphalan, on murine osteoblasts at distinct stages of maturation. VP16 and melphalan delayed maturation of preosteoblasts and altered CXCL12 protein levels, a key regulator of hematopoietic cell homing to the bone marrow. Sublethal concentrations of VP16 and melphalan also decreased the levels of several transcripts which contribute to the composition of the extracellular matrix (ECM) including osteopontin (OPN), osteocalcin (OCN) and collagen 1A1 (Col1a1). The impact of chemotherapy on message and protein levels for some targets was not always aligned, suggesting differential responses at the transcription and translation or protein stability levels. Since one of the main functions of a mature osteoblast is to synthesize ECM of a defined composition, disruption of the ratio of its components may be one mechanism by which chemotherapy affects the ability of osteoblasts to support hematopoietic recovery coincident with altered marrow architecture. Collectively, these observations suggest that the osteoblast compartment of the marrow hematopoietic niche is vulnerable to functional dysregulation by damage imposed by agents frequently used in clinical settings. Understanding the mechanistic underpinning of chemotherapy-induced changes on the hematopoietic support capacity of the marrow microenvironment may contribute to improved strategies to optimize patient recovery post-transplantation.

Keywords: bone marrow microenvironment, osteoblast, extracellular matrix, hematopoietic stem cell, chemotherapy 


\section{Introduction}

Hematopoietic stem (HSC) and progenitor cells require interaction with their niche in the bone marrow microenvironment for regulation of quiescence, cell cycle progression and differentiation [1-3]. Several types of cells in the bone marrow provide support to HSC and their lineage committed progenitors, including endothelial cells [4,5], CXCL12-abundant reticular cells (CAR) [6,7], nestin-positive mesenchymal stem cells (MSC) [8], CD146-positive subendothelial osteoprogenitors [9], and osteoblasts [10-12]. There is evidence to suggest that osteoblasts, as a defining component of the endosteal space, support HSC and regulate the fate of more differentiated hematopoietic progenitors $[10,11]$. Depletion of osteoblasts in mice profoundly affects hematopoiesis, manifested by decreases in HSC as well as lymphoid and myeloid progenitors [12], and B-cell commitment and maturation [13].

Osteoblasts are derived from MSCs through several somewhat poorly defined maturation stages. MSCs differentiate to osteoprogenitor cells through the activation of osteoblast-specific transcription factors such as Runx2 and subsequently Osterix (SP7) [14]. One of the earliest markers of preosteoblast cells is alkaline phosphatase (ALP) and its expression persists in subsequent maturation stages. Preosteoblasts also express Col1a1 protein, while at later stages they also start to produce OPN and further differentiate to mature osteoblasts which synthesize bone matrix [15]. These various markers provide tools to characterize specific stages of osteoblast differentiation.

In the current study we investigated how osteoblasts are affected by chemotherapy by utilizing an in vitro model to include drugs from two distinct classes used in clinical settings; Etoposide (VP16) which induces double strand DNA breaks by inhibition of topoisomerase II [16] and melphalan as an alkylating agent that damages DNA through crosslinking and the addition of adducts [17]. A number of chemotherapy drugs have been documented to functionally impair stromal cells in the bone marrow, including 1,3-bis(2-chloroethyl)-1- 
nitrosourea, busulfan, doxorubicin, VP16, metothrexate, and vincristine $[18,19]$ suggesting their potential to impair hematopoietic support capacity. Bone density and colony forming unit fibroblasts (CFU-F) were shown to decrease in patients following allogeneic stem cell transplant [20]. Earlier work from our laboratory indicated that treatment of primary human osteoblasts with VP16 and melphalan activated the TGF- $\beta 1$ pathway [21], consistent with the finding that bone marrow stromal cells established from leukemia patients treated with chemotherapy have elevated levels of TGF- $\beta 1$ [22]. Chemotherapy exposure was also reported to affect osteoblastspecific proteins including type I collagen and alkaline phosphatase in human primary osteoblasts, as well as the ability of mature osteoblasts to mineralize bone [23].

In the current study we have demonstrated that chemotherapy exposure decreases expression of CXCL12, a key factor mediating homing and hematopoietic cell adhesion in the bone marrow niche, while also decreasing differentiation stage-specific synthesis of osteoblast components of the ECM including OCN, OPN and Col1a1. Treatment of preosteoblasts with VP16 or melphalan impaired their differentiation potential and decreased transcripts associated with osteoblast differentiation (Runx2, SP7, and OCN). VP16 and melphalan also altered hematopoietic cell support provided by osteoblasts, demonstrated by an increased proportion of Lin- Sca1+c-kit+ stem cells and an increased number of viable Sca1-c-kit+IL7R- myeloid progenitor cells following co-culture with chemotherapy damaged osteoblasts. Taken together, these data indicate that functional dysregulation of the osteoblast component of the bone marrow microenvironment might include both chemokine gradient changes as well as altered ECM deposition.

\section{Materials and Methods}




\section{Cell lines, reagents and drug treatment}

Murine pre-osteoblast cell line MC3T3E1, subclone 4, was purchased from ATCC (ATCC CRL-2593). Both MC3T3E1 and 7F2 cell lines were cultured in $\square$-MEM supplemented with 10 $\%$ fetal bovine serum, $2 \mathrm{mM} \mathrm{L-Glutamine,} 1 \%$ sodium pyruvate, and penicillin/streptomycin, at $37^{\circ} \mathrm{C}$ in $6 \% \mathrm{CO}_{2}$. VP16 (Bristol Myers Squibb, New York, NY) was used at 50-100 uM for both MC3T3E1 and 7F2 cells; melphalan (Sigma) was dissolved in diluent containing $2 \%$ sodium citrate, $60 \%$ Propylene Glycol, and $5.2 \% \mathrm{EtOH}, \mathrm{pH} 1.1$ immediately prior to use.

\section{Differentiation of pre-osteoblast cells to mature osteoblasts}

MC3T3E1 and 7F2 cells were plated in 24 well plates as confluent monolayers. To induce osteoblast differentiation medium was supplemented with $100 \mathrm{ug} / \mathrm{ml}$ Ascorbic acid and $10 \mathrm{mM} \beta$-glycerol phosphate. Medium was exchanged every 3 days. 7F2 cells were assayed for differentiation after 7 days in culture and MC3T3E1 cells after 21 days. Cells were stained for alkaline phosphatase according to the manufacturer's protocol (SigmaFast BCIP/NBT kit or Leukocyte Alkaline Phosphatase kit, Sigma). Calcium deposition was monitored by Alizarin Red S staining as previously described [24].

\section{Isolation of RNA and RT-PCR}

RNA was isolated from osteoblasts using the RNeasy Mini kit with on-column DNase I digestion (Qiagen). One-step RT-PCR reactions were performed in triplicate using 50 ng of RNA per well, with the QuiantiTect SYBR Green RT-PCR kit (Qiagen) on an Applied Biosystems 7500 Real Time PCR machine. GUS B, GAPDH or B2M were used as loading controls. The following primer sets were purchased from Invitrogen: OCN (F: ACCCTGGCTGCGCTCTGTCTCT R: GATGCGTTTGTAGGCGGTCTTCA) Runx2 (F: TTTAGGGCGCATTCCTCATC 
R:TGTCCTTGTGGATTAAAAGGACTTG) SP7 (F: ACTCATCCCTATGGCTCGTG R:

GGTAGGGAGCTGGGTTAAGG) Col1a1 (F: TGTGTGCGATGACGTGCAAT

R:GGGTCCCTCGACTCCTACA) PPARG2 (F: TTTATGCTGTTATGGGTGAAACTC

R:AGAGGTCCACAGAGCTGATTCC) Adipoq (F:TGTTCCTCTTAATCCTGCCCA

R:CCAACCTGCACAAGTTCCCTT) CEBPA (F: TGGACAAGAACAGCAACGAG

R:TCACTGGTCAACTCCAGCAC) OPN (F: GTGAAAGTGACTGATTCTGGCA

R:TTTTCTTCAGAGGACACAGCATT) Primers for CXCL12, TGF- 31 , B2M, GUS B, BMP4, and GAPDH were purchased from Real Time Primers. Fold change was calculated by the $\Delta \Delta \mathrm{Ct}$ method [25].

\section{ELISA}

ELISAs for CXCL12 (R\&D) and OPN (R\&D) were performed according to the manufacturer's instructions. Cellular supernatants were evaluated, from osteoblasts that were either untreated, or treated for $24 \mathrm{~h}$ with $100 \mu \mathrm{M}$ VP16 or $25 \mu \mathrm{g} / \mathrm{ml}$ melphalan. For CXCL12 ELISAs medium was diluted 1:4 for 7F2 cells or used undiluted for MC3T3E1 cells. For OPN ELISA supernatants were diluted 1: 200.

\section{Scanning electron microscopy (SEM)}

Adult 20 week old Balb/c mice were treated either with VP16 diluent (65\% polyethylene glycol $300,8 \%$ Tween $80,30 \%$ ethanol, $0.2 \%$ citric acid, and $3 \%$ benzyl alcohol) or $20 \mathrm{mg} / \mathrm{kg}$ VP16 once a day, for $72 \mathrm{~h}$. Twenty four hours after the final treatment the mice were sacrificed and marrow was dislodged by rinsing femurs with PBS at $37^{\circ} \mathrm{C}$ to expose the endosteal surface. Femurs were subsequently washed in $37^{\circ} \mathrm{C}$ PBS prior to immersion fixation in $1 \%$ formaldehyde, $2.5 \%$ glutaraldehyde in $0.15 \mathrm{M}$ sodium cacodylate buffer $\mathrm{pH} 7.2$ for 48 hours at 
$4^{\circ} \mathrm{C}$. Samples were washed in sodium cacodylate buffer and post-fixed in $1 \%$ osmium tetroxide in the cacodylate buffer for $30 \mathrm{~min}$. Bones were rapidly dehydrated in graded steps of acetone (25\%-100\%) and critically point dried using a Tousimis 815 a Critical Point Dryer. Samples were mounted onto aluminum stubs and coated with a $40 \mathrm{~nm}$-thick layer of Platinum using a Temescal BJD 200 E-Beam Evaporator. Samples were examined with a JEOL JSM-7600-F scanning electron microscope.

\section{Isolation of murine hematopoietic stem and progenitor cells}

Adult Balb/c mice were sacrificed with bone marrow collected from femurs and tibia. Bone marrow cells were labeled with biotinylated antibodies specific for CD5, CD45R, CD11b, Gr-1 (Ly6G/C), 7-4 and Ter119 according to the manufacturer's protocol (Lineage cell depletion kit, Miltenyi Biotec). Lineage-negative (Lin-) cells were isolated on an AutoMacs column using the Deplete S program (purity $>90 \%$ ). To assay the effect of drugs on the capacity of osteoblasts to support survival and differentiation of HSC and progenitor cells, 40,000 Lin- cells were co-cultured with a monolayer of MC3T3E1 osteoblasts (170,000 cells per 24-well) for 5 days in RPMl containing $10 \%$ FBS and $10 \mathrm{ng} / \mathrm{ml} \mathrm{IL-3} \mathrm{(murine} \mathrm{rlL-3,} \mathrm{R \& D} \mathrm{Systems).} \mathrm{MC3T3E1}$ were either untreated or pre-treated with $50 \mu \mathrm{M} \mathrm{VP16} \mathrm{or} 25 \mu \mathrm{g} / \mathrm{ml}$ melphalan for $24 \mathrm{~h}$ and washed thoroughly before hematopoietic cells were added to the culture. Hematopoietic cells were collected at the termination of the experiment by collecting both the supernatant and the monolayer to include the hematopoietic cells attached to it. The two fractions of cells were combined and labeled with the following ratamouse antibodies (BD Biosciences): CD45-PECy7, CD45R (B220)-Alexa Fluor 700, CD16/32-FITC, Sca1-APC, CD117-PerCP-Cy5.5 and CD127-PE. The viability of the cells was monitored by staining with Violet Live/Dead fixable dead cell stain (Invitrogen). The samples were run on a FACS Aria flow cytometer (BD Biosciences) and data were analyzed by FCS Express software (De Novo Software). 
Osteoblasts were excluded from analysis by gating out live/CD45- cells.

\section{Statistical analysis}

One-Way ANOVA with Holm-Sidak post hoc multiple comparison was performed using SigmaPlot Version 11.0 to detect differences in RT-PCR and ELISA data. Differences were considered statistically significant when $p$-value was $<0.05$.

\section{$\underline{\text { Results }}$}

To study how osteoblasts at varied differentiation stages react to drug exposure, we used two mouse pre-osteoblast cell lines, MC3T3E1 (subclone 4) and 7F2. 7F2 cells were clonally derived from $\mathrm{p} 53^{-1-}$ mice, while MC3T3E1 are spontaneously immortalized mouse calvarial osteoblasts $[26,27]$. Both were reported to differentiate to mature osteoblasts in medium containing ascorbic acid and $\beta$-glycerol phosphate $[26,27]$. While both control and differentiated cells stained strongly for alkaline phosphatase, consistent with the appearance of strong ALP staining in early preosteoblast cells, only differentiated cells exhibited calcium deposits (Fig. 1 A, B). We further verified the differentiation to mature osteoblasts by monitoring the levels of OCN. Both 7F2 and MC3T3E1 cell lines exhibited induction of OCN mRNA with differentiation (Fig. 2). These observations suggest that the 7F2 and MC3T3E1 cells faithfully recapitulate osteoblast differentiation and are an appropriate model for pre-osteoblast development.

To determine the effect of VP16 and melphalan on the ability of osteoblasts to support hematopoietic cells, we evaluated the changes in osteoblast-specific transcripts and several factors important for hematopoietic support. Based on the rationale of the question, clinically relevant drugs and sub-lethal concentrations were chosen for evaluation to allow investigation of 
functional alterations of the microenvironment. Importantly, no significant reduction in osteoblast viability was observed, evaluated by PrestoBlue, MTT assay, and Trypan blue, in cultures treated at the concentrations of drugs utilized in this study (data not shown). In MC3T3E1 cells we detected an approximate 5 fold increase in the transcript levels of $\mathrm{OCN}$, both in undifferentiated and differentiated cells after VP16 treatment, while melphalan treatment increased OCN levels by 3 fold in undifferentiated cells and 1.5 fold in differentiated cells, respectively (Fig. 2A). OPN levels, which decrease with differentiation, were also elevated after VP16 and melphalan treatment in both control and differentiated MC3T3E1 cells. In contrast, the levels of Runx2, SP7 and Col1a1 decreased in both undifferentiated and differentiated MC3T3E1 cells with treatment. RunX2, SP7, and Col1a1 were affected similarly in 7F2 cells (Fig. 2B). For 7F2 cells, OCN levels were affected differently by VP16 and melphalan. While VP16 induced an increase in OCN transcript levels similar to MC3T3E1 cells, melphalan treatment resulted in decreased OCN levels.

We also evaluated the effect of VP16 and melphalan on the mRNA levels of CXCL12 and BMP4 (Fig. 2 and data not shown). The level BMP4 transcript was not affected by either differentiation or treatment with VP16 or melphalan in both 7F2 and MC3T3E1 cells (data not shown). VP16 treatment resulted in an approximate 2 fold increase in CXCL12, while melphalan decreased CXCL12 transcript levels, by 7.7 fold and 5.6 fold in undifferentiated and differentiated MC3T3E1 cells, respectively (Fig. 2A). 7F2 cells exhibited a decrease in CXCL12 after treatment with either VP16 or melphalan (Fig. 2B).

To investigate the changes in CXCL12 and OPN at a protein level, ELISA of culture supernatants was performed (Fig. 3). CXCL12 and OPN protein response following treatment differed from the transcriptional responses shown in Fig. 2. Secreted CXCL12 levels were significantly lower than untreated controls in undifferentiated and differentiated cells for both MC3T3E1 and 7F2 (Fig. 3 A and B). OPN was affected similarly in MC3T3E1 and 7F2 as well, 
showing a decrease in undifferentiated cells treated with melphalan and also differentiated compared to undifferentiated controls (Fig. 3C and data not shown). Since sublethal doses of chemotherapy altered the composition of extracellular matrix proteins and delayed osteoblast maturation we sought to determine what effect these agents had on the ultrastructure of the endosteum. To observe gross morphology of the endosteum following treatment with VP16 in vivo we performed SEM on diluent controls (Fig. 4, A and B) and VP16 treated (Fig. 4, C and D) long bones. The endosteal surface is composed of cord/rope like structures covered by a smooth surface coat (arrows) in diluent controls. Lacunae vary in size and number but were found to be present over the entire endosteal surface (Fig. 4A). In addition, smooth electron dense patches ( ${ }^{*}$, Fig. 4A) were also identified on the endosteal surface (Fig. 4B). Overall, the endosteal surface was intact and exhibited a uniform surface coat. VP16 treatment caused disruption of the endosteal surface lining (Fig. 4C). Material composing the electron dense patches condensed into clumps ( ${ }^{*}$, Fig. 4C) exposing the underlying matrix. The surface coat covering the cord/rope structures was gone (Fig. 4D) exposing collagen fibers (arrows, inset, Fig. 4D). The appearance of the endosteum following treatment with VP16 provides only a general visual representation of the damage caused by VP16 in the osteoblastic niche but further characterization is required to come to specific conclusions beyond that.

We next determined whether treatment of 7F2 preosteoblasts with VP16 or melphalan would affect their ability to differentiate to mature osteoblasts, utilizing ALP as an indicator. Overall staining for ALP was reduced by drug treatment in cells cultured in both control and differentiation medium (Fig. 5B). At the same time, microscopic examination of the cultures revealed a population of cells staining intensely for ALP (Fig. 5A), which would correspond to cells at an earlier stage of osteoblast differentiation. We further determined the OCN, Runx2, SP7, Col1a1 and CXCL12 transcript levels of cells which were treated with drugs and then allowed to differentiate for 7 days (Fig. 5C). CXCL12 mRNA abundance did not change with 
differentiation or after drug treatment, but OCN mRNA decreased approximately 20 fold after VP16 exposure and 10 fold after melphalan exposure. Similarly, a statistically significant decrease in transcript levels was detected for RUNX2, SP7 and Col1a1. These data are consistent with delayed osteoblast maturation after exposure to VP16 and melphalan. MC3T3E1 cells had similar results (data not shown).

Both 7F2 cells and MC3T3E1 cells treated with VP16 or melphalan exhibited vacuoles in the cells, reminiscent of lipid droplets. Based on reports of adipocyte differentiation after chemotherapy treatment of osteoblasts [28] we stained the cultures for the presence of lipids with Oil Red and confirmed that the observed vacuoles indeed contained lipids (Fig. 5D, top and data not shown). However, there was no upregulation of adipocyte-specific transcripts and instead PPARG2, CEBPA, and Adipoq decreased significantly after drug treatment of 7F2 cells, both in control and differentiation medium (Fig. 5E, bottom). Thus, it is unlikely that drug-treated cells, in this model, undergo adipocyte differentiation.

We next determined the effect of VP16 and melphalan on the ability of MC3T3E1 cells to support HSC utilizing Lineage-negative cells co-cultured with a monolayer of MC3T3E1 cells (untreated or treated with VP16 or melphalan as described in materials and methods). To follow HSC support in vivo, we observed Lin-Sca1+c-kit+ cells (LSK), a cellular subset which would mark about $25 \%$ of the hematopoietic stem/progenitor cells (HSPC) in Balb/c mice [29]. In the Lin- fraction of cells we determined the relative percentage of HSPCs, myeloid progenitors (Sca1-c-kit+IL7R-), lymphoid progenitors (Sca1+c-kit+IL7R+), as well as mature myeloid cells $(\mathrm{CD} 16 / \mathrm{CD} 32+)$ at the day of plating and after 5 days in culture with chemotherapy pre-treated or matched untreated control MC3T3E1 cells. After 5 days in culture about $80 \%$ of the Lin- cells incubated in media alone were viable, while Lin- cells in co-culture with untreated "healthy" osteoblasts were approximately 94\% viable (Fig. 6A). Osteoblasts pre-treated with either VP16 or melphalan also supported the Lin- cell survival to a degree higher than media alone. 
Hematopoietic cell death in co-cultures of chemotherapy pre-treated osteoblasts was noted to be slightly higher than in cultures with control osteoblasts, at approximately $8.5 \%$ and $12.0 \%$, respectively, compared to $6 \%$ for untreated osteoblasts. Osteoblasts generally supported differentiation of Lin- cells to CD16/CD32+ mature myeloid cells (Fig. 6B). Melphalan-treated osteoblasts supported marginally less myeloid cell differentiation compared to untreated cells (88.8\% vs. $95.3 \%$ ), while VP16 had no effect on MC3T3E1 ability to support myeloid differentiation.

Because the Lin- compartment contains not only stem cells but also committed hematopoietic progenitors, we further evaluated the percentage of LSK cells which are IL7R+ (lymphoid progenitors) and the Lin-Sca1-c-kit+IL7R- as myeloid progenitors in contrast to mature CD16/CD32+ myeloid cells noted earlier [30]. We detected a higher percentage of both lymphoid and myeloid progenitors co-cultured with VP16 or melphalan pre-treated osteoblasts compared to untreated osteoblast layers after 5 days in culture (Fig. 6 B and D). Our results indicate that VP16 and melphalan modulate the capacity of osteoblasts to support hematopoiesis and alter the ratio of stem and progenitor cells in this in vitro model, although the quantitative differences were modest.

\section{Discussion}

The current study focused on the effects of VP16 and melphalan on osteoblast cells at different stages of maturation. Cell lines utilized have been confirmed to be able to differentiate to mature osteoblasts by calcium deposition detected by Alizarin Red staining and upregulation of osteocalcin (Fig. 1). Both preosteoblast cells and mature osteoblasts expressed ALP which is consistent with its onset of detection in early preosteoblast cells [31]. We also detected similar amounts of osteoblast-specific transcription factors Runx2 and SP7 in preosteoblasts and 
mature osteoblasts, consistent with the MC3T3E1 and 7F2 cells being downstream of the MSC stage [14]. Collectively these observations suggested a reasonable in vitro model in which to evaluate whether chemotherapy vulnerability varies with stage of differentiation.

VP16 and melphalan altered the expression of several osteoblast-specific transcripts (Fig. 2). The Runx2 and SP7 transcription factors, and Col1a1 were uniformly downregulated in both MC3T3E1 and 7F2 cells regardless of differentiation stage following treatment. On the other hand, OCN is differentially regulated in 7F2 and MC3T3E1 cells; treatment with drugs increases OCN levels in MC3T3E1 cells, while melphalan decreases OCN levels in 7F2 cells. This might result from different basal OCN levels in 7F2 and MC3T3E1 cells, since the lack of p53 in 7F2 cells contributes to faster growth and osteoblast differentiation in this cell line. Since Col1a1 is a major component of the ECM, and OCN and OPN are immobilized on the ECM, these chemotherapy drugs have the potential of altering the adhesion properties of the ECM of both pre- and mature osteoblasts. Consistent with this, we detected disruption of the integrity of the "architecture" of the endosteal region of femurs from VP16-treated mice by SEM (Fig. 4).

More specific analyses will be required to characterize the exact anatomical alterations, and the scope of specific cellular elements that are impacted on, but the observation is consistent with a general vulnerability of this anatomical site to chemotherapy induced stress. Melphalan exposure yielded similar results (data not shown).

We have also observed that VP16 and melphalan impair factors (including CXCL12 and OPN) which are important for hematopoietic cell differentiation (Figs. 2 and 3). We observed that although VP16 treatment of MC3T3E1 cells increased CXCL12 transcripts, secreted protein was decreased in both 7F2 and MC3T3E1 with treatment of either drug relative to untreated controls (Fig. 2 and 3). The differences in CXCL12 transcriptional regulation between 7F2 and MC3T3E1 might be linked to the fact that the cell lines have different basal expressions of CXCL12, produced at much higher levels in 7F2 cells. Again, this could be explained by the fact 
that 7F2 cells lack p53, which has been reported to downregulate secreted CXCL12 in fibroblast cells [32]. Our results are also consistent with a previous report that in human osteoblasts CXCL12 levels are sustainably reduced following treatment with VP16 and melphalan, resulting in diminished adhesion of CXCR4+ hematopoietic cells [21]. An additional report has linked the absence of CXCL12 with HSC quiescence, but also with increased myeloid differentiation [7]. Since in this model CXCL12 was reduced by ablation of CXCL12 abundant reticular cells, which also secrete other cytokines and factors important for HSC [7], we feel that the distinct observations related to the role of CXCL12 in hematopoietic cell support could be explained by differences in the experimental settings and interplay between several factors.

We further evaluated the levels of OPN protein and detected a decrease after melphalan treatment in undifferentiated MC3T3E1 cells (Fig. 3). It has been shown that OPN inhibits HSC proliferation and reduces differentiation of HSCs to myeloid cells in vitro [33]. We have also detected altered Lin- support and hematopoietic cell differentiation of chemotherapy pre-treated MC3T3E1 cells (Fig. 6), consistent with the above observation. Deregulation of OPN in our model provides a potential mechanism by which hematopoiesis can be altered by chemotherapeutics.

Finally, we determined that VP16 and melphalan also disrupt the ability of preosteoblast cells to differentiate to mature osteoblasts. Drug treatment induced delayed osteoblast maturation, as evidenced by a significant decrease in a number of transcripts required for establishment of the mature osteoblast, including OCN, Runx2, SP7, and Col1a1. We also detected the appearance of a population of cells staining intensely for ALP, consistent with ALP being expressed at the highest level in preosteoblast cells (Fig. 5). ALP increases, and Col1a1 decreases, have been noted before in primary human osteoblasts from patients undergoing chemotherapy with various drugs [23], and a preferential drug effect on viability of preosteoblast cell lines compared to cultures containing mature osteoblasts was also reported [19]. 
Additionally, VP16 and melphalan treated osteoblasts exhibited increased lipid content but no coincident upregulation of adipocyte-specific markers (Fig. 5D and E). Increased lipid staining after in vivo treatment with 5-fluorouracil has been interpreted before to indicate preferential adipocyte differentiation of murine CXCL12-expressing cells [6], but we did not see a correlation between the lipid increase and appearance of adipocyte-specific differentiation markers. Thus, the increased lipid content of the chemotherapy treated osteoblasts could be explained by an alternative mechanism, with one possibility being autophagosome formation. Results from the current study contribute to better understanding the scope of effects of genotoxic stress and DNA damage on the bone marrow microenvironment. DNA double strand breaks have been shown to promote cell differentiation in normal B-cell development [34], in neuronal stem and progenitor cells [35], and in melanocyte stem cells [36]. Conversely, DNA damage impairs proper differentiation of myoblasts when applied before induction of differentiation [37]. Our data in a model of pre- and mature osteoblasts are consistent with the assertion that DNA damage can influence differentiation in a component of the marrow microenvironment. This damage is also associated with alteration of ECM gene expression profiles, disrupted structural integrity, and dysregulated support of HSC differentiation. A better understanding of the diversity of vulnerability of populations of cells in the marrow to drugs with distinct mechanisms of action may support improved approaches to pre-transplant conditioning and subsequent restoration of steady state hematopoiesis.

Acknowledgments: This work was supported by National Institutes of Health (NIH) R01 HL056888 (LFG), NIH P20 RR016440 (LFG), National Cancer Institute (NCI) RO1 CA134573 (LFG), the Alexander B. Osborn Hematopoietic Malignancy and Transplantation Program and the WV Research Trust Fund. We are grateful for the support of Kathy Brundage of the Flow Cytometer Facility at WVU supported by P30GM103488 and P30RR032138 (FACS Calibur) and 
P30GM103488, P30RR032138, RR020866, and RC-P1101809 (FACS Aria). SEM was performed at the WVU Shared Research Facilities.

\section{References}

1. Morrison SJ, Spradling AC. Stem Cells and Niches: Mechanisms That Promote Stem Cell Maintenance throughout Life. Cell. 2008; 132: 598-611.

2. Mercier FE, Ragu C, Scadden DT. The bone marrow at the crossroads of blood and immunity. Nature Reviews Immunology. 2011; 12: 49-60.

3. Nagasawa T, Omatsu Y, Sugiyama T. Control of hematopoietic stem cells by the bone marrow stromal niche: the role of reticular cells. Trends in Immunology. 2011; 32: 315-20.

4. Kiel MJ, Yilmaz OH, Iwashita T, Yilmaz OH, Terhorst C, Morrison SJ. SLAM family receptors distinguish hematopoietic stem and progenitor cells and reveal endothelial niches for stem cells. Cell. 2005; 121: 1109-21.

5. Ding L, Saunders TL, Enikolopov G, Morrison SJ. Endothelial and perivascular cells maintain haematopoietic stem cells. Nature. 2012; 481: 457-62.

6. Sugiyama T, Kohara H, Noda M, Nagasawa T. Maintenance of the Hematopoietic Stem Cell Pool by CXCL12-CXCR4 Chemokine Signaling in Bone Marrow Stromal Cell Niches. Immunity. 2006; 25: 977-88.

7. Omatsu Y, Sugiyama T, Kohara H, Kondoh G, Fujii N, Kohno K, Nagasawa T. The Essential Functions of Adipo-osteogenic Progenitors as the Hematopoietic Stem and Progenitor Cell Niche. Immunity. 2010; 33: 387-99.

8. Méndez-Ferrer S, Michurina TV, Ferraro F, Mazloom AR, Macarthur BD, Lira SA, Scadden DT, Ma'ayan A, Enikolopov GN, Frenette PS. Mesenchymal and haematopoietic stem cells form a unique bone marrow niche. Nature. 2010; 466: 829-34.

9. Sacchetti B, Funari A, Michienzi S, et al. Self-renewing osteoprogenitors in bone marrow sinusoids can organize a hematopoietic microenvironment. Cell. 2007; 131: 324-36.

10. Calvi LM, Adams GB, Weibrecht KW, et al. Osteoblastic cells regulate the haematopoietic stem cell niche. Nature. 2003; 425: 841-6.

11. Zhang J, Niu C, Ye L, et al. Identification of the haematopoietic stem cell niche and control of the niche size. Nature. 2003; 425: 836-41.

12. Visnjic D, Kalajzic Z, Rowe DW, Katavic V, Lorenzo J, Aguila HL. Hematopoiesis Is Severely Altered in Mice with an Induced Osteoblast Deficiency. Blood. 2004; 103: 325864 . 
13. Zhu J, Garrett R, Jung Y, et al. Osteoblasts Support B-Lymphocyte Commitment and Differentiation from Hematopoietic Stem Cells. Blood. 2007; 109: 3706-12.

14. Nakashima K, De Crombrugghe B. Transcriptional mechanisms in osteoblast differentiation and bone formation. Trends in Genetics. 2003; 19: 458-66.

15. Kalajzic I, Kalajzic Z, Kaliterna M, Gronowicz G, Clark SH, Lichtler AC, Rowe D. Use of Type I Collagen Green Fluorescent Protein Transgenes to Identify Subpopulations of Cells at Different Stages of the Osteoblast Lineage. Journal of Bone and Mineral Research. 2002; 17: 15-25.

16. Pommier $\mathrm{Y}$, Leo $\mathrm{E}$, Zhang $\mathrm{H}$, Marchand $\mathrm{C}$. DNA topoisomerases and their poisoning by anticancer and antibacterial drugs. Chem. Biol. 2010; 17: 421-33.

17. Hall AG, Tilby MJ. Mechanisms of action of, and modes of resistance to, alkylating agents used in the treatment of haematological malignancies. Blood Rev. 1992; 6: 163-73.

18. Guest I, Uetrecht J. Drugs toxic to the bone marrow that target the stromal cells. Immunopharmacology. 2000; 46: 103-12.

19. Davies JH, Evans BAJ, Jenney MEM, Gregory JW. In vitro effects of chemotherapeutic agents on human osteoblast-like cells. Calcif. Tissue Int. 2002; 70: 408-15.

20. Tauchmanovà L, Serio B, Del Puente A, Risitano AM, Esposito A, De Rosa G, Lombardi G, Colao A, Rotoli B, Selleri C. Long-lasting bone damage detected by dual-energy x-ray absorptiometry, phalangeal osteosonogrammetry, and in vitro growth of marrow stromal cells after allogeneic stem cell transplantation. J. Clin. Endocrinol. Metab. 2002; 87: 505865.

21. Rellick SL, O'Leary H, Piktel D, et al. Bone marrow osteoblast damage by chemotherapeutic agents. PLoS ONE. 2012; 7: e30758.

22. Corazza F, Hermans C, Ferster A, Fondu P, Demulder A, Sariban E. Bone marrow stroma damage induced by chemotherapy for acute lymphoblastic leukemia in children. Pediatr. Res. 2004; 55: 152-8.

23. Davies JH, Evans BAJ, Jenney MEM, Gregory JW. Effects of chemotherapeutic agents on the function of primary human osteoblast-like cells derived from children. J. Clin. Endocrinol. Metab. 2003; 88: 6088-97.

24. Reichert JC, Burke LJ, Clements JA, Hutmacher DW. Preparation of mineralised matrices secreted from human primary osteoblasts for analysis of the interaction of cancer cells and the bone microenvironment. Protocol Exchange [Internet]. 2008 [cited 2012 Jun 12]; .

25. Livak KJ, Schmittgen TD. Analysis of relative gene expression data using real-time quantitative PCR and the 2(-Delta Delta C(T)) Method. Methods. 2001; 25: 402-8.

26. Quarles LD, Yohay DA, Lever LW, Caton R, Wenstrup RJ. Distinct proliferative and differentiated stages of murine MC3T3-E1 cells in culture: an in vitro model of osteoblast development. J. Bone Miner. Res. 1992; 7: 683-92.

27. Thompson DL, Lum KD, Nygaard SC, Kuestner RE, Kelly KA, Gimble JM, Moore EE. The derivation and characterization of stromal cell lines from the bone marrow of p53-/- mice: 
new insights into osteoblast and adipocyte differentiation. J. Bone Miner. Res. 1998; 13: 195-204.

28. Nakamura Y, Arai F, Iwasaki H, Hosokawa K, Kobayashi I, Gomei Y, Matsumoto Y, Yoshihara H, Suda T. Isolation and Characterization of Endosteal Niche Cell Populations That Regulate Hematopoietic Stem Cells. Blood. 2010; 116: 1422-32.

29. Spangrude GJ, Brooks DM. Mouse strain variability in the expression of the hematopoietic stem cell antigen Ly-6A/E by bone marrow cells. Blood. 1993; 82: 3327-32.

30. Kondo M, Wagers AJ, Manz MG, Prohaska SS, Scherer DC, Beilhack GF, Shizuru JA, Weissman IL. BIOLOGY OF HEMATOPOIETIC STEM CELLS AND PROGENITORS: Implications for Clinical Application. Annual Review of Immunology. 2003; 21: 759-806.

31. Kalajzic I, Staal A, Yang W-P, et al. Expression profile of osteoblast lineage at defined stages of differentiation. J. Biol. Chem. 2005; 280: 24618-26.

32. Moskovits N, Kalinkovich A, Bar J, Lapidot T, Oren M. p53 Attenuates cancer cell migration and invasion through repression of SDF-1/CXCL12 expression in stromal fibroblasts. Cancer Res. 2006; 66: 10671-6.

33. Nilsson SK, Johnston HM, Whitty GA, Williams B, Webb RJ, Denhardt DT, Bertoncello I, Bendall LJ, Simmons PJ, Haylock DN. Osteopontin, a key component of the hematopoietic stem cell niche and regulator of primitive hematopoietic progenitor cells. Blood. 2005; 106: 1232-9.

34. Bredemeyer AL, Helmink BA, Innes CL, et al. DNA double-strand breaks activate a multifunctional genetic program in developing lymphocytes. Nature. 2008; 456: 819-23.

35. Zheng $\mathrm{H}$, Ying $\mathrm{H}$, Yan $\mathrm{H}$, et al. $\mathrm{p} 53$ and Pten control neural and glioma stem/progenitor cell renewal and differentiation. Nature. 2008; 455: 1129-33.

36. Inomata K, Aoto T, Binh NT, et al. Genotoxic stress abrogates renewal of melanocyte stem cells by triggering their differentiation. Cell. 2009; 137: 1088-99.

37. Puri PL, Bhakta K, Wood LD, Costanzo A, Zhu J, Wang JYJ. A myogenic differentiation checkpoint activated by genotoxic stress. Nat. Genet. 2002; 32: 585-93. 


\section{Figure Legends}

Figure 1. Differentiation of MC3T3E1 and 7F2 cells to mature osteoblasts.

7F2 (A) or MC3T3E1 (B) cells were incubated either with regular growth medium (undifferentiated) or osteoblast differentiation medium (differentiated) for 7 days (7F2 cells) or 21 days (MC3T3E1 cells), respectively. Cells were stained for Alkaline phosphatase (ALP) and Alizarin Red as a measure of osteoblast differentiation.

Figure 2. Effect of VP16 and melphalan on the expression of osteoblast-specific transcripts. MC3T3E1 cells were incubated either in regular growth medium (undifferentiated) or osteoblast differentiation medium (differentiated) for 21 days, after which the cells were treated with 100 $\mu \mathrm{M}$ VP16 or $25 \mu \mathrm{g} / \mathrm{ml}$ melphalan (A). Total RNA was isolated and qPCR was performed with primers specific for OCN, Runx2, SP7, Col1a1, OPN and CXCL12. Relative expression was normalized to the expression in undifferentiated untreated cells (undifferentiated untr). (B) 7F2 cells were differentiated for 7 days and treated with $100 \mu \mathrm{M}$ VP16 or $25 \mu \mathrm{g} / \mathrm{ml}$ melphalan (B) and then processed as described for (A). Error bars denote standard deviation from triplicate measurements in a representative experiment. * indicates significantly greater or lesser than untreated control (for drug treatments) or undifferentiated untreated control, $p$-value $<0.05$, One-Way ANOVA.

Figure 3. Effect of VP16 and melphalan on the levels of secreted CXCL12 and OPN. MC3T3E1 cells were incubated either in regular growth medium (undifferentiated) or osteoblast differentiation medium (differentiated) for 21 days, after which medium was removed and replaced with fresh medium (untreated) or medium containing $100 \mu \mathrm{M} \mathrm{VP16} \mathrm{or} 25 \mu \mathrm{g} / \mathrm{ml}$ 
melphalan. After 24 hours, medium was removed and ELISAs were performed for CXCL12 (A) and OPN (C). 7F2 cells were differentiated for 7 days then treated as in A prior to ELISA for CXCL12 (B). * indicates significantly greater or lesser than untreated control (for drug treatments) or undifferentiated untreated control, $\mathrm{p}$-value $<0.05$, One-Way ANOVA, $n=3$.

Figure 4. Scanning electron microscopy of murine bone. Representative scanning electron micrographs of mouse control and VP16-treated long bones. In diluent-treated controls (A, B) the endosteum consists of an intact uniform surface coat covering the underlying ECM. (B). Enlarged view of smooth electron dense patches ( ${ }^{*}$, Fig. 3A) found dispersed throughout the endosteum. VP16 treatment (C, D) caused disruption of the endosteal surface coat $\left(^{*}\right)$ exposing the underlying extracellular fibrillar matrix (arrows inset). Bar, $10 \mathrm{uM}$.

Figure 5. Effect of VP16 and melphalan on the differentiation potential of preosteoblast cells.

7F2 cells were exposed for $24 \mathrm{~h}$ to $50 \mu \mathrm{M}$ VP16, $25 \mu \mathrm{g} / \mathrm{ml}$ melphalan, VP16 diluent (VP16 dil) or melphalan diluent (Mel dil), respectively. Following treatment cells were washed and incubated with regular growth medium (undifferentiated) or osteoblast differentiation medium (differentiated) for 7 days. Cells were stained for Alkaline phosphatase (ALP) and images were taken with (A) or without (B) 20x magnification. (C). Total RNA was isolated from cells treated as in A and qPCR was performed with primers specific for OCN, Runx2, SP7, Col1a1 and CXCL12. Relative expression of the genes was normalized to the expression in untreated undifferentiated cells. (D). Oil Red staining for lipids in cells treated as in (A). Real time PCR for the adipocytespecific transcripts PPARG2, CEBPA, and Adipoq (E). Error bars denote standard deviation from triplicate measurements. * indicates significantly greater or lesser than untreated control (for drug treatments) or undifferentiated untreated control, p-value $<0.05$, One-Way ANOVA. 
Figure 6. Support of murine hematopoietic stem and progenitor cells by osteoblasts treated with VP16 or melphalan. MC3T3E1 cells were seeded as monolayers in 24-well plates. Cells were treated with $50 \mu \mathrm{M}$ VP16, $25 \mu \mathrm{g} / \mathrm{ml}$ melphalan, or were left untreated for $24 \mathrm{~h}$. After several washes of the osteoblasts, 40,000 freshly isolated lineage negative cells were added to the osteoblasts in RPMI medium containing $10 \% \mathrm{FBS}$ and $10 \mathrm{ng} / \mathrm{ml} \mathrm{IL-3.} \mathrm{Cultures} \mathrm{were} \mathrm{incubated}$ for 5 days, after which cells were trypsinized and stained with Violet Live/Dead fixable dead cell stain and antibodies to CD45, Sca-1, c-kit, CD16/32, B220 and CD127. Number of dead cells (A), Sca+c-kit+ (LSK) and lymphoid progenitors (CLP) (C), myeloid progenitors (D) and CD16/CD32+ myeloid cells (B) was determined by flow cytometry. 

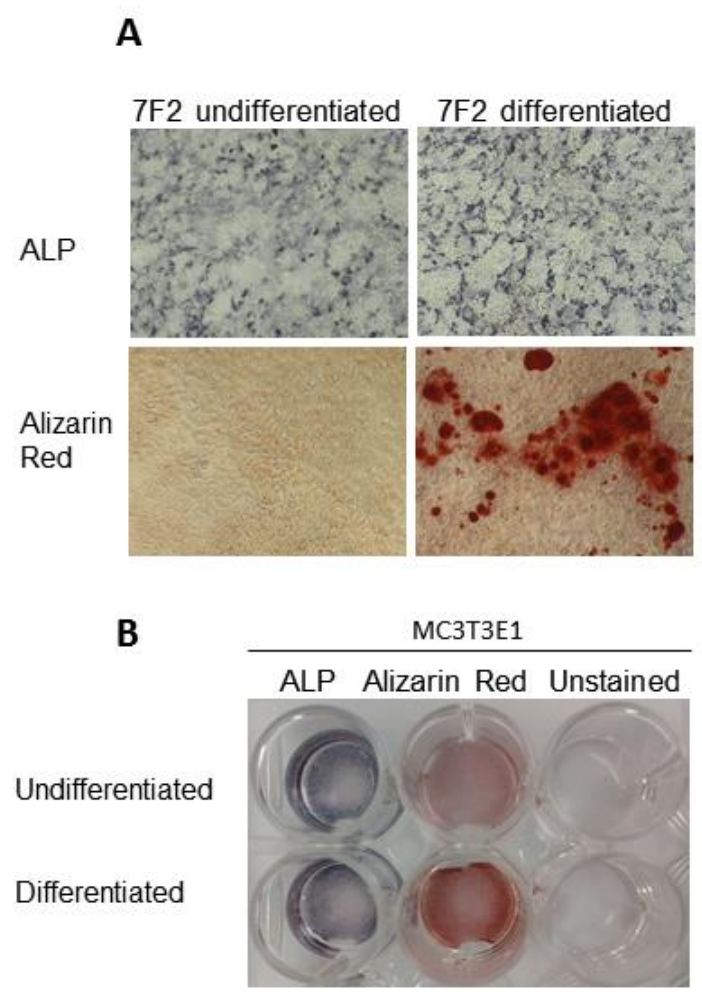

Figure 1. Differentiation of MC3T3E1 and 7F2 cells to mature osteoblasts.

Gencheva and Hare et al. 2013. Bone marrow osteoblast vulnerability to chemotherapy. European Journal of Haematology. Permission Number: 3835731013613. 

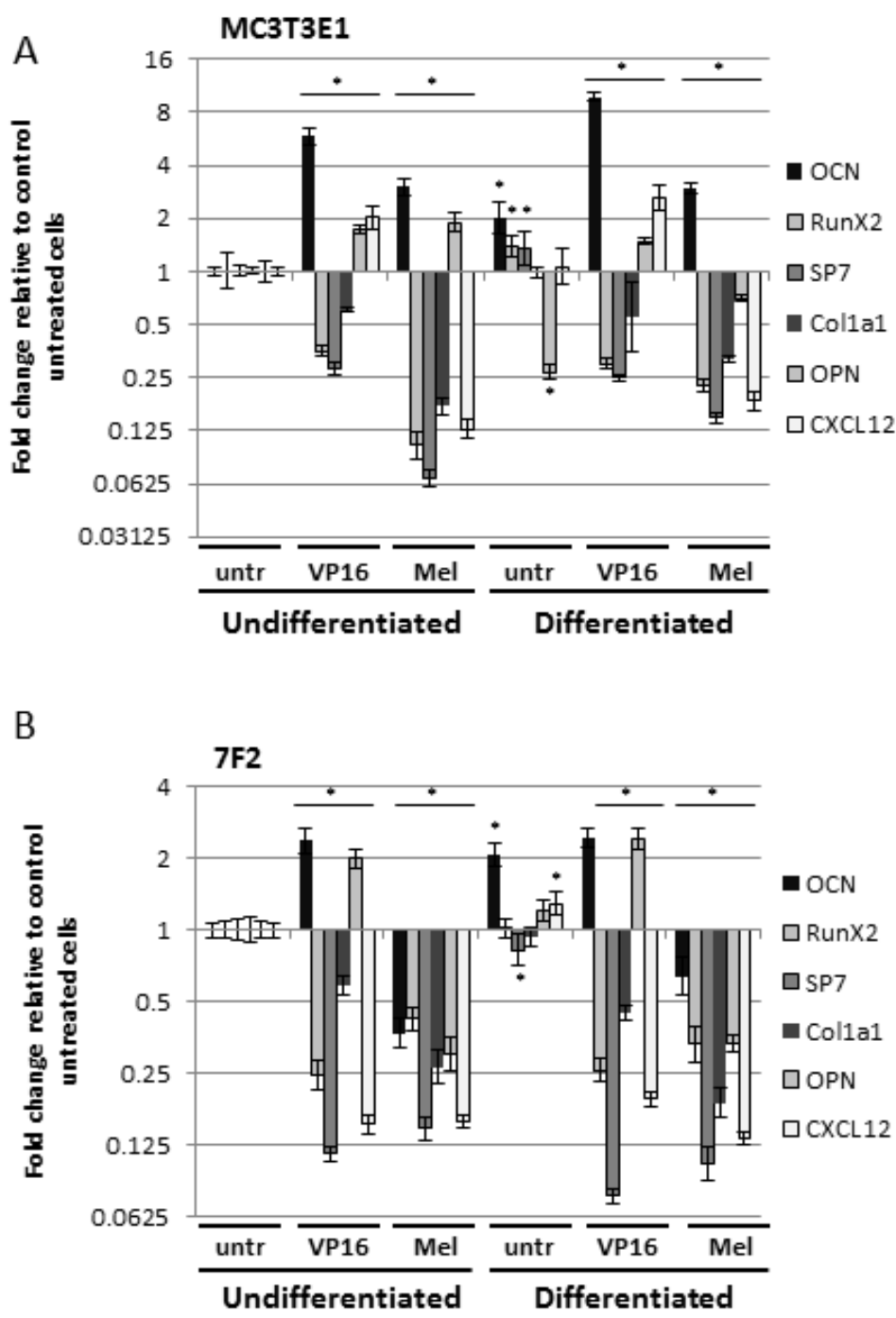

Figure 2. Effect of VP16 and melphalan on the expression of osteoblast-specific transcripts.

Gencheva and Hare et al. 2013. Bone marrow osteoblast vulnerability to chemotherapy. European Journal of Haematology. Permission Number: 3835731013613. 
A
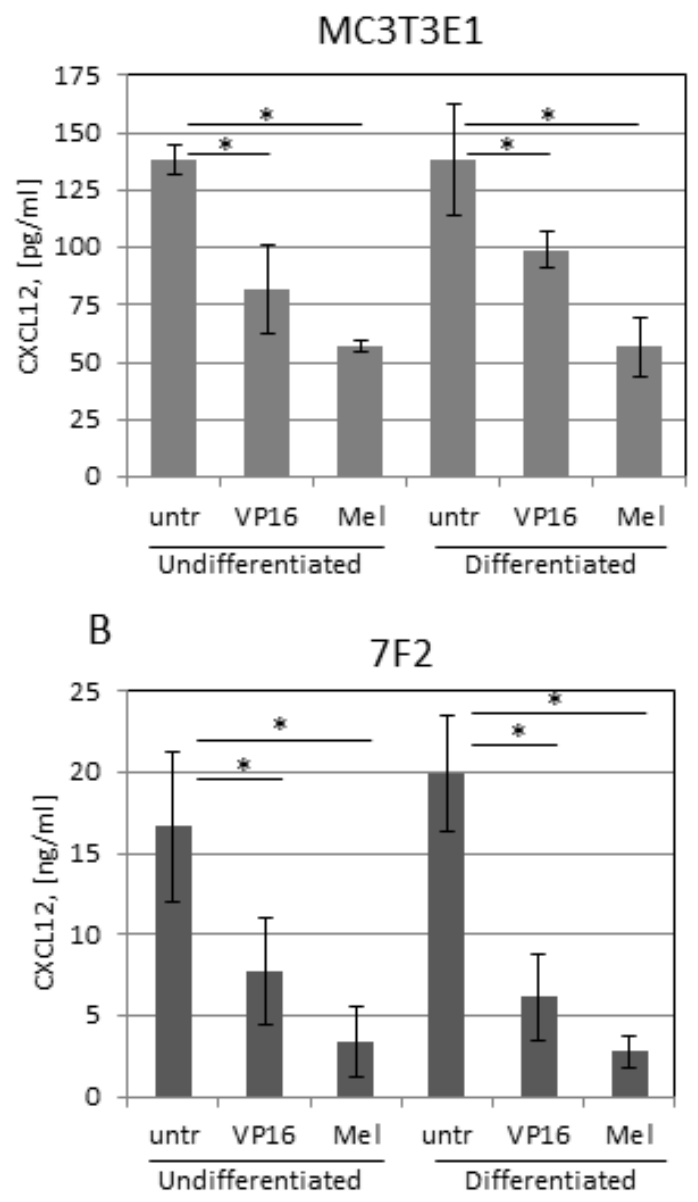

C

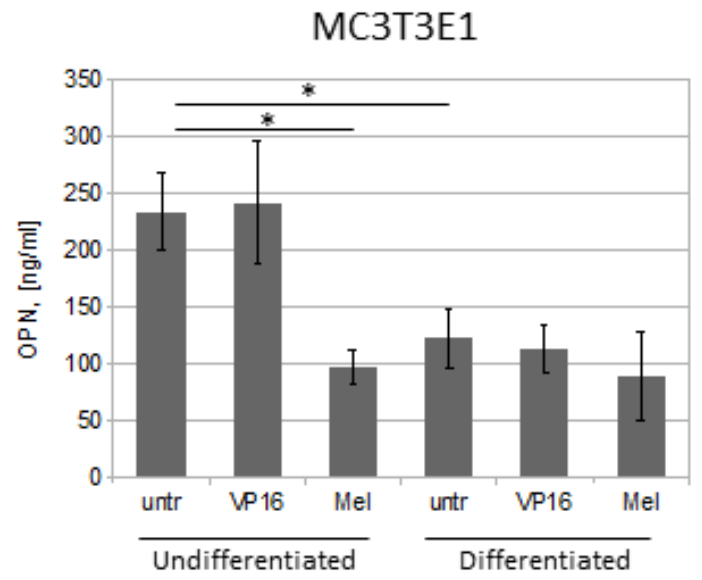

Figure 3. Effect of VP16 and melphalan on the levels of secreted CXCL12 and OPN.

Gencheva and Hare et al. 2013. Bone marrow osteoblast vulnerability to chemotherapy. European Journal of Haematology. Permission Number: 3835731013613. 


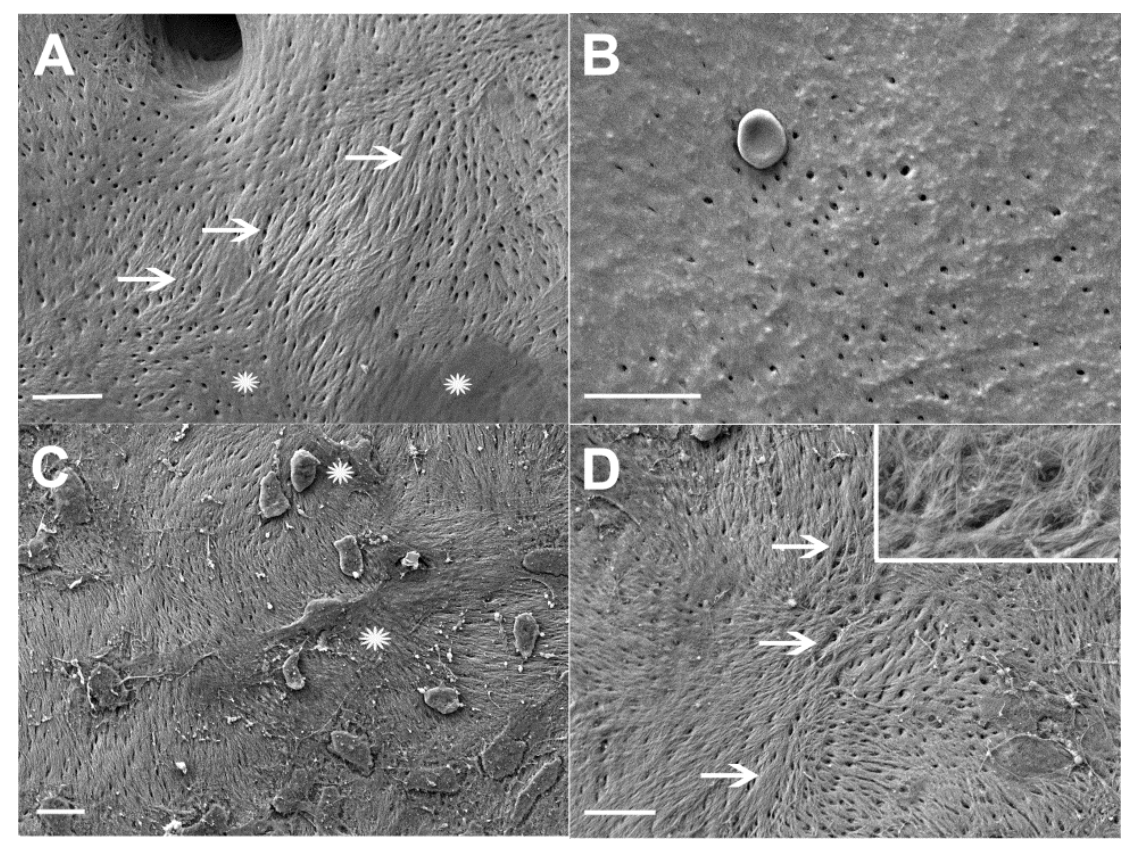

Figure 4. Scanning electron microscopy of murine bone.

Gencheva and Hare et al. 2013. Bone marrow osteoblast vulnerability to chemotherapy. European Journal of Haematology. Permission Number: 3835731013613. 


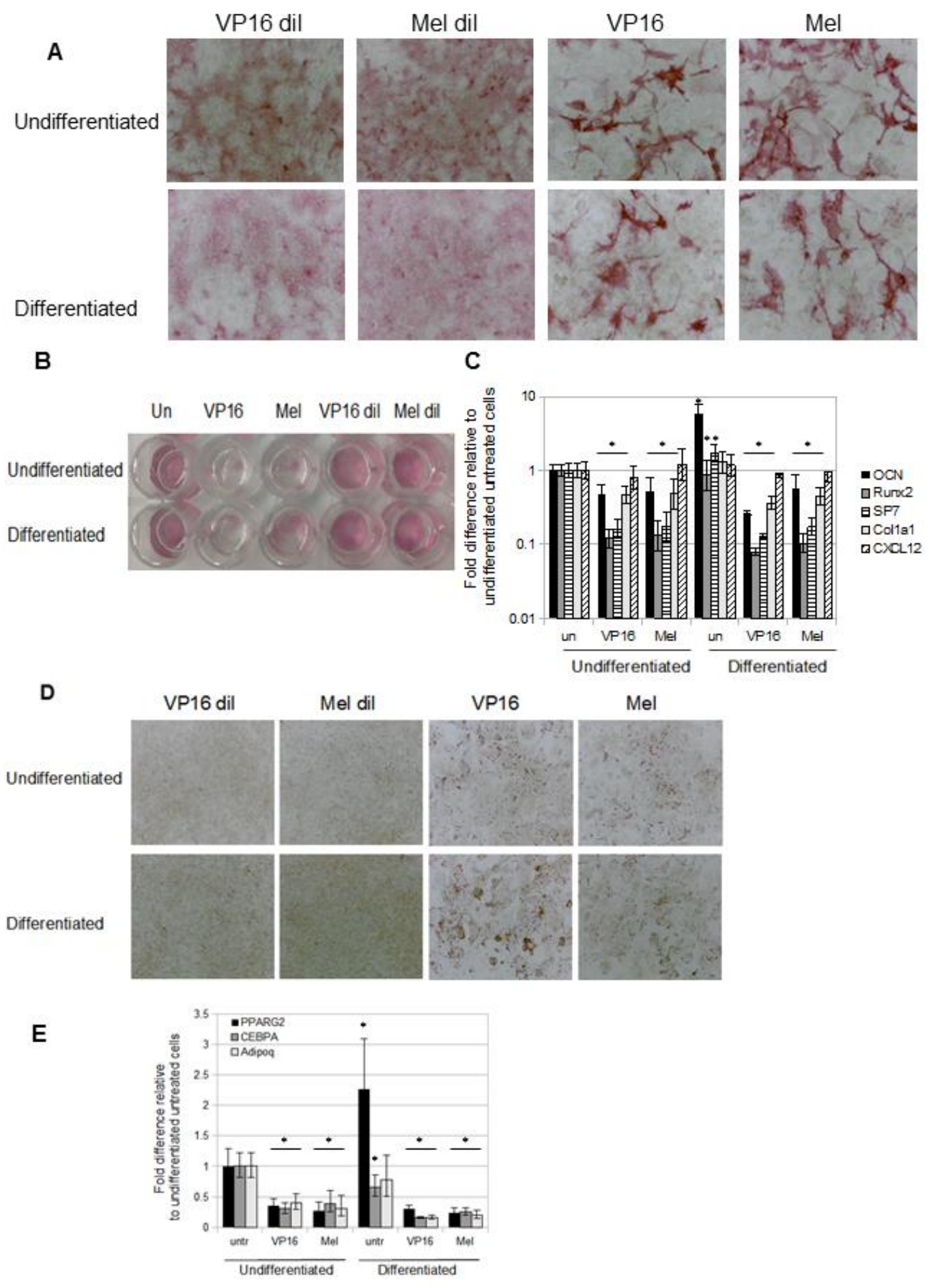

Figure 5. Effect of VP16 and melphalan on the differentiation potential of preosteoblast cells.

Gencheva and Hare et al. 2013. Bone marrow osteoblast vulnerability to chemotherapy.

European Journal of Haematology. Permission Number: 3835731013613. 
A

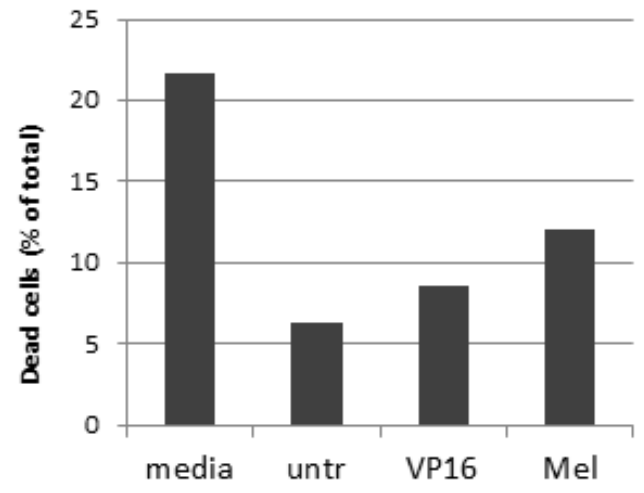

C

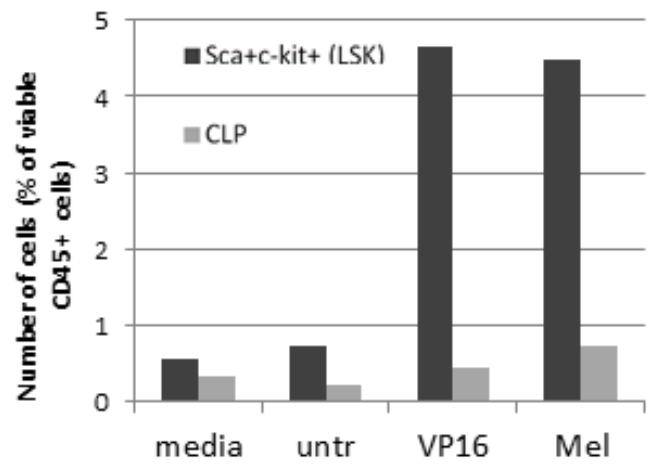

B

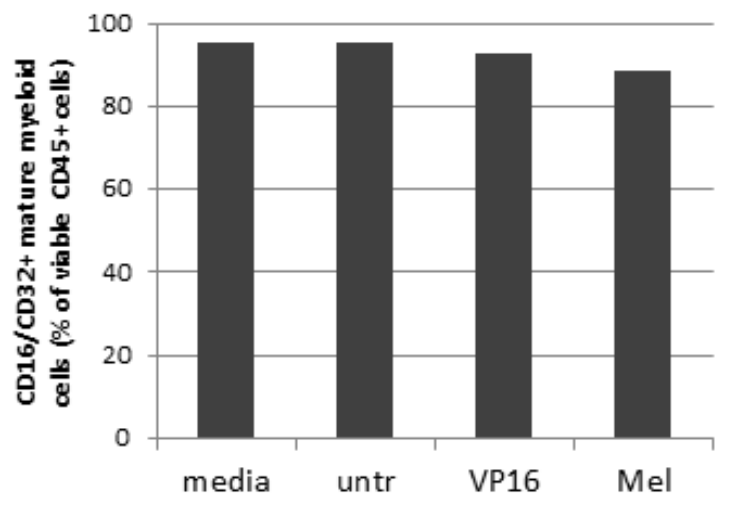

D

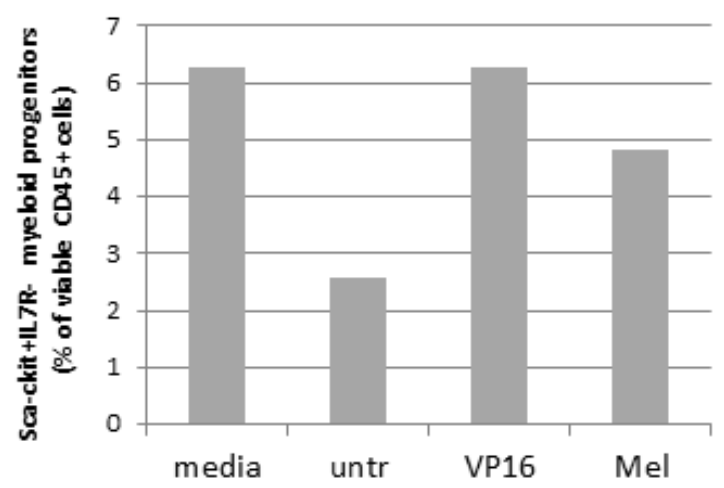

Figure 6. Support of murine hematopoietic stem and progenitor cells by osteoblasts treated with VP16 or melphalan.

Gencheva and Hare et al. 2013. Bone marrow osteoblast vulnerability to chemotherapy. European Journal of Haematology. Permission Number: 3835731013613. 


\title{
Chapter III
}

\section{In Vitro Expansion of Bone Marrow Derived Mesenchymal Stem Cells Alters DNA Double Strand Break Repair of Etoposide Induced DNA Damage}

\author{
Ian Hare ${ }^{1,2}$, Marieta Gencheva ${ }^{1}$, Rebecca Evans ${ }^{1}$, James Fortney ${ }^{1}$, Debbie Piktel ${ }^{1}$, \\ Jeffrey A. Vos ${ }^{1,3}$, David Howell ${ }^{1,3}$, Laura F. Gibson ${ }^{1,2 *}$
}

${ }^{1}$ Alexander B. Osborn Hematopoietic Malignancy and Transplantation Program of the Mary Babb Randolph Cancer Center, Robert C. Byrd Health Sciences Center, West Virginia University School of Medicine, Morgantown, West Virginia, United States of America

${ }^{2}$ Department of Microbiology, Immunology and Cell Biology, Robert C. Byrd Health Sciences Center, West Virginia University School of Medicine, Morgantown, West Virginia, United States of America

${ }^{3}$ West Virginia University Department of Pathology, School of Medicine, West Virginia University, Morgantown, West Virginia, United States of America

${ }^{*}$ Corresponding author

This work is published in Stem Cells International, 25 November, 2015 


\section{Abstract}

Mesenchymal stem cells (MSCs) are of interest for use in diverse cellular therapies. Ex vivo expansion of MSCs intended for transplantation must result in generation of cells that maintain fidelity of critical functions. Previous investigations have identified genetic and phenotypic alterations of MSCs with in vitro passage but little is known regarding how culturing influences the ability of MSCs to repair double strand DNA breaks (DSBs), the most severe of DNA lesions. To investigate the response to DSB stress with passage in vitro, primary human MSCs were exposed to etoposide (VP16) at various passages with subsequent evaluation of cellular damage responses and DNA repair. Passage number did not affect susceptibility to VP16 or the incidence and repair kinetics of DSBs. Non-homologous end joining (NHEJ) transcripts showed little alteration with VP16 exposure or passage, however, homologous recombination $(\mathrm{HR})$ transcripts were reduced following VP16 exposure with this decrease amplified as MSCs were passaged in vitro. Functional evaluations of NHEJ and HR showed that MSCs were unable to activate NHEJ repair following VP16 stress in cells after successive passage. These results indicate that ex vivo expansion of MSCs alters their ability to perform DSB repair, a necessary function for cells intended for transplantation. 


\section{Introduction}

MSCs are a mesoderm derived stromal population defined functionally by their ability to differentiate into various cell types in vitro. Osteoblasts, adipocytes, and chondrocytes have been shown to arise from MSC precursors under various culture conditions [1]. MSCs have also been shown to have immunomodulatory properties, displaying the ability to suppress adaptive and innate immune responses through the secretion of anti-inflammatory cytokines [2]. In addition to these functional characteristics MSCs are able to persist in culture, making it possible to alter gene expression of the cells through various transfection techniques. Such an approach has been utilized in a rat model of myocardial infarction to deliver HIF-1 $\alpha$ expressing MSCs to damaged heart tissue [3]. These cellular attributes have made MSCs an attractive candidate for the development of stem cell therapies in humans. MSCs can be acquired from various tissues of the body including the bone marrow [4]. The injection of bone marrow derived MSCs is currently undergoing Phase III clinical trials in the United States for the treatment of Crohn's disease and myocardial infarction (clinicaltrial.gov identifiers NCT00482092 and NCT01394432, respectively). In addition, several pre-clinical applications have been described in animal models of disease, such as autoimmune encephalitis, graft vs. host disease, rheumatoid arthritis, type I diabetes, and inflammatory bowel disease [5].

The use of MSCs for cellular therapies requires the ability of ex vivo expansion generating adequate numbers of cells for treatment. Although there is significant evidence documenting the clinical utility of MSCs, they are a heterogeneous population of cells that differ based on the means by which they are acquired and how they are cultured in vitro [6]. Given their utility, it is important to understand how they are altered during the necessary ex vivo expansion prior to patient administration. It has been shown previously that ex vivo expansion of MSCs results in alterations in genome stability [7, 8], epigenetics [9, 10], and functional abilities to differentiate into osteogenic cells $[11,12]$. However, these studies have been performed in 
non-stressed conditions, and little has been shown regarding how the activity of MSCs may be altered once administered to a patient where they may encounter cellular stresses, such as DNA damage. Eukaryotes have evolved means to recover from many types of DNA damage, the most lethal of which are double strand breaks (DSBs). DSBs are repaired by two major repair pathways, non-homologous end joining (NHEJ) and homologous recombination (HR) [13]. NHEJ involves the resection of nucleotides from both sides of a DSB, followed by the binding of Ku70 and Ku80 proteins with DNA-PK ligation of the break [14]. NHEJ is capable of repairing incompatible ends regardless of cell cycle status. When a sister chromatid is present (during S/G2/M phases of cell cycle), HR is capable of repairing a break by resecting both ends of a break, followed by insertion of the 3 ' resected end into the homologous sequence thereby using it as a template for repair. Due to the presence of a homologous sequence, HR is less error prone than NHEJ, however, the necessity of a reference template limits the utilization of $\mathrm{HR}$ to S/G2/M phases of cell cycle [15].

To determine how ex vivo expansion alters the response of MSCs to stress, we utilized etoposide (VP16), a DNA type-II topoisomerase inhibitor that specifically induces DSBs following DNA replication [16]. DSBs are the most lethal of DNA lesions, resulting in a larger degree of somatic mutation or apoptosis than other DNA lesions [17]. To determine how ex vivo expansion alters the response of MSCs to DSB stress, we passaged bone marrow derived MSCs in vitro, evaluating their responses to cellular stress and DSB repair following VP16 exposure.

\section{Materials and Methods}

\section{Human MSC Isolation and Cell Culture}


Bone marrow aspirates were de-identified samples from patients treated at the West Virginia University Healthcare System. Cells were cultured in a-MEM supplemented with 10\% fetal bovine serum (BSA), 2mM L-glutamine, $100 \mathrm{U} / \mathrm{mL}$ penicillin, $100 \mu \mathrm{g} / \mathrm{mL}$ streptomycin, and housed at $37^{\circ} \mathrm{C}, 6 \% \mathrm{CO}_{2}$. MSCs were derived from donors who had no previous exposure to chemotherapy or irradiation, and no history of malignancy.

\section{Surface Staining of MSCs}

Cells were trypsinized and washed in $1 \times$ phosphate buffered saline (PBS). Primary antibodies (1ug) specific for human CD45, CD44, CD105, and CD166 (BD Pharmingen, San Jose, California, United States) were added and incubated on ice for 20 minutes in PBS/3\% BSA. Cells were washed in PBS/3\% BSA, then incubated with 1ug donkey anti-mouse-AF488 (BD Pharmingen, San Jose, California, United States) for 20 minutes on ice. Cells were then washed in PBS/3\% BSA, resuspended in 400uL PBS, and immediately analyzed using a FACS Fortessa (BD Biosciences, Franklin Lakes, New Jersey, United States).

\section{Differentiation of MSCs}

To induce osteogenic differentiation in human MSC cultures, cells were plated at $90 \%$ confluence then cultured in Stempro® Osteogenesis Differentiation Kit Medium (Life Technologies, Carlsbad, California, United States) for 21 days. Differentiation medium was changed every 3 days. To induce adipogenic differentiation, cells were treated similarly only cultured in Stempro® Adipogenesis Differentiation Kit Medium (Life Technologies, Carlsbad, California, United States) for 10 days. Differentiated cells were compared to undifferentiated controls, cultured in normal MSC medium (see "Human MSC Isolation and Cell Culture").

\section{Alizarin Red and Oil Red Staining}


Human MSCs were fixed in 4\% paraformaldehyde (Sigma, St. Louis, Missouri, United States) for 4 hours prior to staining. Alizarin red and oil red staining were performed as described previously $[18,19]$. Cells were washed in deionized water and imaged immediately at 100x magnification using a Leica DMIL LED Inverted Microscope and Leica DFC 295 Digital Microscope Color Camera (Leica Microsystems, Wetzlar, Germany).

\section{Presto Blue Viability Assay}

Human MSCs were plated at $90 \%$ confluence in 96 -well plates, each plate containing unexposed and VP16 exposed cells, 5 wells per group. Cells were exposed to $25 \mu \mathrm{M}$ VP16 or medium only control for 24 hours. After incubation, cells were washed 3 times and allowed 0, 6, or 48 hours to recover. At each time point, viability was assessed using Presto Blue® Cell Viability Reagent (Life Technologies, Carlsbad, California, United States) as per manufacturer's recommendation. Well ODs were blanked to wells containing medium and Presto Blue® Cell Viability Reagent alone prior to analysis.

\section{Etoposide Exposure}

VP16 (Bristol-Myers Squibb, New York, New York, United States) was stored in $33.98 \mathrm{mM}$ aliquots at $-20^{\circ} \mathrm{C}$ and diluted to $25 \mu \mathrm{M}$ immediately prior to use in MSC medium (see "Human MSC Isolation and Cell Culture").

\section{Fluorescent Microscopy}

Cells were plated at $90 \%$ confluence on glass coverslips in 24 -well plates, then exposed to $25 \mu \mathrm{M}$ VP16 or medium alone for 24 hours. Following incubation, cells were washed three times, then allowed 0, 6, or 48 hours to recover. At each recovery time, coverslips were washed with 1x PBS, then fixed for 6 hours in 4\% paraformaldehyde. Following fixing, cells were permeabilized with $0.5 \%$ Triton X-100 then treated with Image-iT TM FX Signal Enhancer (Life 
Technologies, Carlsbad, California, United States) for 20 minutes. Following a 20 minute block with 5\% BSA, cells were incubated with $Y-H 2 A X$ antibody (1:400 Dilution, Millipore, Billerica, Massachusetts, United States) overnight at $4^{\circ} \mathrm{C}$. Following incubation, the cells were washed in 1x PBS then incubated for 1 hour in Goat anti-Rabbit-FITC secondary antibody (1:200, Cell Signaling, Danvers, Massachusetts, United States) prior to mounting on coverslips with ProLong Gold Antifade Reagent with DAPI (Life Technologies, Carlsbad, California, United States). Antibodies were diluted in 5\% BSA. Following staining, cells were imaged on a Zeiss LSM 510 Laser Scanning Confocal Microscope (Zeiss, Jena, Germany). Y-H2AX was quantitated as cells expressing 10 or more foci, or manually counted at the 6 hour recovery time point to determine Y-H2AX on a per cell basis. The 6 hour recovery time point was utilized for counting because foci were too abundant at 0 hours recovery to discern individual foci.

\section{RNA Isolation and qPCR}

RNA was isolated using Qiagen RNeasy Minikit (Qiagen, Valencia, California, United States) and stored at $-80^{\circ} \mathrm{C}$ prior to $\mathrm{gPCR}$. RNA stock solutions were diluted to $50 \mathrm{ng} / 11 \mu \mathrm{L}$ concentration prior to qPCR analysis. One step qPCR reactions were performed using QuantiTect SYBR Green RT-PCR Kit (Qiagen, Valencia, California, United States) and a 7500 Applied Biosystems Thermalcycler (Applied Biosystems, Foster City, California, United States). Primers sequences are indicated in Supplementary Table 1. PCR data were analyzed using the $\Delta \Delta$ Ct Method [20].

\section{Cell Cycle Analysis}

Following trypsinization, cells were fixed in $70 \%$ ethanol for 24 hours prior to cell cycle analysis. Once fixed, cells were washed in 1x PBS, then stained with propidium iodide staining solution ( $0.1 \%$ Triton X-100, $0.2 \mathrm{mg} / \mathrm{mL}$ RNaseA, $0.02 \mathrm{mg} / \mathrm{mL}$ propidium iodide) for 30 minutes at room temperature. Cells were then resuspended in 1x PBS and ran on a Beckman FACS 
Calibur (BD Biosciences, Franklin Lakes, New Jersey, United States). Analysis of cell cycle data was performed using FCS Express 4 Software (De Novo Software, Glendale, California, United States).

\section{Western Blot Analysis}

Protein was isolated from whole cell lysates prior to Western analysis using reducing conditions. Blots were probed using Rad51 (Cell Signaling, Danvers, Massachusetts, United States) and XRCC3 (Novus Biologicals, Littleton, Colorado, United States) antibodies, and antirabbit-HRP (Cell Signaling, Danvers, Massachusetts, United States). Immobilon Western ECL reagents (EMD Millipore, Billerica, Massachusetts, United States) were used to develop membranes.

\section{NHEJ and HR Reporter Assays}

Functional contributions of NHEJ and HR to DSB repair was evaluated using reporter assays developed and kindly provided by Dr. Vera Gorbunova (University of Rochester, Rochester, NY). NHEJ and HR constructs are designed with a Pem1 adenoviral intron interrupting the reading frame of GFP. The Pem1 intron is flanked by I-Scel restriction sites that when repaired by NHEJ or HR restores the reading frame of GFP, resulting in expression which can be quantitated by flow cytometry along with a DsRed loading control to evaluate transfection efficiency. The total \%GFP $/ \% \mathrm{DsRed}^{+}$gives the repair efficiency, a number that quantitatively reflects the degree to which MSCs have utilized NHEJ or HR to repair the reporter plasmid [21]. Cells were exposed to $25 \mu \mathrm{M}$ VP16 for 24 hours prior to isolation of cells for analysis as previously described [22]. Cells were nucleofected using an Amaxa Nucleofector (Lonza, Basel, Switzerland), program U-23. Cells were nucleofected with $2 \mu \mathrm{g} \mathrm{HR}$ or $0.5 \mu \mathrm{g}$ NHEJ constructs and $0.5 \mu \mathrm{g}$ DsRed loading control. Prior to nucleofection NHEJ and HR constructs were linearized with I-Scel (New England Biolabs, Ipswich, Massachusetts, United 
States) as previously described [22]. 10 $\mu \mathrm{g}$ of EGFP-N1 or DsRed-Express-DR (Clontech, Mountain View, California, United States) plasmids were included as positive controls. Following nucleofection, cells were cultured for 72 hours then evaluated for GFP and DsRed expression using a FACS Fortessa flow cytometer.

\section{Statistical Analysis}

For Presto Blue® viability analysis, two-way Student's T-tests were performed comparing untreated to treated cells at each recovery time. Y-H2AX quantitation and NHEJ/HR reporter assay data were evaluated by One-Way ANOVA with Holm-Sidak Post Hoc. Y-H2AX data in Supplementary Figure 2 were evaluated using the Kruskal-Wallis test. Statistical significance was defined as p-value $\leq 0.05$ using SigmaPlot Version 11 (Systat Software Inc., San Jose, California, United States). Experiments have been repeated at least twice using cell lines derived from different patients, and three times for surface marker phenotyping, Presto Blue $\circledast$, cell cycle analysis, $Y-H 2 A X$ microscopy, and NHEJ/HR qPCR experiments. Error bars in Figures indicate standard error.

\section{$\underline{\text { Results }}$}

\section{MSC Characteristics with Passage ex vivo}

Consistent with an MSC phenotype [23, 24], bone marrow derived MSCs showed an ability to perform both osteogenic and adipogenic differentiation, (Figure $1 \mathrm{~A}$ and $\mathrm{B}$ ) and were $\mathrm{CD}^{\circ} \mathrm{CD}^{\circ} 44^{+} \mathrm{CD} 105^{+} \mathrm{CD} 166^{+}$(Figure 1C). The adipogenic differentiation potential of MSCs appeared consistent up to passage 12 (Figure 1B). Previously, MSCs have been shown to display reduced osteogenic differentiation potential following prolonged passage in vitro [11, 12]. In addition, extensive culturing of MSCs has been shown to reduce the proportion of cells in S- 
phase [25]. Consistent with these observations, we found that the osteogenic differentiation potential of passage $12 \mathrm{MSCs}$ was reduced relative to less passaged cells (Figure 1A). The cell cycle distribution of MSCs was similar in Passage 6 to Passage 10 cells, however, the proportion of cells in S-phase was reduced at Passage 12 (Figure 3A, Untreated). These results indicate that our cells were characteristic of MSCs, and displayed a functional phenotype consistent with extended passage ex vivo by passage 12.

In addition to differentiating into various mesenchymal lineages, MSCs functionally contribute to the regulation of the differentiation and proliferation of hematopoietic cells [26]. MSCs also provide chemotactic gradients that enable hematopoietic cell homing to the bone marrow [27], a process that we have previously shown to be negatively affected by chemotherapy exposure of bone marrow stromal cells and osteoblasts [28, 29]. A preliminary set of experiments did not provide evidence for passage related alterations of the ability of VP16 exposed MSCs to regulate the proliferation or chemotaxis of a stromal cell dependent murine pro-B cell clone, or the differentiation of normal human $\mathrm{CD} 34^{+}$hematopoietic progenitor cells (data not shown).

\section{Sub-Lethal Concentrations of VP16 Induce Cell Cycle Arrest in MSCs Regardless of Passage}

To determine how MSCs respond to stress with successive passage in vitro, cells were exposed to VP16 for 24 hours at 90\% confluence, then washed three times in complete medium and allowed 0, 6, or 48 hours to recover prior to analyses. Cells were exposed to VP16 at $90 \%$ confluence due to the cell cycle specific nature of both VP16 and HR mediated repair of DSBs. VP16 specifically induces DSBs during mitotic events [16], therefore sub-confluent cells were used in our model. $25 \mu \mathrm{M}$ VP16 was utilized because it was the highest concentration of VP16 that did not result in overt cell death up to 48 hours recovery time (Figure 2 and data not shown) 
and therefore represented sub-lethal stress in our model. Exposure of MSCs to VP16 resulted in occasional statistically significant drops in viability, however no passage related trends were present. Consistent with the absence of passage related trends in the viability of MSCs following VP16 exposure, the abundance of pro-apoptotic (PUMA and NOXA) and anti-apoptotic (BCL-XL and BCL-2) transcripts were similar with passage following VP16 stress (Figure S1). These results suggest that MSCs do not display alterations in susceptibility to VP16 up to passage 12 in vitro.

Exposure of MSCs to sub-lethal concentrations of VP16 resulted in a transcriptional induction of p21 which was similar among all passages (Figure 3B). p21 was elevated approximately 4 to 6 fold after 24 hours exposure to VP16 and remained elevated following 48 hours recovery. Consistent with increased p21, VP16 exposure resulted in a reduction in the proportion of cells in S/G2/M phase of cell cycle (Figure 3A). The transcriptional abundance of p16 and p53 were gradually decreased following exposure to VP16 (Figure 3B), suggesting that the observed G1 arrest was due to the earlier and relatively more robust induction of p21 following VP16 exposure. These results suggest that VP16 induces cell cycle arrest at all passages in ex vivo expanded MSCs.

\section{Ex vivo Passage of MSCs Does Not Alter Incidence or Repair Kinetics of DSBs Following VP16 Exposure}

To visualize DSBs in MSCs following VP16 exposure immunofluorescent staining of $Y$ H2AX was utilized, as described previously [30]. MSCs displayed a large number of DSBs following 24 hours exposure to VP16 (Figure 4A). After 48 hours recovery time, the abundance of DSBs decreased, resulting in less than $20 \%$ of cells displaying 10 or more $Y-H 2 A X$ foci (Figure 4A and B). The proportion of cells with 10 or more $\mathrm{Y}-\mathrm{H} 2 \mathrm{AX}$ foci did not appear influenced by passage number at any time point, suggesting that the repair kinetics of DSBs are 
similar among MSCs of all passages. To more accurately quantitate the number of DSBs on a per cell basis, $Y-H 2 A X$ foci were manually counted at 6 hours recovery, showing no significant change with passage (Figure 4C). Based on these findings, it appears that the incidence and repair kinetics of DSBs following VP16 induced stress do not change with passage in vitro.

\section{Alterations in NHEJ and HR Mediated Repair of DSBs with Passage and VP16 Exposure}

To determine which repair pathways MSCs utilize to repair DSBs, as well as whether pathway dependence is altered by in vitro passage, transcriptional responses of NHEJ and HR associated genes were evaluated in our model. KU70, KU80 and DNA-PK were used to evaluate NHEJ, while XRCC2, XRCC3, and RAD51 were used to evaluate HR. Following VP16 stress, NHEJ associated transcripts remained relatively unaltered (less than 2 fold changes from baseline) and displayed no passage associated trends in abundance (Figure 5A). However, VP16 exposure reduced the abundance of HR associated transcripts, and this reduction was augmented with passage in vitro (Figure 5B). The decreased presence of HR transcripts following VP16 is consistent with the induction of cell cycle arrest displayed by our cells, given that HR can only be performed during S/G2 phases of the cell cycle [15]. The augmented decrease in HR associated transcripts with passage (following VP16 exposure) does not appear to be due to the reduced cycling-status of MSCs with extended passage, as the HR transcript decreases are present immediately following Passage 6 while extended culture associated decreases in S/G2/M are not present until Passage 12 (Figure 3A, Untreated). Consistent with qPCR results, protein abundance of Rad51 was decreased following VP16 stress at all passages. However, the abundance of XRCC3 was unaltered (Figure 5C). These data suggest that the reliance of MSCs on HR is reduced following VP16 stress, and that there is altered double strand DNA repair pathway utilization with in vitro passaging of MSCs that precedes the changes in cell cycle distribution associated with in vitro culture. 
To evaluate the functional contribution of NHEJ and HR to DSB repair in MSCs following VP16 exposure, NHEJ and HR plasmid reporter assays were utilized. NHEJ and HR reporter assays serve as a means to quantitatively evaluate the functional ability of cells to perform NHEJ or HR, reported as repair efficiency [22]. The average repair efficiency of NHEJ in untreated Passage 6 cells was approximately 0.165 , compared to 0.03 for $\mathrm{HR}$, indicating that NHEJ is the predominant repair pathway of DSBs in MSCs, consistent with other cell types of the body [31] (Figure 5D). The repair efficiency of NHEJ in untreated cells remained consistent with passage of MSCs, however, the repair efficiency of HR was significantly reduced by passage 12 (Figure 5D). Coincident with reduced HR repair efficiency, untreated cells displayed reduced Rad51 protein abundance with passage (Figure 5E). Following VP16 exposure, Passage 6 and 9 cells displayed significantly elevated repair efficiency for NHEJ, while the efficiency of HR was significantly reduced (Figure 5D). Interestingly, passage 12 cells did not display significant changes in repair efficiency following VP16 exposure relative to untreated controls (Figure 5D). These results indicate that NHEJ is primarily used to repair DSBs in MSCs, and that NHEJ is increased in the context of VP16 stress while HR is decreased. However, once cells have undergone extended passage in vitro, MSCs are less able to utilize HR for repair, and DSB repair using NHEJ is not functionally increased following VP16 exposure. These data suggest that prolonged passage of MSCs in vitro can alter the ability to utilize NHEJ and HR following exposure to sub-lethal VP16 induced stress.

\section{Discussion}

The plasticity and immunomodulatory potential of MSCs have attracted attention regarding their application in cellular therapies for numerous diseases. The ability of MSCs to expand in vitro has further increased enthusiasm for clinical application, circumventing potential 
problems with the acquisition of sufficient cell numbers for transplantation. In addition, MSCs can be acquired from various tissues of the body [4], making it possible to utilize cells from a patient autologously, nullifying the risks of graft vs. host disease. The ability of MSCs to expand ex vivo is beneficial towards their use clinically, highlighting the necessity of understanding how cells are changed during culture in vitro.

In vitro culture has been shown to epigenetically regulate gene expression in MSCs. Passage related increases in HDAC activity correlate with increased expression of HDAC4, HDAC5, and HDAC6, resulting in reduced $\mathrm{H} 3$ and $\mathrm{H} 4$ acetylation and reduced OCT4 expression [9]. Another study documented passage associated alterations in methylation at specific CpG sites, many of which regulate differentiation associated genes including RUNX3 [10], which has been implicated in osteogenesis [32]. In addition to alterations in gene regulation, in vitro passaging of MSCs reduces osteogenic differentiation capacity $[11,12]$. Consistent with these observations, we showed a reduced ability of passage 12 MSCs to differentiate under osteogenic conditions relative to lower passages (Figure 1A), indicating that our cells had been cultured sufficiently to elicit changes in MSC function. However, we did not observe reduced adipogenic differentiation potential up to passage 12 (Figure 1B) which defined the endpoint of our model. These studies display important cellular characteristics that are altered with ex vivo passage, but little has been done to address how passaging alters their response to stresses resulting in DSB formation. Part of the reason DSBs are the most damaging of DNA lesions is the result of increased likelihood of erroneous repair, especially following NHEJ [33]. Erroneous repair is associated with increased cellular transformation, a phenomenon that has been documented with in vitro passage of MSCs [7, 8], alluding to the importance of maintaining not only survival, but genomic integrity of ex vivo expanded MSCs. The specific induction of DSBs by VP16 enabled us to specifically evaluate MSC responses regarding DSB repair. Although any type of DNA lesion can be harmful to a cell, DSBs are 
considered the most serious and potentially mutagenic [13], hence their focus in our investigation.

To model cellular stress as a consequence of DSB presence, we utilized sub-lethal concentrations of VP16 that displayed no passage associated changes in the susceptibility of MSCs to VP16 induced cell death (Figure 2). VP16 did not result in overt death, but did increase p21 mRNA and elicited a reduction in the proportion of cells in S/G2/M phases of cell cycle indicating cell cycle arrest at all passages (Figures 3A and B). Although capable of initiating G1 arrest following cellular stress [34], we found p16 and p53 transcripts to be reduced by 6 hours recovery time (Figure 3B). The earlier and more robust presence of p21 may have chiefly contributed to the induction of cell cycle arrest, consistent with previous observations in stressed MSCs [35]. These observations show that MSCs display signs of cellular stress in our model of VP16 exposure in a manner that is sub-lethal. The absence of cellular death in our model enabled us to evaluate the incidence, repair kinetics, and cellular repair pathways of DSBs within MSCs with passage.

Of the numerous types of DNA lesions, VP16 specifically generates DSBs [36]. Within minutes following the formation of a DSB within the nucleus, various kinases (including DNAPK, ATM and ATR) detect the presence of the break and phosphorylate histone 2A moieties. Phosphorylated histone $2 \mathrm{~A}(\mathrm{Y}-\mathrm{H} 2 \mathrm{AX})$ present as nuclear puncta corresponding to an individual DSB that can be visualized by immunofluorescence [30]. When evaluating $Y-H 2 A X$ foci at each time point after VP16 exposure, changes were not observed between passages (Figure 4B) suggesting that the rate by which MSCs repair VP16 induced DNA damage is not affected by passage in vitro. Notably, fewer than $20 \%$ of cells contained 10 or more $\mathrm{Y}-\mathrm{H} 2 \mathrm{AX}$ foci by 48 hours recovery (Figure 4B). The greatly reduced presence of DSBs following 48 hours recovery time suggests that MSCs are capable of recovering from 25 MM VP16 exposure, consistent with 
the sub-lethal nature of the model. These results indicate that the incidence and repair kinetics of DSBs following VP16 exposure were similar across passage number in vitro.

The resolution of DSBs following 48 hours recovery from VP16 exposure suggests the intact presence of double strand DNA repair pathways within MSCs for all passages observed. DSBs are repaired through two major pathways, NHEJ and HR [15]. To elucidate the contribution of these pathways to repair with passage in the context of VP16 stress, transcriptional responses of a panel of NHEJ and HR genes were evaluated. Although NHEJ transcripts displayed little change, HR associated transcripts were reduced with VP16 exposure (Figure 5A and B). Evaluations of Rad51 and XRCC3 protein showed that although XRCC3 was unaltered by passage or VP16 exposure, Rad51 was reduced by VP16, consistent with qPCR results (Figure 5C). Although these results served as evidence for VP16 exposure and passage playing a role in the means by which MSCs repair DNA, qPCR cannot describe which pathways are being utilized functionally by MSCs, and to what extent. To functionally and quantitatively evaluate the contribution of NHEJ and HR to DSB repair in VP16 stressed MSCs, plasmid based reporter assays were utilized. We showed that at baseline, NHEJ was the primary DSB repair pathway utilized by MSCs (Figure 5D), consistent with most cell types of the body [17]. In lower passage cells (Passages 6 and 9) NHEJ is increased while HR is decreased following VP16 stress (Figure 5D). However, in Passage 12 cells, there was a reduced presence of HR at baseline, possibly due to the reduced abundance of Rad51 (Figure 5E), and VP16 induced increases or decreases in NHEJ or HR (respectively) were not present (Figure 5D). These results suggested that in lower passage cells, NHEJ is increased to repair DNA damage while $\mathrm{HR}$ is decreased, however, later passage cells are unable to increase NHEJ mediated repair following VP16 stress. Passaging and irradiation of fibroblasts have been shown to alter the abundance and localization of Ku70/80 [37], possibly playing a role in the inability of late passage MSCs to increase NHEJ efficiency following VP16 stress (Figure 5D). Quantitation of 
$\mathrm{Y}-\mathrm{H} 2 \mathrm{AX}$ foci in untreated cells with passage did not show significant changes (Figure S2), suggesting that the genomic integrity of untreated cells is not affected by defects in HR repair with ex vivo expansion. In addition, the inability of Passage 12 MSCs to increase NHEJ following VP16 exposure did not result in alterations of DSB presence or viability when compared to lesser passaged MSCs (Figures 2 and 4). These results are most likely due to the sub-lethal nature of our model. It is possible that at higher concentrations of VP16, the consequences of less efficient DNA repair would affect the presence or repair kinetics of DSBs. However, due to the nature of our assays only evaluating living cells, the phenomenon would likely not be detected (a problem evaded by our use of non-lethal concentrations of VP16). Nevertheless, our results suggest a defective ability of MSCs to increase NHEJ, their primary repair pathway of DSBs, in the context of VP16 stress following successive passage in vitro.

Our results showing reduction in the efficiency of HR following in vitro culture of MSCs are consistent with previous findings in fibroblasts [38]. However, when Seluanov et al. evaluated NHEJ efficiency in fibroblasts with successive passaging (up to 70 population doublings), NHEJ efficiency was found to be decreased [39]. Our results with normal primary human MSCs did not show significant changes in NHEJ efficiency in untreated cells regardless of passage, possibly due to the fact that our cells were passaged to a lesser extent (Passage 12). The results presented in this report contribute unique information by evaluating passage related changes in DSB repair in the context of cellular stress, a common circumstance that will be encountered when the ability to repair DNA is crucial. In addition, DSB repair being quantitatively evaluated in MSCs adds to our understanding of the characteristics of these clinically valuable stem cells. Given recent observations that NHEJ utilization varies by tissue type in vivo [31] the specific evaluation of DNA repair in human primary marrow derived MSCs is relevant to developing optimal models to expand cells ex vivo for diverse cellular therapies. 


\section{Conclusions}

In conclusion, we have determined that extended culture of human primary bone marrow derived MSCs results in an inability to functionally increase NHEJ when encountering sub-lethal VP16 stress, and reduced utilization of HR in the absence of stress. Given the necessity of $e x$ vivo expansion of MSCs for use in cellular therapies, these results serve as a guideline for improving strategies to sufficiently expand MSCs without inducing culture associated alterations that could have negative effects on the ability of the cells to persist following transplantation. Both the inability of MSCs to increase NHEJ following VP16 stress and reduced osteogenic differentiation capacity were detected at Passage 12 (Figures 5D and 1A, respectively). Although we do not propose that these events are directly related, they highlight the possibility of utilizing a biomarker to determine when ex vivo expanded MSCs display impaired DSB repair abilities in the context of stress. The discovery of such biomarkers would enable screening for DNA repair deficiencies without the time, cell, and labor intensive requirements of performing plasmid based DSB repair assays prior to utilization of ex vivo expanded MSCs for cellular therapy.

\section{Conflict of Interests}

The authors declare that there is no conflict of interest regarding the publication of this paper.

\section{Acknowledgements}

We would like to thank Dr. Vera Gorbunova (University of Rochester, United States) for providing NHEJ and HR reporter plasmids, Dr. Peter Stoilov (West Virginia University, United States) for assistance regarding plasmid preparation and characterization, Dr. James Coad 
(West Virginia University, United States) for providing de-identified bone marrow aspirate specimens, and the Dr. Scott Weed laboratory (West Virginia University, United States) for assistance with nucleofection. We would also like to thank Blake Moses, William Slone, Debbie Piktel, Rebecca Evans, and Patrick Thomas for assistance in manuscript editing. Funding was provided by National Institutes of Health (NIH) R01 HL056888 (LFG), NIH P20 RR016440 (LFG), National Cancer Institute (NCl) RO1 CA134573 (LFG), the Alexander B. Osborn Hematopoietic Malignancy and Transplantation Program, and the WV Research Trust Fund. Imaging was performed in the West Virginia University Microscope Imaging Facility, which has been supported by the Mary Babb Randolph Cancer Center and NIH grants P20 RR016440, P30 GM103488 and P20 GM103434. Flow cytometry was performed in the West Virginia University Flow Cytometry Core and has been supported by the Mary Babb Randolph Cancer Center and NIH grants GM103488/RR032138, and OD016165.

\section{References}

1. Murphy MB, Moncivais K, Caplan Al: Mesenchymal stem cells: environmentally responsive therapeutics for regenerative medicine. Exp Mol Med 2013, 45:e54.

2. Bernardo ME, Fibbe WE: Mesenchymal Stromal Cells: Sensors and Switchers of Inflammation. Cell Stem Cell 2013, 13:392-402.

3. Huang B, Qian J, Ma J, Huang Z, Shen Y, Chen X, Sun A, Ge J, Chen H: Myocardial transfection of hypoxia-inducible factor-1 $\alpha$ and co-transplantation of mesenchymal stem cells enhance cardiac repair in rats with experimental myocardial infarction. Stem Cell Res Ther 2014, 5:22.

4. Otto WR, Wright NA: Mesenchymal stem cells: from experiment to clinic. Fibrogenesis Tissue Repair 2011, 4:20.

5. Glenn JD: Mesenchymal stem cells: Emerging mechanisms of immunomodulation and therapy. World J Stem Cells 2014, 6:526.

6. Wagner W, Ho AD: Mesenchymal Stem Cell Preparations-Comparing Apples and Oranges. Stem Cell Rev 2007, 3:239-248. 
7. Zhou YF, Bosch-Marce M, Okuyama H, Krishnamachary B, Kimura H, Zhang L, Huso DL, Semenza GL: Spontaneous Transformation of Cultured Mouse Bone Marrow-Derived Stromal Cells. Cancer Res 2006, 66:10849-10854.

8. Røsland GV, Svendsen A, Torsvik A, Sobala E, McCormack E, Immervoll H, Mysliwietz J, Tonn J-C, Goldbrunner R, Lønning PE, Bjerkvig R, Schichor C: Long-term Cultures of Bone Marrow-Derived Human Mesenchymal Stem Cells Frequently Undergo Spontaneous Malignant Transformation. Cancer Res 2009, 69:5331-5339.

9. Zhu Y, Song X, Han F, Li Y, Wei J, Liu X: Alteration of Histone Acetylation Pattern during Long-Term Serum-Free Culture Conditions of Human Fetal Placental Mesenchymal Stem Cells. PLOS ONE 2015, 10:e0117068.

10. Bork S, Pfister S, Witt H, Horn P, Korn B, Ho AD, Wagner W: DNA methylation pattern changes upon long-term culture and aging of human mesenchymal stromal cells. Aging Cell 2010, 9:54-63.

11. Koch CM, Reck K, Shao K, Lin Q, Joussen S, Ziegler P, Walenda G, Drescher W, Opalka B, May T, Brümmendorf T, Zenke M, Šarić T, Wagner W: Pluripotent stem cells escape from senescence-associated DNA methylation changes. Genome Res 2013, 23:248259.

12. Kretlow JD, Jin Y-Q, Liu W, Zhang WJ, Hong T-H, Zhou G, Baggett LS, Mikos AG, Cao Y: Donor age and cell passage affects differentiation potential of murine bone marrowderived stem cells. BMC Cell Biol 2008, 9:60.

13. Lord CJ, Ashworth A: The DNA damage response and cancer therapy. Nature 2012 , 481:287-294.

14. Polo SE, Jackson SP: Dynamics of DNA damage response proteins at DNA breaks: a focus on protein modifications. Genes Dev 2011, 25:409-433.

15. Chapman JR, Taylor MRG, Boulton SJ: Playing the End Game: DNA Double-Strand Break Repair Pathway Choice. Mol Cell 2012, 47:497-510.

16. Nitiss JL: Targeting DNA topoisomerase II in cancer chemotherapy. Nat Rev Cancer 2009, 9:338-350.

17. Furgason JM, Bahassi EM: Targeting DNA repair mechanisms in cancer. Pharmacol Ther 2013, 137:298-308.

18. Reichert JC, Burke LJ, Clements JA, Hutmacher DW: Preparation of mineralised matrices secreted from human primary osteoblasts for analysis of the interaction of cancer cells and the bone microenvironment. Protoc Exch 2008.

19. Takahashi $Y$, Ohoka N, Hayashi H, Sato R: TRB3 suppresses adipocyte differentiation by negatively regulating PPARy transcriptional activity. J Lipid Res 2008, 49:880-892.

20. Livak KJ, Schmittgen TD: Analysis of relative gene expression data using real-time quantitative PCR and the 2(-Delta Delta C(T)) Method. Methods San Diego Calif 2001, 25:402-408. 
21. Mao Z, Jiang Y, Liu X, Seluanov A, Gorbunova V: DNA Repair by Homologous Recombination, But Not by Nonhomologous End Joining, Is Elevated in Breast Cancer Cells. Neoplasia N Y N2009, 11:683-691.

22. Seluanov A, Mao Z, Gorbunova V: Analysis of DNA double-strand break (DSB) repair in mammalian cells. J Vis Exp JoVE 2010.

23. Pittenger MF, Mackay AM, Beck SC, Jaiswal RK, Douglas R, Mosca JD, Moorman MA, Simonetti DW, Craig S, Marshak DR: Multilineage Potential of Adult Human Mesenchymal Stem Cells. Science 1999, 284:143-147.

24. McMurray RJ, Gadegaard N, Tsimbouri PM, Burgess KV, McNamara LE, Tare R, Murawski K, Kingham E, Oreffo ROC, Dalby MJ: Nanoscale surfaces for the long-term maintenance of mesenchymal stem cell phenotype and multipotency. Nat Mater 2011, 10:637-644.

25. Fu W-L, Li J, Chen G, Li Q, Tang X, Zhang C-H: Mesenchymal Stem Cells Derived from Peripheral Blood Retain Their Pluripotency, but Undergo Senescence During LongTerm Culture. Tissue Eng Part C Methods 2015.

26. Morrison SJ, Scadden DT: The bone marrow niche for haematopoietic stem cells. Nature 2014, 505:327-334.

27. Mercier FE, Ragu C, Scadden DT: The bone marrow at the crossroads of blood and immunity. Nat Rev Immunol 2011, 12:49-60.

28. Gibson LF, Fortney J, Landreth KS, Piktel D, Ericson SG, Lynch JP: Disruption of bone marrow stromal cell function by etoposide. Biol Blood Marrow Transplant J Am SoC Blood Marrow Transplant 1997, 3:122-132.

29. Rellick SL, O'Leary H, Piktel D, Walton C, Fortney JE, Akers SM, Martin KH, Denvir J, Boskovic G, Primerano DA, Vos J, Bailey N, Gencheva M, Gibson LF: Bone marrow osteoblast damage by chemotherapeutic agents. PloS One 2012, 7:e30758.

30. Bonner WM, Redon CE, Dickey JS, Nakamura AJ, Sedelnikova OA, Solier S, Pommier Y: |[gamma]|H2AX and cancer. Nat Rev Cancer 2008, 8:957-967.

31. Vaidya A, Mao Z, Tian X, Spencer B, Seluanov A, Gorbunova V: Knock-in reporter mice demonstrate that DNA repair by non-homologous end joining declines with age. PLoS Genet 2014, 10:e1004511.

32. Bauer O, Sharir A, Kimura A, Hantisteanu S, Takeda S, Groner Y: Loss of Osteoblast Runx3 Produces Severe Congenital Osteopenia. Mol Cell Biol 2015, 35:1097-1109.

33. Mao Z, Bozzella M, Seluanov A, Gorbunova V: DNA repair by nonhomologous end joining and homologous recombination during cell cycle in human cells. Cell Cycle Georget Tex 2008, 7:2902-2906.

34. Sperka T, Wang J, Rudolph KL: DNA damage checkpoints in stem cells, ageing and cancer. Nat Rev Mol Cell Biol 2012, 13:579-590. 
35. Mehrara BJ, Avraham T, Soares M, Fernandez JG, Yan A, Zampell JC, Andrade VP, Cordeiro AP, Sorrento CM: p21cip/WAF is a key regulator of long-term radiation damage in mesenchyme-derived tissues. FASEB J 2010, 24:4877-4888.

36. Bruserud O, Reikvam H, Kittang AO, Ahmed AB, Tvedt THA, Sjo M, Hatfield KJ: High-dose etoposide in allogeneic stem cell transplantation. Cancer Chemother Pharmacol 2012, 70:765-782.

37. Seluanov A, Danek J, Hause N, Gorbunova V: Changes in the level and distribution of Ku proteins during cellular senescence. DNA Repair 2007, 6:1740-1748.

38. Mao Z, Tian X, Meter MV, Ke Z, Gorbunova V, Seluanov A: Sirtuin 6 (SIRT6) rescues the decline of homologous recombination repair during replicative senescence. Proc Natl Acad Sci 2012, 109:11800-11805.

39. Seluanov A, Mittelman D, Pereira-Smith OM, Wilson JH, Gorbunova V: DNA end joining becomes less efficient and more error-prone during cellular senescence. Proc Natl Acad Sci U S A 2004, 101:7624-7629. 


\section{Figure Legends}

Figure 1. Differentiation and surface phenotype of bone marrow derived mesenchymal stem cell (MSCs). (A) Osteogenic and (B) adipogenic differentiation at various passages evaluated by alizarin red and oil red staining, respectively. (C) Flow cytometry detecting surface expression of MSC surface markers. Black lines represent isotype controls, red lines represent indicated surface markers.

Figure 2. Viability of MSCs with passage following 24 hours etoposide (VP16) exposure. MSCs at various passages were exposed to $25 \mu \mathrm{M}$ VP16 for 24 hours, then allowed 0,6 , or 48 hours to recover in fresh medium before evaluation of viability by Presto Blue viability reagent. Values are reported relative to untreated controls. * Indicates a significant decrease in viability relative to untreated control, Student's T-test, p-value $<0.05$.

Figure 3. Effects of VP16 on cell cycle distribution and cell cycle inhibitor transcript abundance with passage. (A) Cell cycle distribution of MSCs at various passages exposed to $25 \mu \mathrm{M}$ VP16 or medium only control for 24 hours. (B) qPCR evaluation of cell cycle inhibitor mRNA expression following exposure of MSCs to $25 \mu \mathrm{M}$ VP16 for 24 hours followed by 0,6 , or 48 hours recovery in fresh medium. Values are indicated as fold change relative to untreated control.

Figure 4. DNA double strand break incidence and repair kinetics in MSCs exposed to $25 \mu \mathrm{M}$ VP16. (A) Representative Y-H2AX staining (Yellow) of Passage 6 MSCs exposed to VP16 for 24 hours followed by 0,6 , or 48 hours recovery in fresh medium. Y-H2AX (Yellow) displays nuclear co-localization with DAPI (blue). (B) Percentage of MSCs displaying 10 or greater $\mathrm{Y}$ - 
$\mathrm{H} 2 \mathrm{AX}$ foci at each time point at various passages. (C) Average number of $Y-H 2 A X$ foci per cell at 6 hours recovery time for passages 6 through 12. "NS" indicates no significant difference between any passage by One-Way ANOVA with Holm-Sidak Post Hoc, p-value $>0.05$.

Figure 5. Non-homologous end joining (NHEJ) and homologous recombination (HR) transcriptional, protein, and functional repair responses to $25 \mu \mathrm{M}$ VP16 with passage. qPCR evaluation of (A) NHEJ and (B) HR associated mRNA expression following exposure of MSCs to VP16 for 24 hours followed by 0 or 48 hours recovery in fresh medium. Fold changes are indicated relative to untreated controls. (C) Western analysis of Rad51 and XRCC3 after VP16 exposure with passage. 'Untr' indicates untreated cells. '0', '6', or ' 48 ' indicates recovery time (in hours) following 24 hours exposure to 25uM VP16. (D) NHEJ and HR plasmid reporter assays for Passage 6, 9, and 12 MSCs exposed to VP16 or medium only control for 24 hours. (E) Western analysis of Rad51 in untreated MSCs with passage. \# Indicates significant change relative to untreated control, ${ }^{*}$ represents significant change relative to indicated group, OneWay ANOVA with Holm-Sidak Post Hoc, p-value $<0.05$.

Supplementary Figure 1. Apoptosis associated transcriptional responses of MSCs following VP16 exposure with passage. (A) Pro-apoptotic and (B) anti-apoptotic mRNA expression evaluated by qPCR in MSCs exposed to $25 \mu \mathrm{M}$ VP16 for 24 hours followed by 0,6 , or 48 hours recovery in fresh medium. Fold changes are indicated relative to untreated controls. 
Supplementary Figure 2. Average number of $\mathrm{Y}-\mathrm{H} 2 \mathrm{AX}$ foci per cell in untreated MSCs for passages 6 through 12. "NS" indicates no significant difference between any passage by Kruskal-Wallis test, $\mathrm{p}$-value $>0.05$. 
A
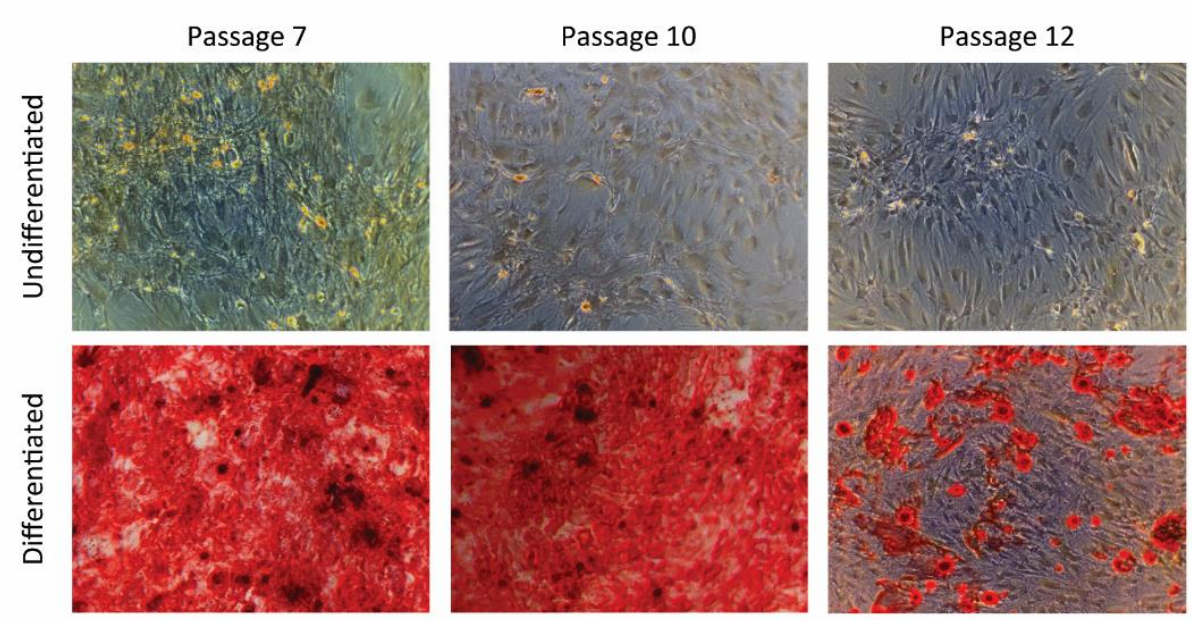

C
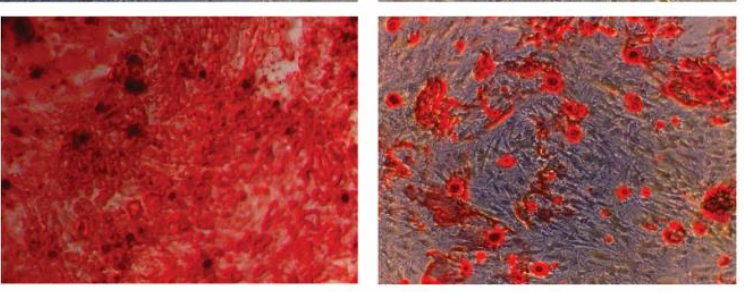

B

Passage 7

Passage 10

Passage 12
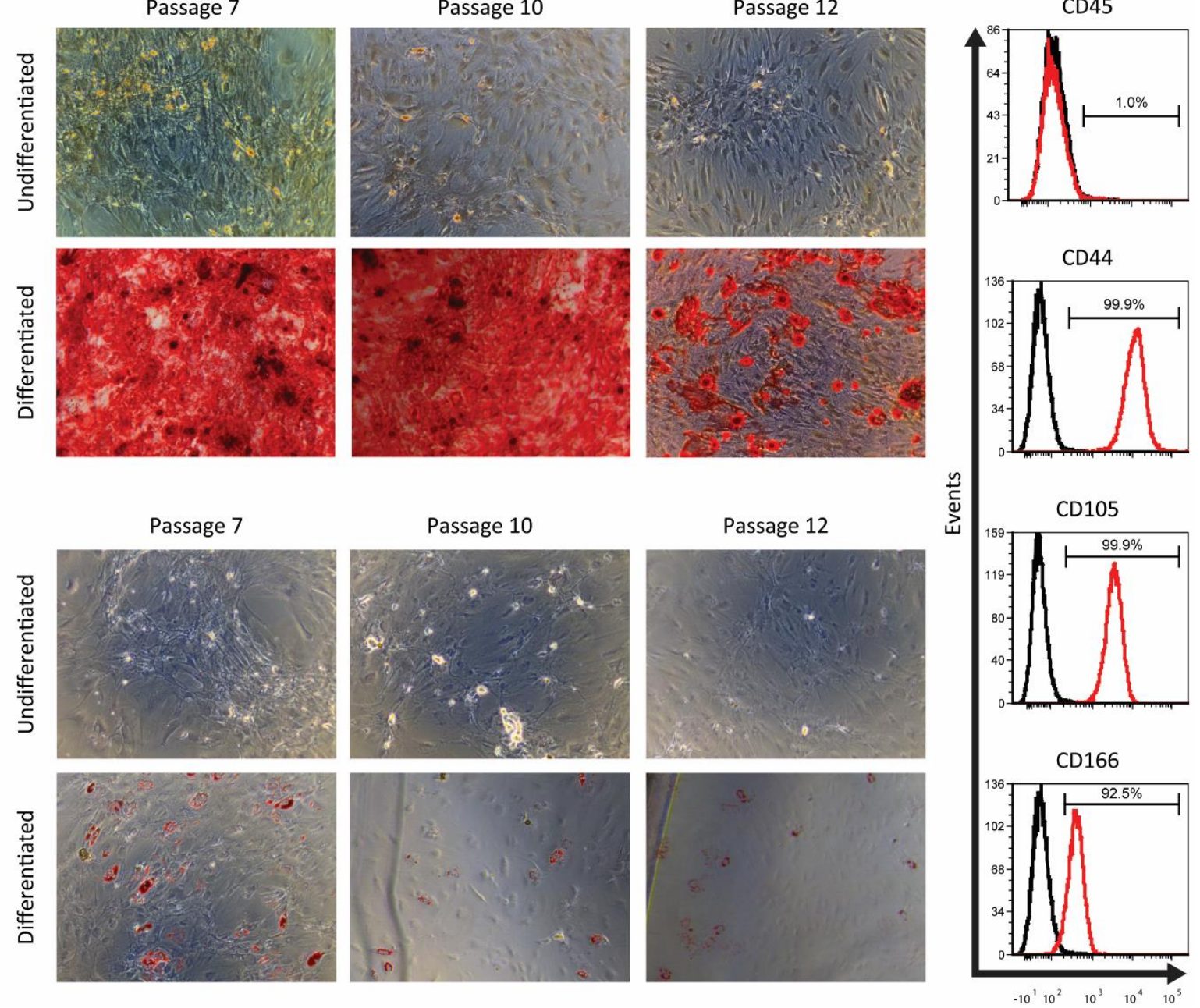

Figure 1. Differentiation and surface phenotype of bone marrow derived mesenchymal stem cell (MSCs).

Hare et al. 2016. In Vitro Expansion of Bone Marrow Derived Mesenchymal Stem Cells Alters DNA Double Strand Break Repair of Etoposide Induced DNA Damage. Stem Cells International. DOI: $10.1155 / 2016 / 8270464$. 


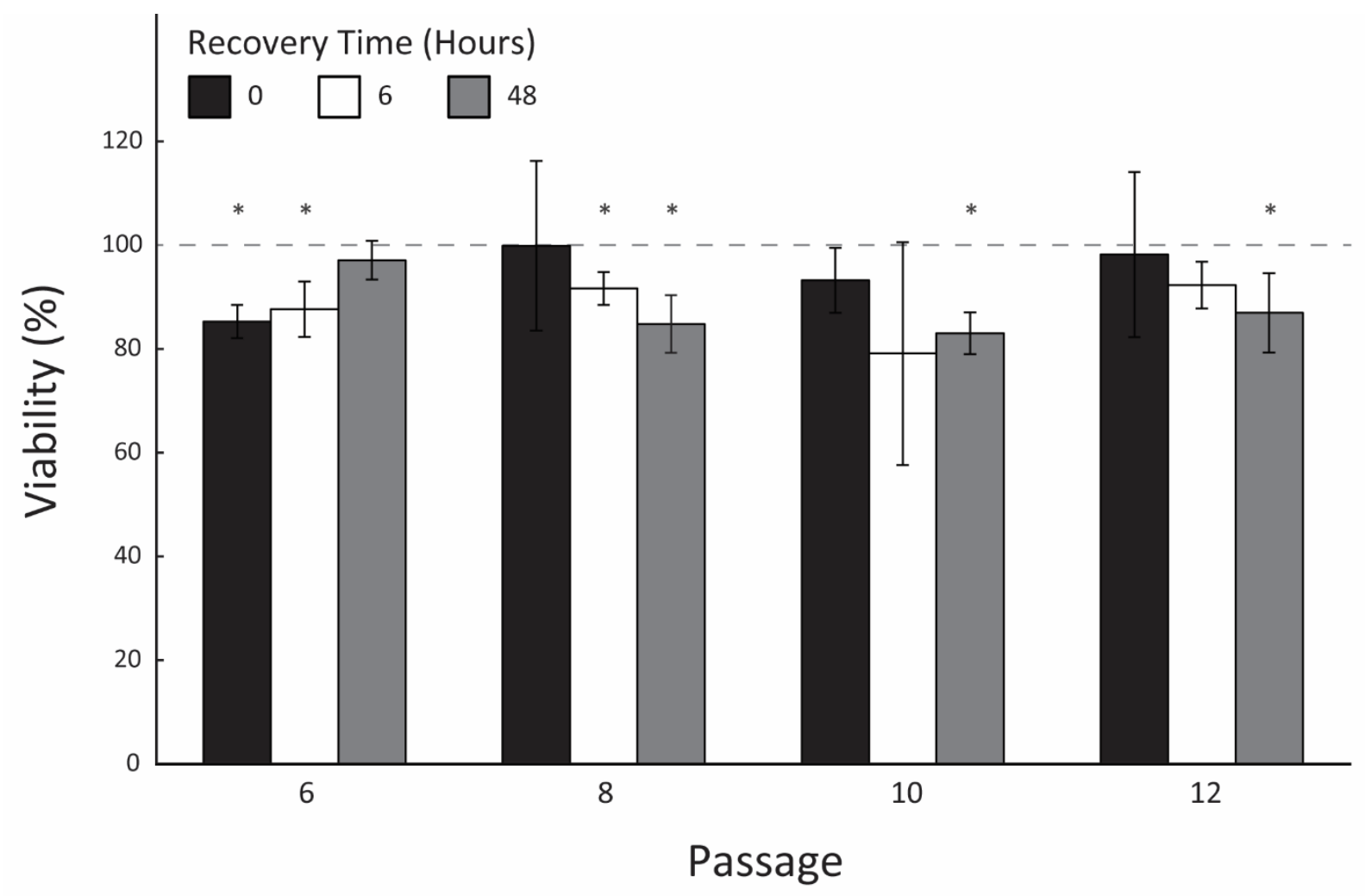

Figure 2. Viability of MSCs with passage following 24 hours etoposide (VP16) exposure.

Hare et al. 2016. In Vitro Expansion of Bone Marrow Derived Mesenchymal Stem Cells Alters DNA Double Strand Break Repair of Etoposide Induced DNA Damage. Stem Cells International. DOI: $10.1155 / 2016 / 8270464$. 
A

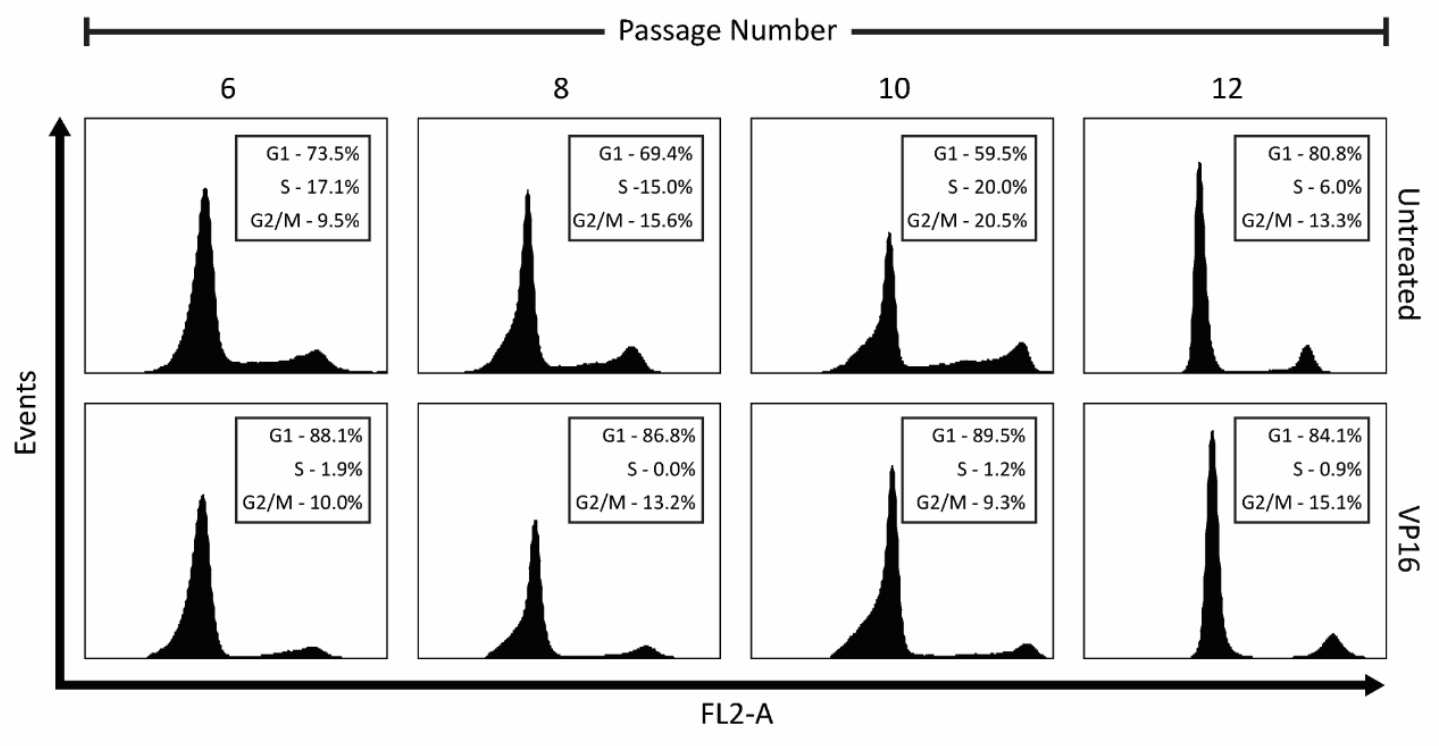

B

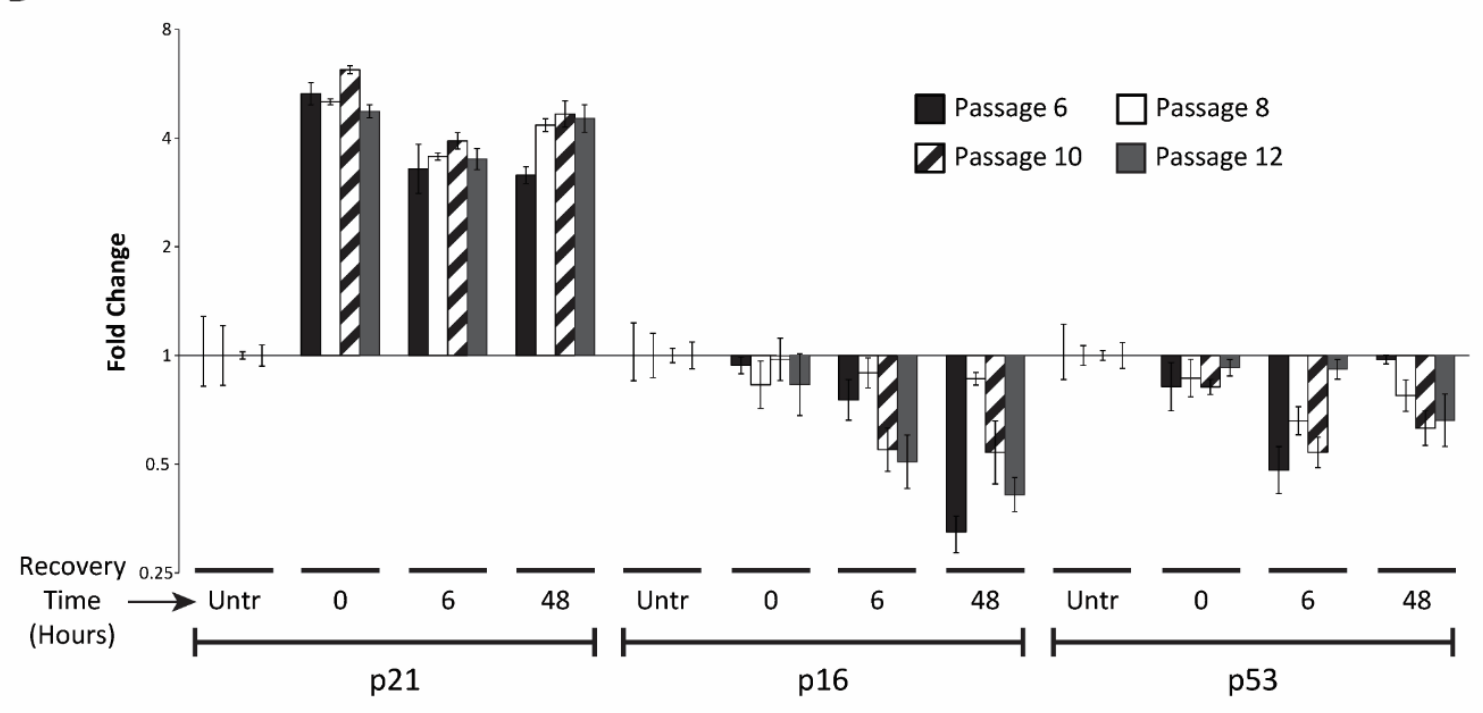

Figure 3. Effects of VP16 on cell cycle distribution and cell cycle inhibitor transcript abundance with passage.

Hare et al. 2016. In Vitro Expansion of Bone Marrow Derived Mesenchymal Stem Cells Alters DNA Double Strand Break Repair of Etoposide Induced DNA Damage. Stem Cells International. DOI: 10.1155/2016/8270464. 


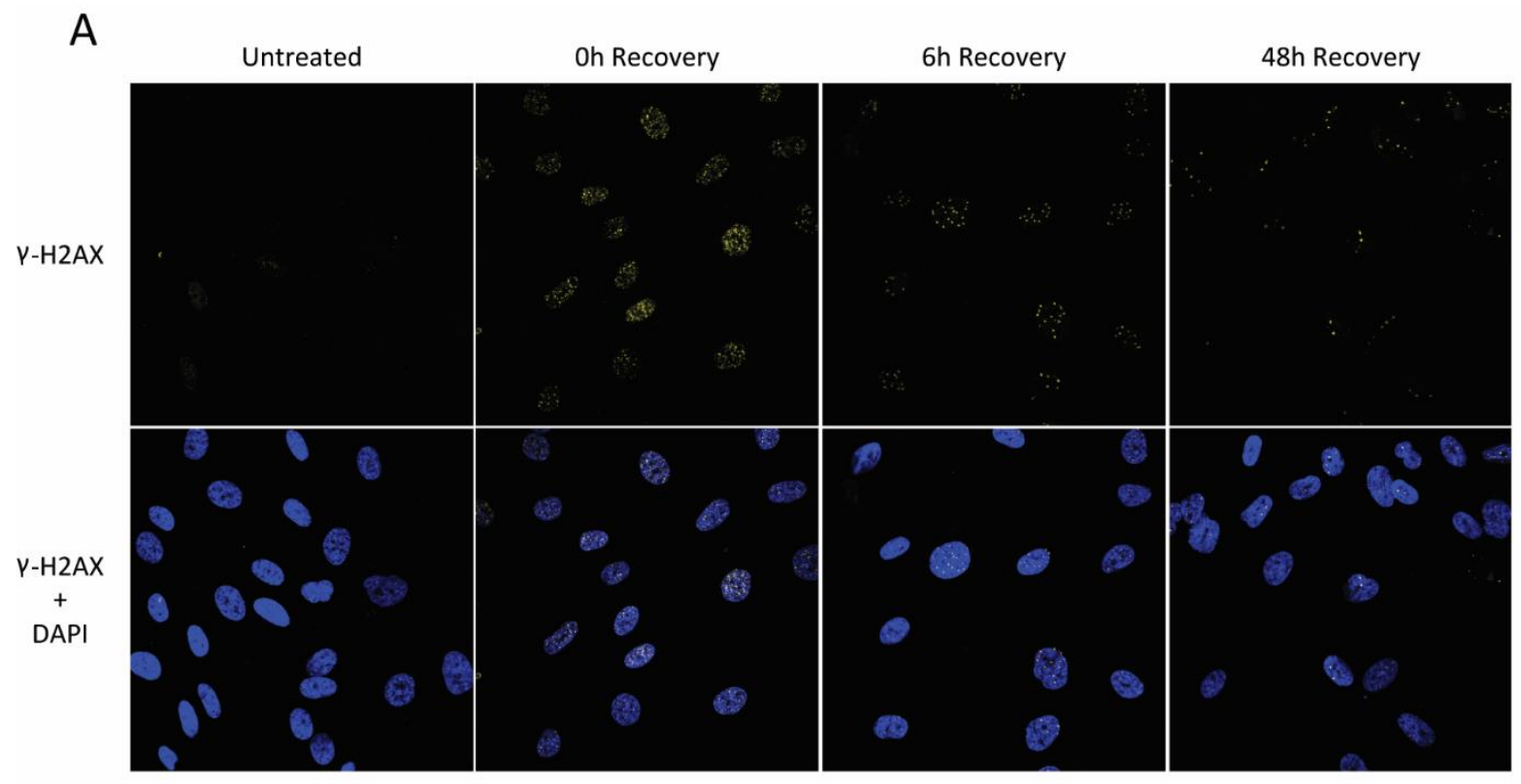

B

C
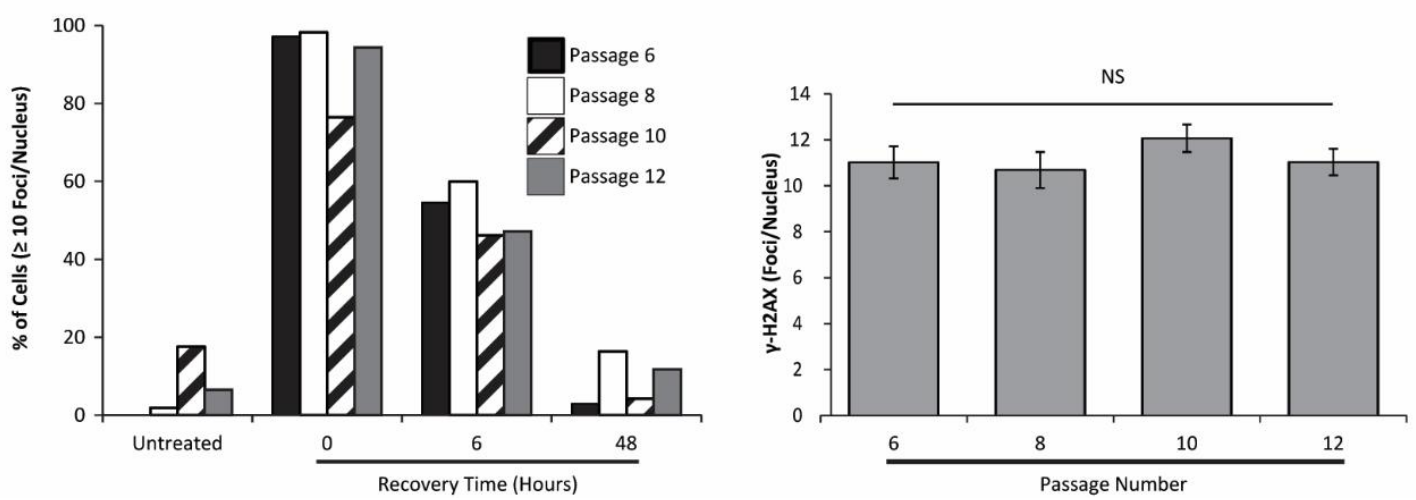

Figure 4. DNA double strand break incidence and repair kinetics in MSCs exposed to 25 $\mu \mathrm{M}$ VP16.

Hare et al. 2016. In Vitro Expansion of Bone Marrow Derived Mesenchymal Stem Cells Alters DNA Double Strand Break Repair of Etoposide Induced DNA Damage. Stem Cells International. DOI: 10.1155/2016/8270464. 
A

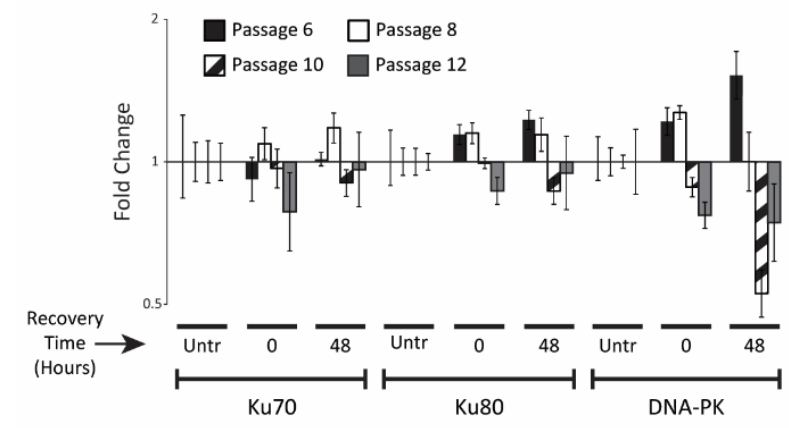

B

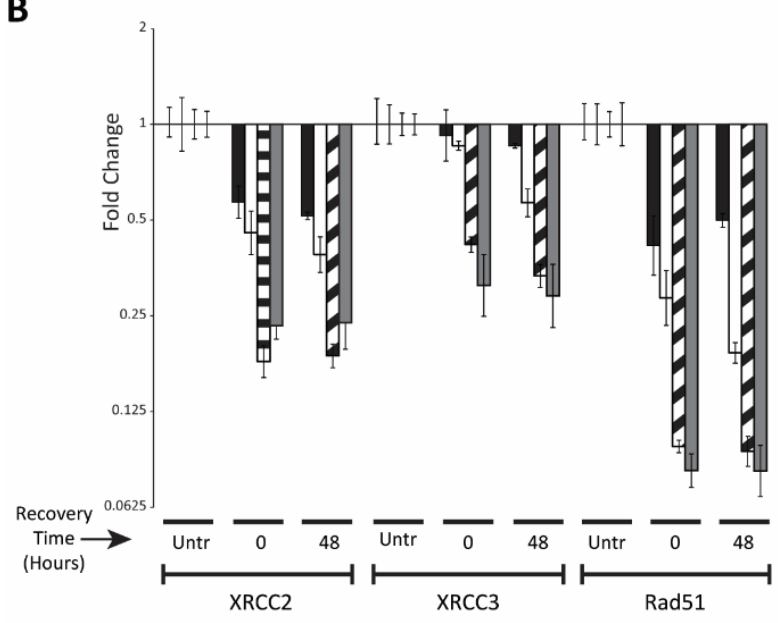

C

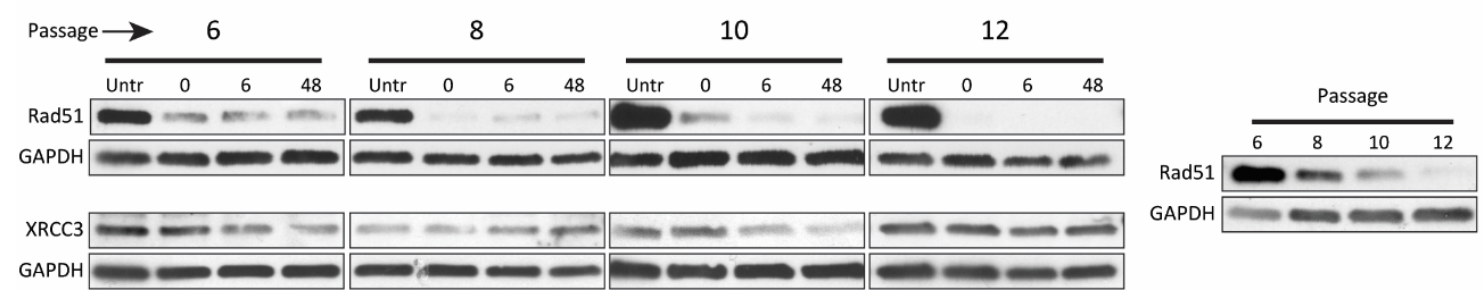

Figure 5. Non-homologous end joining (NHEJ) and homologous recombination (HR) transcriptional, protein, and functional repair responses to $25 \mu \mathrm{M}$ VP16 with passage.

Hare et al. 2016. In Vitro Expansion of Bone Marrow Derived Mesenchymal Stem Cells Alters DNA Double Strand Break Repair of Etoposide Induced DNA Damage. Stem Cells International. DOI: $10.1155 / 2016 / 8270464$.
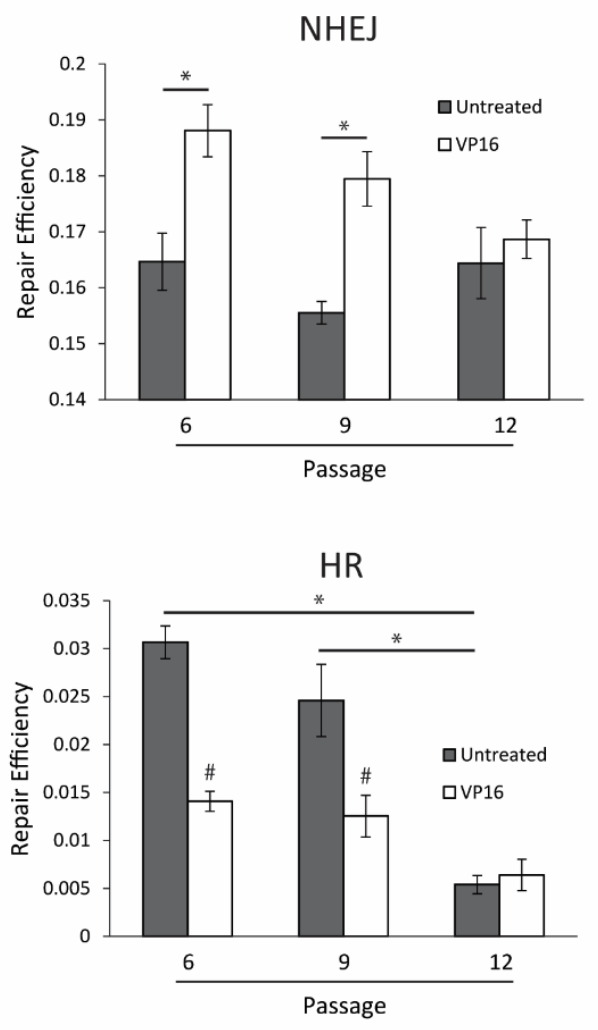

$\mathbf{E}$ 

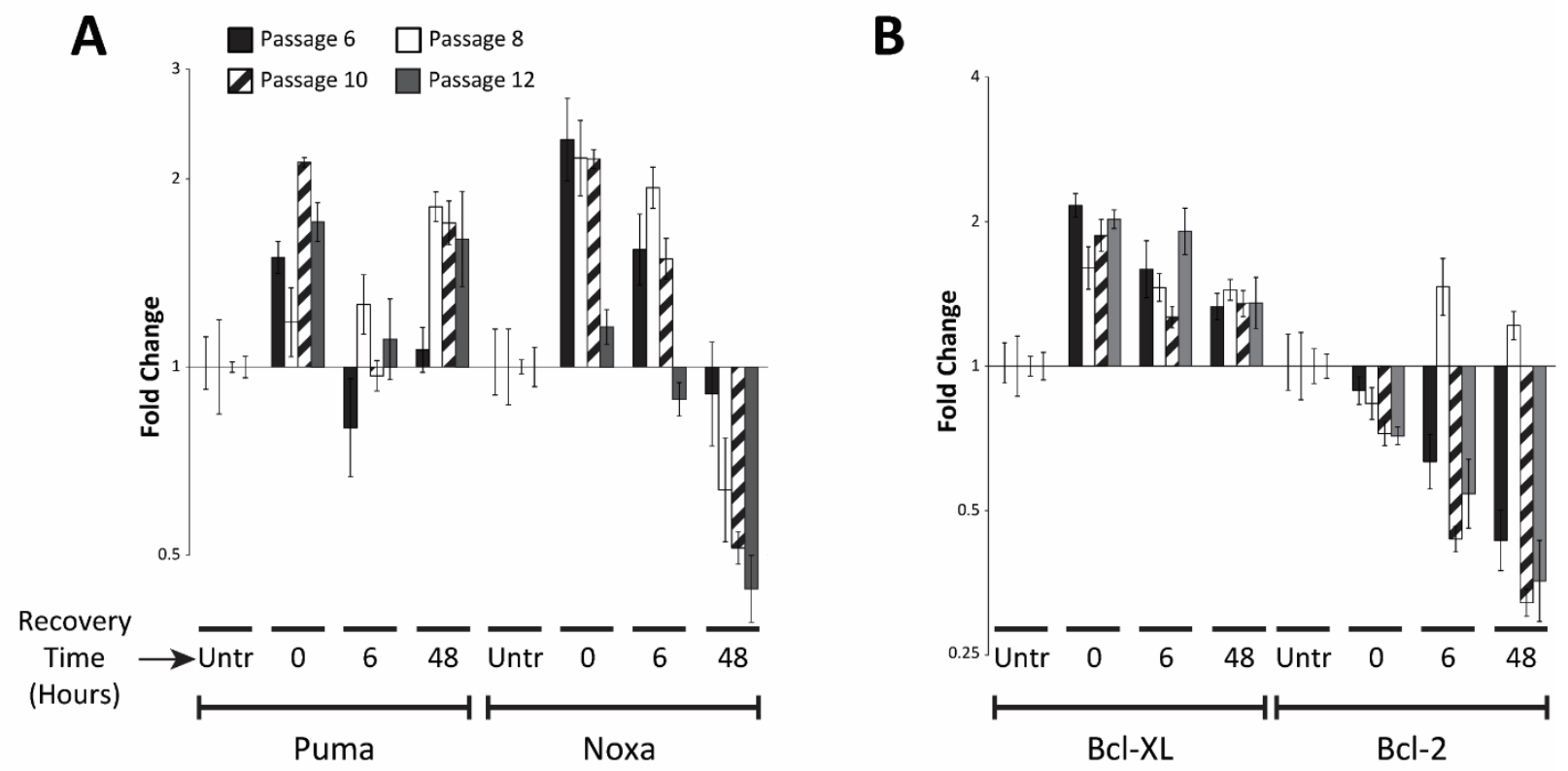

\section{Supplementary Figure 1. Apoptosis associated transcriptional responses of MSCs following VP16 exposure with passage.}

Hare et al. 2016. In Vitro Expansion of Bone Marrow Derived Mesenchymal Stem Cells Alters DNA Double Strand Break Repair of Etoposide Induced DNA Damage. Stem Cells International. DOI: 10.1155/2016/8270464. 


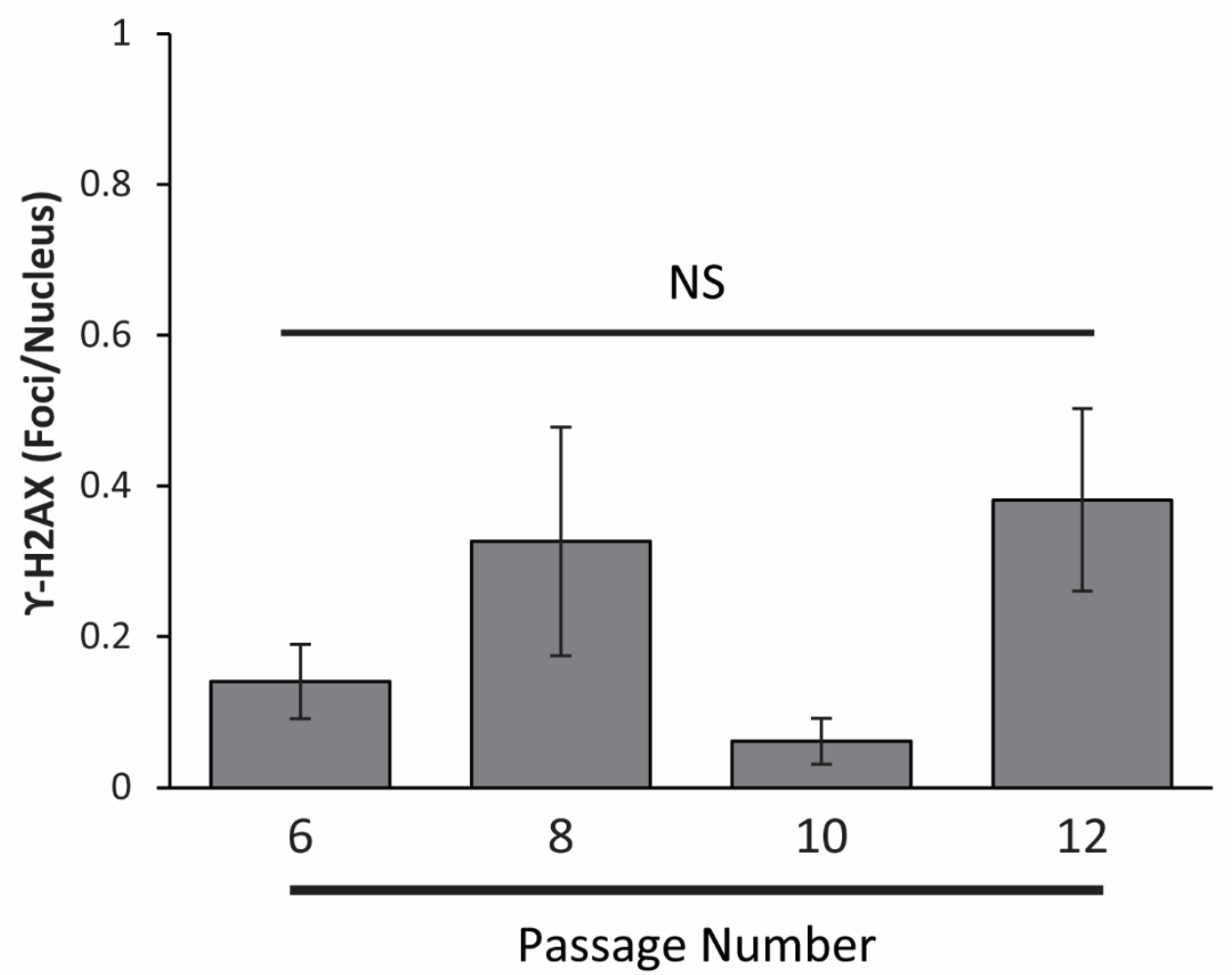

Supplementary Figure 2. Average number of $\mathrm{Y}$-H2AX foci per cell in untreated MSCs for passages 6 through 12.

Hare et al. 2016. In Vitro Expansion of Bone Marrow Derived Mesenchymal Stem Cells Alters DNA Double Strand Break Repair of Etoposide Induced DNA Damage. Stem Cells International. DOI: $10.1155 / 2016 / 8270464$. 


\begin{tabular}{|l|l|l|}
\hline Gene & Forward & Reverse \\
\hline GUSB & AAACGATTGCAGGGTTTCAC & CTCTCGTCGGTGACTGTTCA \\
\hline CDKN1A (p21) & CCTGGCACCTCACCTGCTC & CGGCGTTTGGAGTGGTAGA \\
\hline CDKN2A (p16) & GGGGTCGGGTAGAGGAGGT & CCGTGGAGCAGCAGCAGC \\
\hline TP53 (p53) & GCACATGACGGAGGTTGTGAG & ATGGTGGTACAGTCAGAGCCAAC \\
\hline KU70 & CCAATAAAGCTCTATCGGGAAAC & TTTCTCCAGTATAATCTGACGACTCC \\
\hline KU80 & AAAATTAAAGACTGAGCAAGGGG & TAGAACACGGAAGTTTTCAGCAG \\
\hline PRKDC (DNA-PK) & GCGAAGCACTGGCTTAGC & CTAACACTTCATCTTTAGGGACCC \\
\hline XRCC2 & GCAGTTGGTGAATGGCGTT & GCACAGGTGAATCTTCATCAGC \\
\hline XRCC3 & CGGCATCACTGAGCTGGC & AGCTCTCCTGGAACGTCAGTG \\
\hline RAD51 & GTCTCTCTGGCAGTGATGTCCT & TCTGTAAAGGGCGGTGGC \\
\hline BBC3 (Puma) & AGACAAGAGGAGCAGCAGCG & CTGGGTAAGGGCAGGAGTCC \\
\hline PMAIP1 (Noxa) & AGCTGGAAGTCGAGTGTGCTACT & GCAAGTTTTTGATGCAGTCAGG \\
\hline BCL2 (Bcl-2) & TGTCGCAGAGGGGCTACG & GGATGCGGCTGGATGGG \\
\hline BCL2L1 (Bcl-XL) & TCCAGGAGAACGGCGGC & GAGCCCAGCAGAACCACG \\
\hline
\end{tabular}

\section{Supplementary Table 1. qPCR Primer sequences (5' to $\left.3^{\prime}\right)$.}

Hare et al. 2016. In Vitro Expansion of Bone Marrow Derived Mesenchymal Stem Cells Alters DNA Double Strand Break Repair of Etoposide Induced DNA Damage. Stem Cells International. DOI: $10.1155 / 2016 / 8270464$. 


\section{Chapter IV}

\section{Chemotherapy Induced Dkk-1 Expression by Primary Human Mesenchymal Stem Cells is p53 Dependent}

Ian Hare ${ }^{1,2}$, Rebecca Evans ${ }^{1}$, James Fortney ${ }^{1}$, Blake Moses ${ }^{1}$, Debbie Piktel ${ }^{1}$, William Slone $^{1}$, and Laura F. Gibson ${ }^{1,2}$

\footnotetext{
${ }^{1}$ Alexander B. Osborn Hematopoietic Malignancy and Transplantation Program of the Mary Babb Randolph Cancer Center, Robert C. Byrd Health Sciences Center, West Virginia University School of Medicine, Morgantown, WV, United States of America ${ }^{2}$ Department of Microbiology, Immunology, and Cell Biology, Robert C. Byrd Health Sciences Center, West Virginia University School of Medicine, Morgantown, WV, United States of America
} 


\section{Abstract}

Mesenchymal stem cells (MSCs) are abundant throughout the body, and regulate signaling within tumor microenvironments. Wnt signaling is an extrinsically regulated pathway that has been shown to regulate tumorigenesis in many types of cancer. After evaluating a panel of Wnt activating and inhibiting molecules, we show that primary human MSCs increase the expression of Dkk-1, an inhibitor of Wnt signaling, into the extracellular environment following chemotherapy exposure in a p53 dependent manner. Dkk-1 has been shown to promote tumor growth in several models of malignancy, suggesting that MSC derived Dkk-1 could counteract the intent of cytotoxic chemotherapy, and that pharmacologic inhibition of Dkk1 in patients receiving chemotherapy treatment for certain malignancies may be warranted. 


\section{Materials and methods}

\section{MSC acquisition and cell culture}

MSCs cultures were derived from de-identified bone marrow specimens from patients at the West Virginia University Cancer Institute and cultured as previously described [1]. Patients had no history of exposure to chemotherapy, radiation, or malignancy. HS-5 and HS-27A cell lines were purchased from ATCC (Manassas, VA, USA) and cultured as suggested by the supplier.

\section{Chemotherapy and drug exposures}

Chemotherapy exposure was at sub-lethal concentrations for all experiments. Etoposide (VP16) and melphalan were prepared as previously described [2] and 5-FU (Selleck Chemicals, Boston, MA, USA) was diluted to $10 \mu \mathrm{g} / \mathrm{mL}$ in DMSO prior to use. GolgiStop (BD Biosciences, San Jose, CA, USA) was used following manufacturer guidelines. pifithrin- $\alpha$, nutlin-3, and RU486 (Selleck Chemicals, Boston, MA, USA) were diluted in DMSO, and recombinant Wnt3a (R\&D Systems, Minneapolis, MN, USA) was dissolved in phosphate buffered saline prior to use.

\section{RNA isolation and qPCR}

RNA was isolated and analyzed by qPCR as previously described [1]. The following primer sequences were used (5' to 3'), DKK1 (F-CGTCACGCTATGTGCTGCC, RGCTTTCAGTGATGGTTTCCTCA), SFRP1(F-AGTTCTTCGGCTTCTACTGGC, RAACTCGTTGTCACAGGGAGGAC), WNT2B (F-TTGACAACTCTCCAGATTACTGTGT, RATTTCACAACCGTCTGTTCCTT), WNT3A (F-GATGGTGTCTCGGGAGTTCG, RGTGGCACTTGCACTTGAGGT), WNT4 (F-GGTCACGCACTGAAGGAGAAG, RCAAGTACACCAGGTCCTCATCTGT), WNT5A (F-CTCTGTTTTTGGCAGGGTGA, RGCAGCCGCAGGTGGACA), WNT10B (F-GGTCCACGAGTGTCAGCAC, R- 
CAGCCAGCATGGAGAAGGA), GUSB (F-AAACGATTGCAGGGTTTCAC, R-

CTCTCGTCGGTGACTGTTCA).

\section{Western blotting}

Western blotting was performed as previously described [1], using the following antibodies from Cell Signaling Technologies (Danvers, MA, USA), Dkk-1 (\#4687),p53 (\#2524), and Phosphorylated-p53 (\#9286). Antibodies were diluted as directed by manufacturer.

\section{Dkk-1 ELISA}

Dkk-1 ELISA was performed using Human DuoSet Dkk-1 ELISA (R\&D Systems, Minneapolis, MN, USA) following manufacturer recommendations. Cellular supernatants were diluted 1:4 prior to analysis.

\section{p53 siRNA Knockdown}

p53 specific siRNA and scramble controls were utilized obtained GE Dharmacon (Lafayette, CO, USA), and used following manufacturer protocol. Knockdowns were performed overnight, followed by 48 hours recovery in basal culture medium prior to chemotherapy exposure.

\section{Introduction}

MSCs are a mesenchymal derived stromal population that is capable of differentiating into osteoblasts, adipocytes, and chondrocytes [3]. Although abundant in bone and adipose tissues, MSCs have been shown to be actively recruited specifically to sites of the body where they regulate angiogenesis, inflammation, and invasion of tumor cells [4]. Once within this functionally distinct tumor niche, MSCs influence the behavior of a tumor through the expression 
of various proteins which regulate signaling pathways that influence survival and proliferation [5]. The Wnt signaling pathway has been described as influencing malignancy in certain tumor microenvironments, extrinsically regulated by the abundance of secreted activating and inhibitory molecules into the extracellular milieu [6]. Humans express 19 Wnt activating ligands, and several inhibitory proteins including soluble Frizzled proteins (SFRP) and Dickkopf proteins (Dkk), which inhibit Wnt signaling by quenching extracellular Wnt ligands and preventing the assembly of the Wnt surface receptor complex, respectively [7]. MSC derived Wnt ligands have been shown to initiate an epithelial-mesenchymal transition phenotype of colon cancer cells [8] and activation of Wnt signaling with lithium chloride reduced tumor burden in a murine model of myeloma [9], highlighting the importance of Wnt signaling in the tumor microenvironment.

We have reported previously that stromal cells of the bone marrow have a reduced ability to support optimal hematopoietic cell function following exposure to chemotherapy $[2,10,11]$. Given the observation that MSCs express Wnt activating and inhibiting molecules [12], and the importance of Wnt signaling within the tumor microenvironment, we evaluated the expression of Wnt regulating molecules by primary human MSCs following chemotherapy exposure. In the current study, we show that Dkk-1, an inhibitor of Wnt signaling that has been implicated in the progression of various tumors, is elevated in primary human MSCs after exposure to various chemotherapeutic agents.

\section{$\underline{\text { Results }}$}

\section{Dkk-1 expression is elevated in primary human MSCs after chemotherapy exposure}

To determine whether chemotherapy exposure alters the expression of MSC derived Wnt regulating molecules, MSCs were exposed to etoposide (VP16) for 24 hours followed by qPCR analysis. Of a panel of Wnt activating and inhibitory molecules, VP16 significantly 
increased the abundance of DKK1 mRNA (Figure 1a). DKK1 transcripts were elevated following exposure to VP16, melphalan, and fluorouracil (5-FU), indicating that the response was consistent among chemotherapeutics with various mechanisms of action (Figure 1b). Dkk-1 protein was also elevated, evaluated by Western blot analysis (Figure 1c), following inhibition of secretion using GolgiStop (BD Biosciences). The requirement for inhibition of secretion for detectable protein accumulation suggests that Dkk-1 is quickly secreted following transcription (Figure 1c). Finally, VP16, melphalan, and 5-FU elevated the abundance of Dkk-1 protein in culture supernatants (Figure 1d). These results indicate that primary human MSCs display elevated Dkk-1 expression following exposure to cytotoxic stress by drugs with various mechanisms of action.

\section{Elevated Dkk-1 expression is regulated by $p 53$}

The necessity of GolgiStop to visualize intracellular Dkk-1 by Western (Figure 1c) suggested that the protein is very rapidly secreted and that elevated expression of Dkk-1 following chemotherapy exposure was potentially regulated at the mRNA level. To determine the mechanism by which Dkk-1 is elevated following chemotherapy induced stress, we investigated the potential influence of signaling pathways with promoting elements within the DKK1 promoter. The promoter region of DKK1 has been shown to contain several TCF/LEF response elements, enabling $\beta$-catenin mediated gene transcription following activation of the Wnt signaling pathway [13]. Given that exogenous activation of Wnt signaling by rWnt3a does not increase the transcriptional abundance of DKK1, and the nuclear abundance of $\beta$-catenin is not increased following VP16 exposure (Supplemental Figure 1), it is unlikely that Wnt signaling regulates DKK1 expression in MSCs following chemotherapy exposure. Glucocorticoid response elements (GRE) are also present within the DKK1 promoter [14], consistent with the elevation of DKK1 mRNA following dexamethasone exposure (Supplemental Figure 2a). However, inhibition of GRE signaling using RU-486 does not diminish chemotherapy induced 
DKK1 elevations following chemotherapy exposure (Supplemental Figure 2b), suggesting that glucocorticoid signaling does not regulate DKK1 in MSCs after chemotherapy.

Previously, the promoter region of DKK1 was shown to contain a p53 response element [15]. Exposure of MSCs to VP16, melphalan, or 5-FU resulted in increased levels of phosphorylated p53 (Figure 2a). Inhibition of the transcriptional function of p53 with pifithrin- $\alpha$ resulted in a dose-dependent decrease in DKK1 abundance when combined with melphalan exposure (Figure 2b). In addition, inhibition of p53 by targeted siRNA resulted in decreased abundance of soluble Dkk-1 from control, as well as chemotherapy exposed, MSCs (Figure 2e). Conversely, activation of p53 using nutlin-3, an MDM2 inhibitor, increased DKK1 abundance in a dose-dependent manner when combined with melphalan (Figure 2c), as well as when used with VP16, melphalan, or 5-FU (Figure 2d). Contrary to primary MSCs, HS-5 and HS-27A human cell lines display deregulated p53 function due to the expression of human papillomavirus virus E6 and E7 proteins [16]. Consistent with the necessity of p53 to elevate Dkk-1 expression following chemotherapy in primary MSCs, exposure of HS-5 and HS-27A cells to sub-lethal concentrations of chemotherapy or nutlin-3 did not elevate Dkk-1 expression (Supplemental Figure 3), unlike primary human MSCs (Figures 1d and 2c). These results suggest that p53 regulates the elevated expression of Dkk-1 following exposure of MSCs to various chemotherapeutics.

\section{Discussion}

Our results show that MSC derived Dkk-1 is elevated in cells following cytotoxic drug exposure suggesting that it could be elevated in the tumor microenvironment following treatment with chemotherapy. VP16, a topoisomerase II inhibitor, melphalan, a DNA alkylating agent, and 5-FU, a pyrimidine analog that inhibits thymidine synthase [17-19] were all capable of 
increasing Dkk-1 expression, indicating the broad spectrum of stressors which can elicit such an effect. Elevated Dkk-1 could have negative consequences for patients suffering from certain tumors. For example, Dkk-1 has been shown to promote the migration and invasion of hepatocellular carcinoma cells [20], and to promote the growth of certain esophageal, non-small cell lung cancers, and myeloma cells [21-23]. The effects of Dkk-1 appear tumor specific, since Dkk-1 has been shown to act as a tumor suppressor in certain cancers, such as melanoma and colon [24,25]. Nevertheless, these findings suggest that chemotherapy could be having an undesired effect in these cancers, potentially leading to unsuccessful treatment or relapse of disease.

To our knowledge, this is the first time Dkk-1 has been shown to be elevated in MSCs following exposure to chemotherapy. However, it has been shown previously that certain cancer cell lines with functional p53 react similarly in response to chemotherapy induced stress [26]. Importantly, our observations are the first to include primary human MSCs which have been shown to be a component of the tumor microenvironment. Wang et al. and Shou et al. have also described the role of p53 in chemotherapy induced Dkk-1 expression, supporting and refuting the notion in tumor cell lines, respectively $[15,27]$. Our data are consistent with the assertion that p53 is playing a role in this regulation, however, it is likely that the phenomenon is regulated differently between cell types. The necessity of functional p53 for normal cellular function makes targeting the p53 pathway unfavorable in conjunction with cytotoxic therapies, suggesting that pharmacologic targeting of this response would be best directed at soluble Dkk-1 protein.

These observations align with a recent publication describing increased Dkk-1 protein in the serum of patients who have received chemotherapy [28], indicating that MSCs could be one potential source of this response. BHQ-880, a monoclonal anti-Dkk-1 antibody which has cleared phase Ib clinical trials [29], could theoretically be used in conjunction with chemotherapy to prevent the undesired effects of Dkk-1 on tumor phenotype in patients being treated with 
chemotherapy for certain malignancies. A more in depth analysis needs to be performed to understand which tumors respond to Dkk-1 as an oncoprotein and which respond to Dkk-1 as a tumor suppressor prior to use in vivo. Overall, our findings show that chemotherapy treatment may have an undesirable effect on the tumor microenvironment with future work required to evaluate whether MSC derived Dkk-1 negatively influences tumor behavior in the context of certain malignancies.

\section{Acknowledgements}

This work was funded by National Institutes of Health (NIH) R01 HL056888 (LFG), NIH P20 RR016440 (LFG), National Cancer Institute (NCI) RO1 CA134573 (LFG), WV CTR-IDEA NIH

1U54 GM104942, CoBRE P30GM103488, The Alexander B. Osborn Hematopoietic Malignancy and Transplantation Program, and The WV Research Trust Fund. The authors would like to thank Dr. James Coad for providing de-identified bone marrow specimens.

\section{Conflict of interest}

The authors declare no conflicts of interest regarding the publication of this manuscript.

\section{References}

1. Hare I, Gencheva M, Evans R, Fortney J, Piktel D, Vos JA, et al. In Vitro Expansion of Bone Marrow Derived Mesenchymal Stem Cells Alters DNA Double Strand Break Repair of Etoposide Induced DNA Damage. Stem Cells Int. 2016;2016:8270464.

2. Gencheva M, Hare I, Kurian S, Fortney J, Piktel D, Wysolmerski R, et al. Bone marrow osteoblast vulnerability to chemotherapy. Eur. J. Haematol. 2013;90:469-78.

3. Pittenger MF, Mackay AM, Beck SC, Jaiswal RK, Douglas R, Mosca JD, et al. Multilineage Potential of Adult Human Mesenchymal Stem Cells. Science. 1999;284:143-7. 
4. Rhee K-J, Lee JI, Eom YW. Mesenchymal Stem Cell-Mediated Effects of Tumor Support or Suppression. Int. J. Mol. Sci. 2015;16:30015-33.

5. Sun Z, Wang S, Zhao RC. The roles of mesenchymal stem cells in tumor inflammatory microenvironment. J. Hematol. Oncol.J Hematol Oncol. 2014;7:14.

6. Macheda ML, Stacker SA. Importance of Wnt signaling in the tumor stroma microenvironment. Curr. Cancer Drug Targets. 2008;8:454-65.

7. Cruciat C-M, Niehrs C. Secreted and Transmembrane Wnt Inhibitors and Activators. Cold Spring Harb. Perspect. Biol. 2013;5:a015081.

8. Chen D, Liu S, Ma H, Liang X, Ma H, Yan X, et al. Paracrine factors from adiposemesenchymal stem cells enhance metastatic capacity through Wnt signaling pathway in a colon cancer cell co-culture model. Cancer Cell Int. 2015;15:42.

9. Edwards CM, Edwards JR, Lwin ST, Esparza J, Oyajobi BO, McCluskey B, et al. Increasing Wnt signaling in the bone marrow microenvironment inhibits the development of myeloma bone disease and reduces tumor burden in bone in vivo. Blood. 2008;111:2833-42.

10. Rellick SL, O'Leary H, Piktel D, Walton C, Fortney JE, Akers SM, et al. Bone marrow osteoblast damage by chemotherapeutic agents. PloS One. 2012;7:e30758.

11. Wang L, Clutter S, Benincosa J, Fortney J, Gibson LF. Activation of Transforming Growth Factor- $\beta 1 / p 38 / S m a d 3$ Signaling in Stromal Cells Requires Reactive Oxygen SpeciesMediated MMP-2 Activity During Bone Marrow Damage. STEM CELLS. 2005;23:1122-34.

12. Etheridge SL, Spencer GJ, Heath DJ, Genever PG. Expression profiling and functional analysis of wnt signaling mechanisms in mesenchymal stem cells. Stem Cells Dayt. Ohio. 2004;22:849-60.

13. Niida A, Hiroko T, Kasai M, Furukawa Y, Nakamura Y, Suzuki Y, et al. DKK1, a negative regulator of Wnt signaling, is a target of the beta-catenin/TCF pathway. Oncogene. 2004;23:8520-6.

14. Moors M, Bose R, Johansson-Haque K, Edoff K, Okret S, Ceccatelli S. Dickkopf 1 mediates glucocorticoid-induced changes in human neural progenitor cell proliferation and differentiation. Toxicol. Sci. Off. J. Soc. Toxicol. 2012;125:488-95.

15. Wang J, Shou J, Chen X. Dickkopf-1, an inhibitor of the Wnt signaling pathway, is induced by p53. Oncogene. 2000;19:1843-8.

16. Roecklein BA, Torok-Storb B. Functionally distinct human marrow stromal cell lines immortalized by transduction with the human papilloma virus E6/E7 genes. Blood. 1995;85:997-1005.

17. Pommier $\mathrm{Y}$, Leo $\mathrm{E}$, Zhang $\mathrm{H}$, Marchand $\mathrm{C}$. DNA topoisomerases and their poisoning by anticancer and antibacterial drugs. Chem. Biol. 2010;17:421-33.

18. Hall AG, Tilby MJ. Mechanisms of action of, and modes of resistance to, alkylating agents used in the treatment of haematological malignancies. Blood Rev. 1992;6:163-73. 
19. Longley DB, Harkin DP, Johnston PG. 5-Fluorouracil: mechanisms of action and clinical strategies. Nat. Rev. Cancer. 2003;3:330-8.

20. Chen L, Li M, Li Q, Wang C-J, Xie S-Q. DKK1 promotes hepatocellular carcinoma cell migration and invasion through $\beta$-catenin/MMP7 signaling pathway. Mol. Cancer. 2013;12:157.

21. Yamabuki T, Takano A, Hayama S, Ishikawa N, Kato T, Miyamoto M, et al. Dikkopf-1 as a novel serologic and prognostic biomarker for lung and esophageal carcinomas. Cancer Res. 2007;67:2517-25.

22. Sato N, Yamabuki T, Takano A, Koinuma J, Aragaki M, Masuda K, et al. Wnt inhibitor Dickkopf-1 as a target for passive cancer immunotherapy. Cancer Res. 2010;70:5326-36.

23. Yaccoby S, Ling W, Zhan F, Walker R, Barlogie B, Shaughnessy JD. Antibody-based inhibition of DKK1 suppresses tumor-induced bone resorption and multiple myeloma growth in vivo. Blood. 2007;109:2106-11.

24. Mikheev AM, Mikheeva SA, Rostomily R, Zarbl H. Dickkopf-1 activates cell death in MDAMB435 melanoma cells. Biochem. Biophys. Res. Commun. 2007;352:675-80.

25. Qi L, Sun B, Liu Z, Li H, Gao J, Leng X. Dickkopf-1 inhibits epithelial-mesenchymal transition of colon cancer cells and contributes to colon cancer suppression. Cancer Sci. 2012;103:828-35.

26. Colla S, Zhan F, Xiong W, Wu X, Xu H, Stephens O, et al. The oxidative stress response regulates DKK1 expression through the JNK signaling cascade in multiple myeloma plasma cells. Blood. 2007;109:4470-7.

27. Shou J, Ali-Osman F, Multani AS, Pathak S, Fedi P, Srivenugopal KS. Human Dkk-1, a gene encoding a Wnt antagonist, responds to DNA damage and its overexpression sensitizes brain tumor cells to apoptosis following alkylation damage of DNA. Oncogene. 2002;21:878-89.

28. Xu H, Wu J, Chen B, Li M, Tian Y, He M, et al. Serum Dickkopf-1 (DKK1) is significantly lower in patients with lung cancer but is rapidly normalized after treatment. Am. J. Transl. Res. 2014;6:850-6.

29. Iyer SP, Beck JT, Stewart AK, Shah J, Kelly KR, Isaacs R, et al. A Phase IB multicentre dose-determination study of BHQ880 in combination with anti-myeloma therapy and zoledronic acid in patients with relapsed or refractory multiple myeloma and prior skeletalrelated events. Br. J. Haematol. 2014;167:366-75. 


\section{Figure Legends}

Figure 1 Dkk-1 is elevated in MSCs following chemotherapy exposure. (A) qPCR evaluating

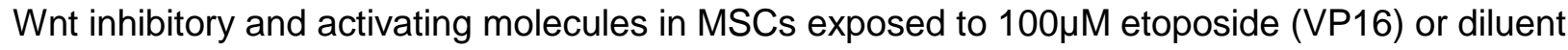
control for 24 hours. (B) qPCR evaluating DKK1 expression in MSCs exposed to 100 $\mu \mathrm{M}$ VP16, $25 \mu \mathrm{g} / \mathrm{mL}$ melphalan (Mel), $300 \mu \mathrm{g} / \mathrm{mL}$ fluorouracil (5-FU), or medium-only control. VP16 and melphalan exposures were 24 hours, 5-FU was incubated with MSCs for 1 hour followed by 23 hours incubation in normal growth medium. These chemotherapy conditions were kept consistent throughout the remaining experiments unless otherwise specified. (C) Western blot analysis of Dkk-1 in MSCs exposed to chemotherapy or medium-only control, in the presence of GolgiStop or diluent alone for 24 hours. Recombinant human Dkk-1 (rDkk-1) was included as a control. (D) Dkk-1 ELISA analysis of supernatants from MSCs exposed to chemotherapy or medium-only control for 72 hours. 5-FU was administered for 1 hour followed by 72 hours incubation in basal medium. *Indicates $p$-value $<0.05$, using Student's T-test $(\mathrm{A})$ or One-Way ANOVA with Dunnett's Post Hoc (B and D).

Figure 2 p53 regulates Dkk-1 following chemotherapy exposure of MSCs. (A) Western blot analysis of phosphorylated (phospho) and total p53 protein in MSCs following 6 hours exposure to chemotherapy or medium-only control. (B) qPCR evaluation of DKK1 in MSCs exposed to melphalan in combination with increasing concentrations of pifithrin- $\alpha$ (PTHa) for 24 hours. Cells were pre-treated with PTHa for 20 minutes prior to chemotherapy, and PTHa was spiked into culture vessels every 8 hours. (C) qPCR evaluation of DKK1 in MSCs exposed to melphalan in combination with increasing concentrations of nutlin-3 for 24 hours. Cells were pre-treated with nutlin-3 for 20 minutes prior to chemotherapy. (D) qPCR analysis of MSCs exposed to 
chemotherapy in the presence of $25 \mu \mathrm{M}$ nutlin-3 or diluent control for 24 hours. (E) Dkk-1 ELISA analysis of MSCs transfected with two separate siRNA targeting p53 mRNA (or scramble control), then exposed to chemotherapy or medium-only control for 24 hours. Cells conditioned medium for 72 hours prior to analysis. *Indicates $p$-value $<0.05$, One-Way ANOVA with HolmSidak Post Hoc.

Supplementary Figure $1 \beta$-catenin mediated signaling does not regulate chemotherapy induced DKK1 expression in MSCs. (A) rWnt3a was cultured with MSCs for 24 hours at indicated concentrations prior to RNA isolation and qPCR evaluation of DKK1. (B) MSCs were exposed to 100 uM VP16 for 24 hours, followed by nuclear fractionation and evaluation of $\beta$ catenin by Western blotting. HDAC1 and GAPDH were used as nuclear and cytosolic loading controls (respectively).

Supplementary Figure 2 Glucocorticoid signaling does not regulate chemotherapy induced DKK1 expression in MSCs. (A) MSCs were cultured with indicated concentrations of dexamethasone for 24 hours prior to RNA isolation and qPCR evaluation of DKK1. (B) MSCs were exposed to $100 \mathrm{uM} \mathrm{VP16}$ or $25 \mu \mathrm{g} / \mathrm{mL}$ melphalan (Mel) for 24 hours in the presence of $10 \mu \mathrm{M}$ RU-486 (glucocorticoid receptor antagonist) or DMSO control followed by qPCR analysis of DKK1.

Supplementary Figure 3 Dkk-1 is not elevated in p53 deregulated cell lines following chemotherapy or nutlin-3 exposure. HS-5 (A) and HS-27A (B) cells were exposed to sub-lethal concentrations of VP16 or melphalan (Mel) for 72 hours, or 5-FU for 1 hour followed by 72 hours 
incubation in basal medium, then evaluated by Dkk-1 ELISA. (C) HS-5 and HS-27A cells were exposed to indicated concentrations of nutlin-3 for 24 hours, followed by DKK1 evaluation by qPCR. 
A

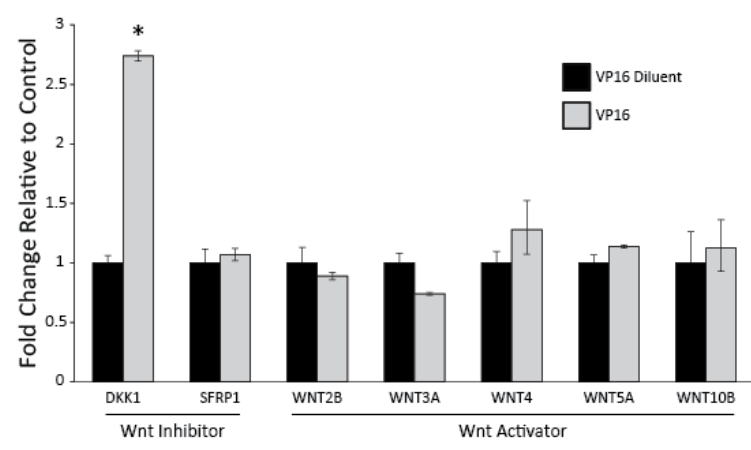

C

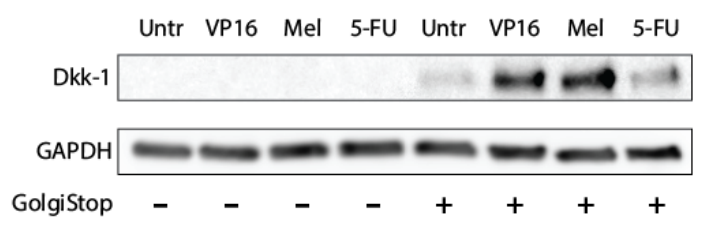

B

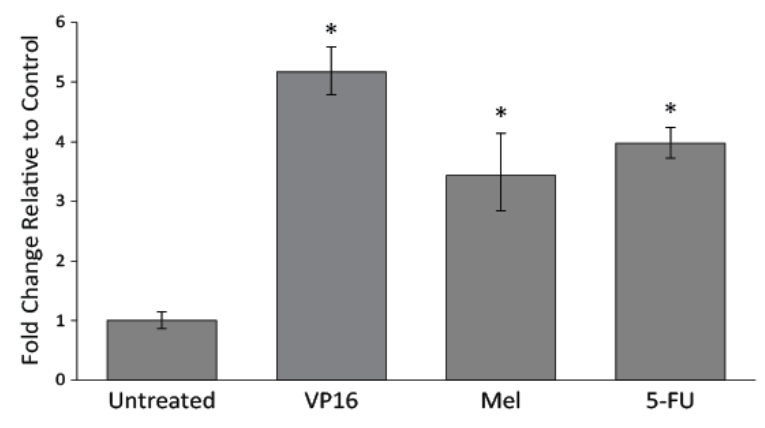

D

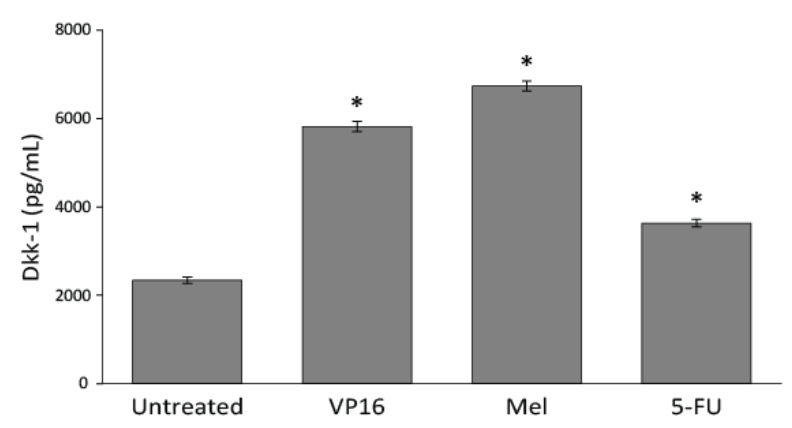

Figure 1. Dkk-1 is elevated in MSCs following chemotherapy exposure. 
A

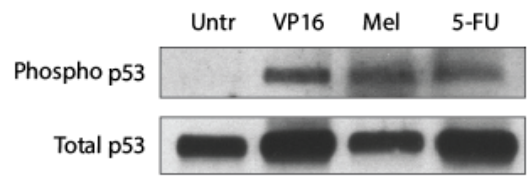

B

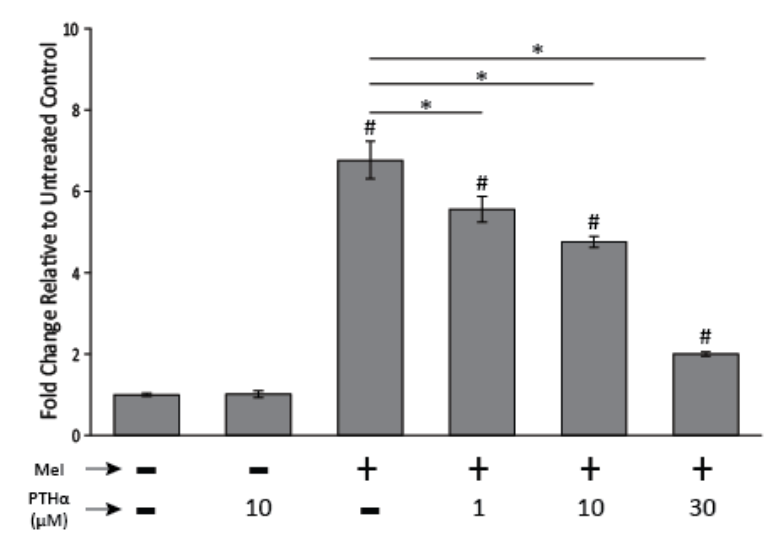

D

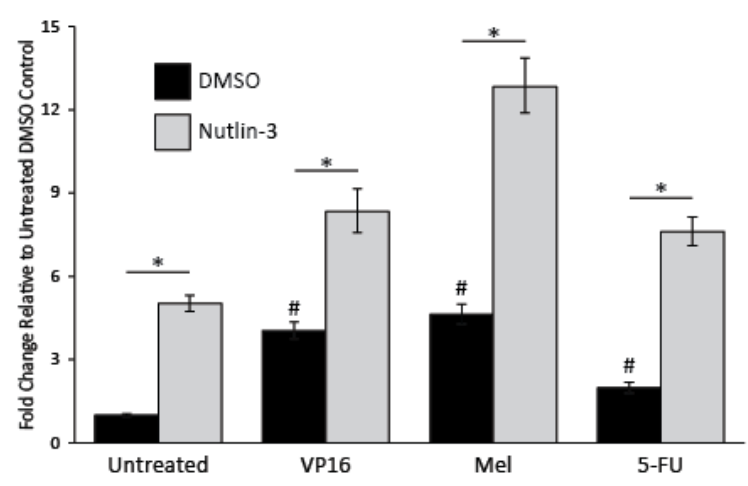

C

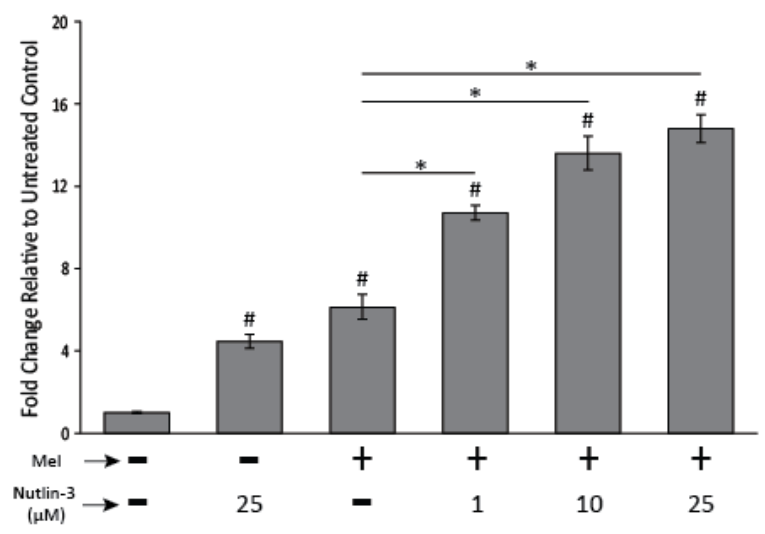

E

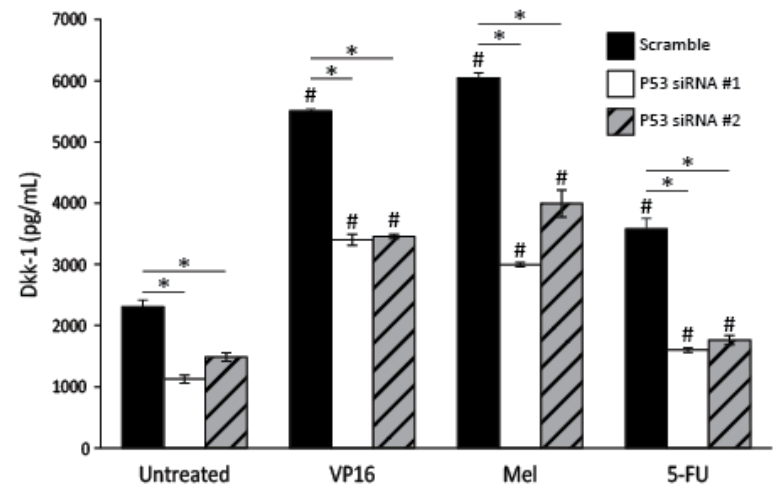

Figure 2. p53 regulates Dkk-1 following chemotherapy exposure of MSCs. 
A

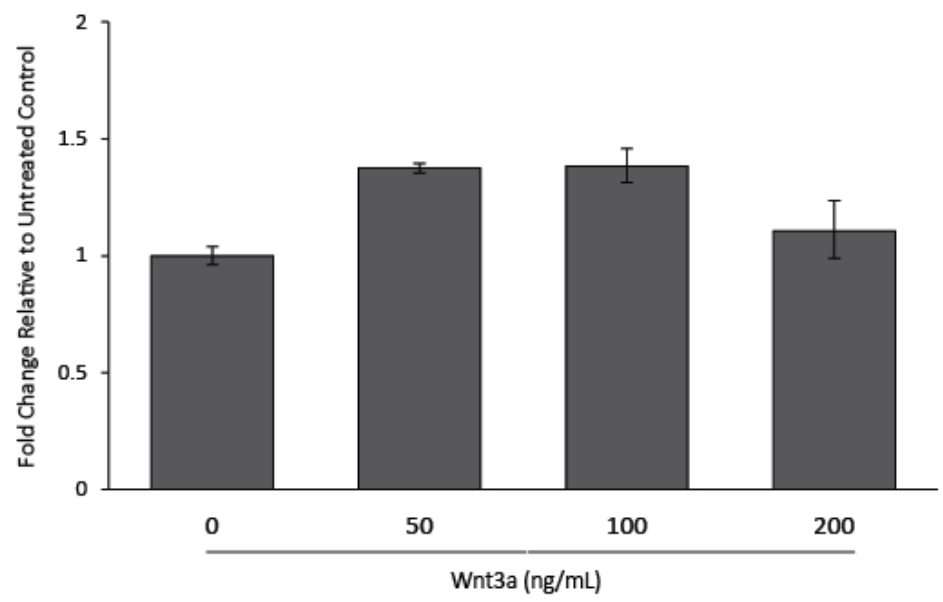

B

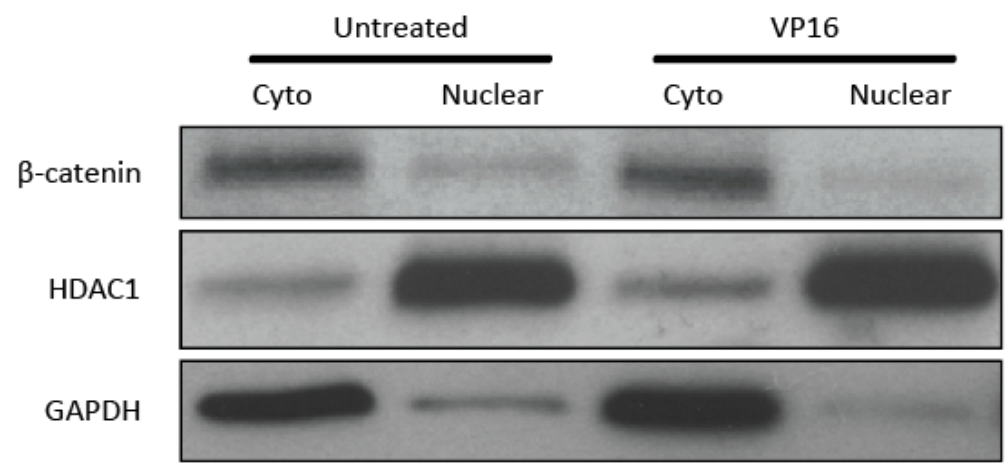

Supplementary Figure 1. $\beta$-catenin mediated signaling does not regulate chemotherapy induced DKK1 expression in MSCs. 
A

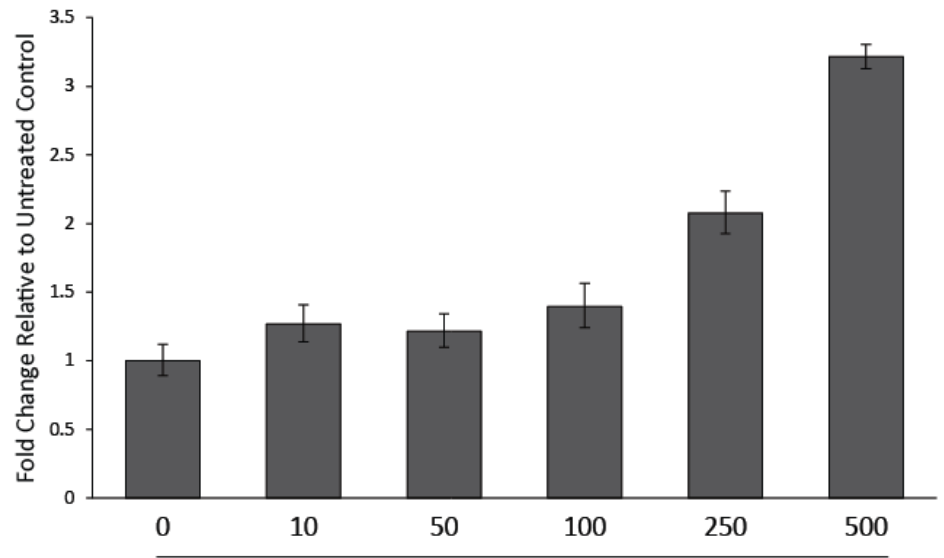

Dexamethasone (nM)

B

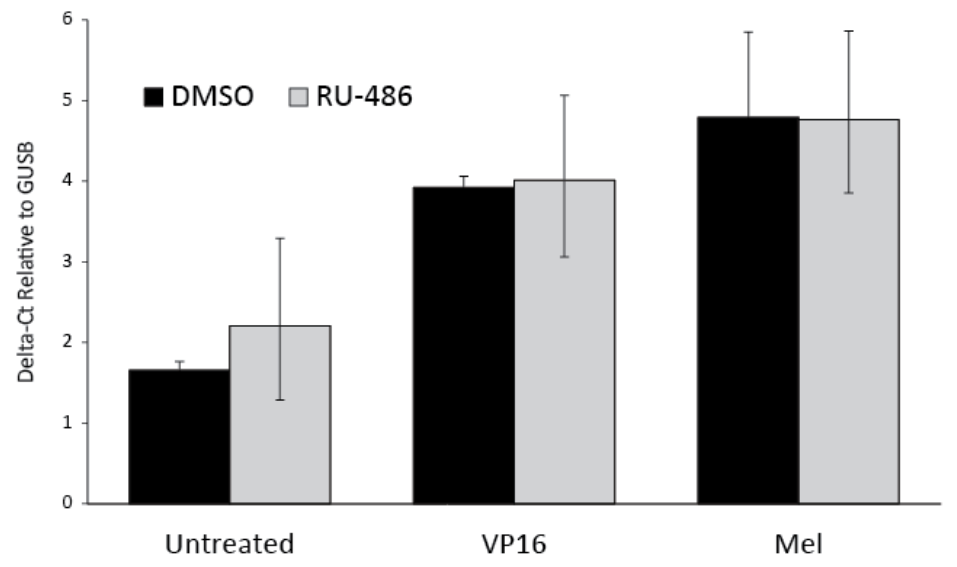

Supplementary Figure 2. Glucocorticoid signaling does not regulate chemotherapy induced DKK1 expression in MSCs. 
A
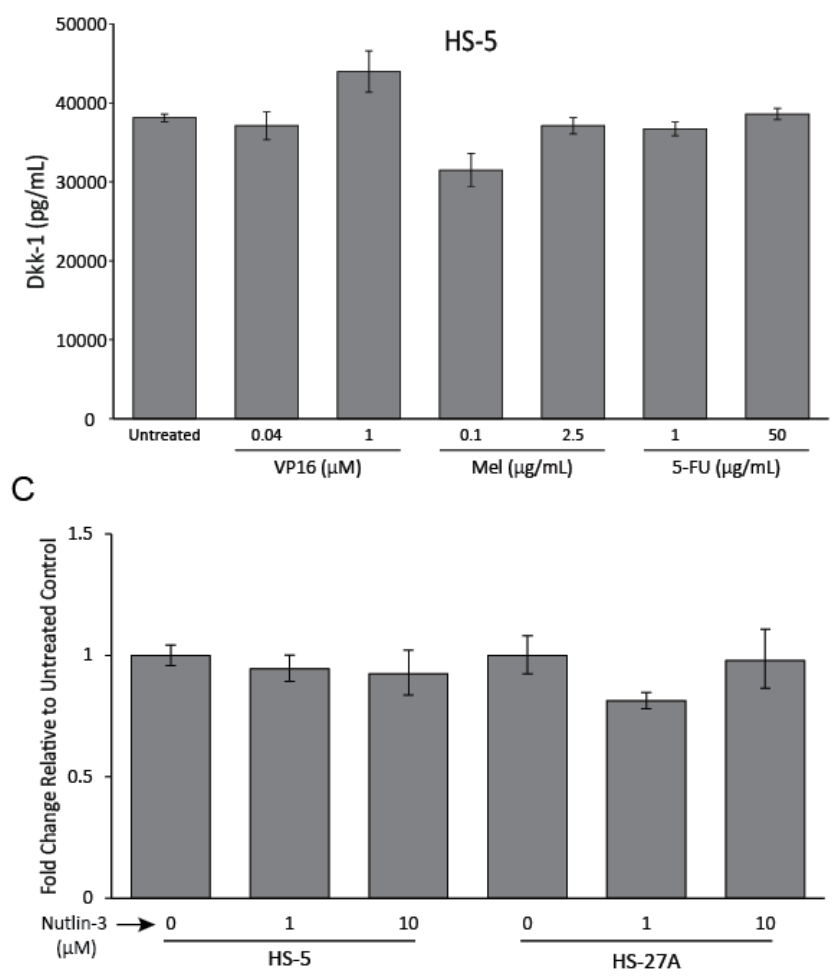

B

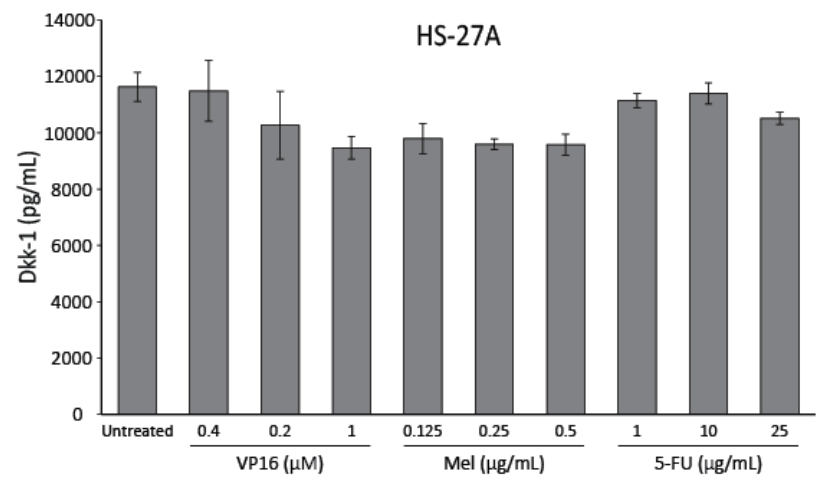

Supplementary Figure 3. Dkk-1 is not elevated in p53 deregulated cell lines following chemotherapy or nutlin-3 exposure. 
Chapter V

General Discussion 
The Friedenstein laboratory observed the presence of stromal cells within the bone marrow in $1976^{1}$. It was not until 1987 that the ability of these cells to undergo osteogenic differentiation was appreciated, following observations of mineralized ECM after expansion ex vivo $^{2}$. Bone marrow stromal support of hematopoietic cells was addressed by Michael Dexter after developing the first in vitro culture system of HSCs, using bone marrow stromal cell feeder layers ${ }^{3,4}$. Once the supportive nature of bone marrow stromal cells was understood, work by David Scadden, Paul Frenette, Daniel Link, and Sean Morrison laboratories, among others, contributed greatly to the understanding of their heterogeneity reflected as the various cellular phenotypes described in Chapter I. Although these findings displayed the plasticity of various bone marrow stromal cell populations, it was Pittenger et al. who first characterized a population of mesenchymal precursor cells capable of differentiating into osteoblasts, chondrocytes, and

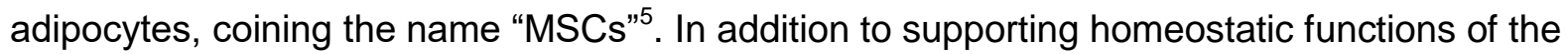
body, MSCs have been observed to influence the activities of malignant cells. Evidence for this phenomenon was proposed by Stephen Paget in 1889. In a report outlining his "seed and soil" hypothesis, Paget postulated that the propensity of metastatic cells to induce secondary tumors is influenced by the environment in which they reside ${ }^{6}$. This early observation later cumulated into an understanding of what is known as the tumor microenvironment, shown to be influenced, in part, by actively recruited MSCs from local environments as well as more distant anatomical sites $^{7}$.

As the understanding of the biology of MSCs grew, their attributes beyond stem cell regeneration and support became apparent. MSCs have been shown to produce an immune suppressive environment, in part, through the secretion of anti-inflammatory cytokines ${ }^{8}$. These attributes, in combination with their plasticity and ability to support hematopoietic stem and progenitor cells, led to investigations focused on potential application in MSC transplantation therapies. Edwin Horwitz was among the first to conceptualize this idea, pioneering the use of 
MSC transplantation for the treatment of osteogenesis imperfecta ${ }^{9}$. These initial successes led to the development of current MSC therapies utilized for the treatment of GVHD, and in preclinical animal models of systemic lupus erythematosus and rheumatoid arthritis ${ }^{10}$. These attributes of MSCs highlight their importance in vivo, as well as for use in cellular therapies. Collectively, these observations underpin the necessity to better understand the biology of these cells in a variety of contexts.

Previous studies in our laboratory have focused on MSCs and osteoblasts in their ability to support hematopoiesis following exposure to high dose chemotherapy regimens, such as those prior to bone marrow transplantation ${ }^{11,12}$. Patients who have undergone high dose chemotherapy treatment for bone marrow transplantation as well as the treatment of numerous malignancies have been shown to display hematopoietic cell deficits for years following treatment. For example, Corre et al. described deficiencies in $\mathrm{CD} 4^{+} \mathrm{T}$ cell counts in patients two years following myeloablative chemotherapy and allogenic HSC transplantation ${ }^{13}$. This observation suggests an inability of transplanted HSCs to adequately repopulate blood and lymphoid tissues, or sustained damage to the supportive bone marrow microenvironment as a consequence of chemotherapy treatment. The latter of these two possibilities has been previously investigated by our laboratory. For example, Clutter et al. showed the protein abundance of CXCL12 to be decreased by chemotherapy exposed bone marrow stromal cells, resulting in the reduced ability to chemoattract a murine pro-B cell line towards the supportive stromal monolayer ${ }^{14}$. Previous members of our laboratory have also shown that the expression of cytokines relevant to the regulation of hematopoietic support, such as interleukin-6, neurotrophins, and TGF- $\beta^{11,15,16}$ are dysregulated by the exposure of stromal components of the bone marrow microenvironment to chemotherapy. These observations illustrate the vulnerability of cells comprising this critical environment to damage that alters their ability to regulate hematopoiesis. The work described in this dissertation expands upon these observations, as 
well as looking more broadly into ways by which the function of bone marrow stromal cells is affected by chemotherapy beyond the realm of hematopoietic support.

As discussed in Chapter I, osteoblasts contribute to the support of hematopoietic cell development within the bone marrow niche. Rellick et al. evaluated the effects of chemotherapy on TGF- $\beta$ and interleukin- 6 expression by osteoblasts, showing increased and decreased expression, respectively, following exposure to a variety of chemotherapeutic agents ${ }^{11,15}$. The findings described in Chapter II of this dissertation further investigated the alteration of osteoblast cells by chemotherapy exposure, expanding observations to both hematopoietic support factors and effects on cellular plasticity. Utilizing murine pre-osteoblast cell lines at previously described states of differentiation ${ }^{17,18}$, we showed that chemotherapy induced reductions in the mRNA abundance of RUNX2 and SP7 (the gene that encodes osterix). Consistent with this observation, exposure of MC3T3E1 and 7F2 cell lines to VP16 or melphalan reduced osteogenic differentiation potential ${ }^{19}$. These results suggested a reduced ability of pre-osteoblasts to differentiate into a more mature osteogenic phenotype following chemotherapy exposure. A potential consequence of reduced osteogenic differentiation within the bone marrow would include a deficit in mature osteoblast cells, which has been shown by Ding and Morrison to regulate the proliferation and differentiation of common lymphoid progenitors $^{20}$. Bone is continually degraded by osteoclasts, then subsequently regenerated by osteoblasts in a process known as bone remodeling ${ }^{21}$. A deficiency in osteoblast progenitor differentiation could lead to an imbalance in the process, favoring bone degeneration and ultimately resulting in a reduced number of osteoblasts within the bone marrow microenvironment. Given the necessity of osteoblasts in the support of lymphoid progenitors, chemotherapy induced reduction in osteogenic differentiation could potentially account for lymphoid mediated immune deficits documented in patients who have received chemotherapy treatment. For example, Wiser et al. observed reduced immunoglobulin concentrations in 
women years after receiving chemotherapy treatment for breast cancer ${ }^{22}$. Chemotherapy induced deficits in osteogenesis could also have negative effects on the skeletal system. Reduced bone mineral density and increased fracture incidence are a common side effect of patients who have been treated with high doses of chemotherapy. For example, a study by Tillmann et al. described these deficiencies in children who had been treated with high dose chemotherapy for acute lymphoblastic leukemia ${ }^{23}$ and Hui et al. observed a similar phenomenon in women who had been previously treated for various gynecologic cancers ${ }^{24}$. More work needs to be done to understand the events that mediate chemotherapy induced deficiencies in osteogenesis in vivo, and how these can be altered to prevent such toxicities during chemotherapy treatment.

In addition to reduced osteogenic differentiation potential, observations discussed in Chapter II described deficiencies in the ability of osteoblasts to generate ECM and ECMassociated proteins that have been shown to regulate hematopoiesis ${ }^{19}$. We showed that in preosteoblast and differentiated osteoblast cells Col1a1 mRNA was decreased following exposure to chemotherapy ${ }^{19}$. Consistent with this decrease, visible deficits in endosteal ultrastructure were observed by scanning electron microscopy when evaluating femurs from mice treated with VP16 ${ }^{19}$. These results suggested that the ECM surrounding osteoblast cells is damaged following chemotherapy stress both in vitro and in vivo, a phenomenon that could have negative consequences for hematopoietic cell regulation. As discussed in Chapter I, various hematopoietic regulating molecules depend on ECM within the hematopoietic niche to regulate cytokine concentration gradients and promote the retention of necessary molecules near the niche. One such molecule is OPN, which we showed to also be reduced in pre-osteoblasts exposed to melphalan ${ }^{19}$. Interestingly, the promoter regions of Col1a1 and OPN both contain response elements for RUNX2, which we showed was decreased in both pre- and mature osteoblast cells ${ }^{19}$, suggesting that reduced RUNX2 expression following chemotherapy 
exposure could potentially mediate deficits in Col1a1 and OPN following chemotherapy exposure. More work needs to be done to determine whether actionable targets mediating RUNX2 abundance after chemotherapy exposure exist, and means by which they could be pharmacologically modulated to prevent chemotherapy induced alterations in osteoblast function following chemotherapy treatment in vivo. In addition to ECM related deficits, we showed that CXCL12 protein was reduced in both pre-osteoblasts and mature osteoblast cells following VP16 or melphalan exposure ${ }^{19}$. This is consistent with our previous observations in lesser differentiated bone marrow stromal cells ${ }^{14}$ as well as primary human osteoblasts ${ }^{11}$, highlighting the breadth of this response between varying stromal differentiation states and species models. CXCL12 has been shown to be vital to the support of hematopoietic cells within the bone marrow ${ }^{25}$, and chemotherapy-induced decreases in its expression could hamper hematopoietic regeneration following insult such as chemotherapy treatment. Liang et al. showed that co-transplantation of MSCs overexpressing CXCL12 with CD34 ${ }^{+}$cells after myeloablative chemotherapy promoted hematopoietic reconstitution in a murine transplant model $^{26}$. These results show the potential promise of MSC transplantation to promote hematopoietic regeneration following chemotherapy treatment.

Given the potential therapeutic applications of MSCs, including the promotion of hematopoietic regeneration as well as treating many other diseases (discussed in Chapter I), it is important to better understand their biology so they can be optimally utilized for transplantation therapies. In a recent clinical trial, MSC transplantation was utilized to treat osteogenesis imperfecta ${ }^{27}$ and only showed efficacy when $1 \times 10^{7}$ MSCs per kilogram were administered to patients. Similar cell numbers have been needed to treat GVHD and myocardial infarction ${ }^{10}$, displaying the difficulty in acquiring enough cells for human therapies. To isolate enough MSCs for use clinically, ex vivo expansion is required, highlighting the necessity of understanding how cells are altered during expansion and the consequences such expansion 
could have once cells are administered in vivo. In Chapter III, we evaluated phenotypical changes of MSCs following ex vivo expansion, as well as changes in the means by which they responded to DNA double strand break stress, using VP16 as a way of eliciting such damage.

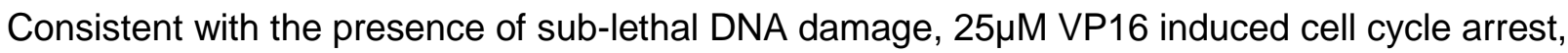
coincident with elevated $\mathrm{p} 21$ and $\mathrm{Y}-\mathrm{H} 2 \mathrm{AX}$, without eliciting overt cell death ${ }^{28}$. Although the cellular response and repair kinetics of DNA damage were consistent with passage, the means by which the cells repaired DNA was altered over time. VP16 reduced the mRNA and protein abundance of HR associated genes, consistent with functional repair along the HR pathway being reduced as evaluated by a plasmid based reporter assay ${ }^{28}$. Although gene expression for NHEJ associated proteins was not altered by passage or VP16 exposure, the ability of MSCs to enact NHEJ repair was reduced with passage in vitro ${ }^{28}$. These results illustrate the potential for extensively passaged MSCs to demonstrate impaired NHEJ in the context of genotoxic stress, a phenomenon that would not be desirable when transplanting cells into a human being. These findings indicate that MSCs should not be expanded extensively in vitro prior to patient administration. Efforts have been contributed towards the optimization of in vitro culture conditions during MSC expansion. For example, Doucet et al. have shown that human platelet lysate was favorable to fetal bovine serum for culture supplementation, resulting in increased MSC expansion potential ${ }^{29}$. Whether the addition of culture supplements can prevent culture associated phenotypic changes (such as in DNA repair capabilities) needs to be addressed further. Another approach to lessen culture associated changes in MSC phenotype would be optimizing MSC isolation techniques to maximize cellular yield. Starting with an increased number of MSCs would lessen the number of population doublings necessary to reach clinically relevant cell numbers for transplantation. An attractive means of achieving this goal would be to use adipose derived MSCs. The majority of clinical trials utilizing MSCs have used cells derived from the bone marrow due to the fact that they are very well characterized ${ }^{30}$. In addition, MSCs derived from adipose tissue have been shown to have a reduced differentiation potential 
towards the osteogenic linage ${ }^{31}$. Nevertheless, adipose derived MSCs are generally easier to acquire given the less invasive nature of their isolation (liposuction), and the willingness of patients to part with the specimen, providing an abundant source of MSCs for use in clinical therapies. The clinical potential of adipose derived MSCs needs to be better characterized in the context of transplantation to provide confidence towards their use in human therapies.

Findings outlined in Chapters II and III have described dysregulations of the beneficial and homeostatic functions of MSCs within our bodies following chemotherapy exposure. However, damaged MSCs can also elicit pathogenic effects in certain scenarios. A potential example of this phenomenon is described in Chapter IV, where Dkk-1, a negative regulator of certain tumor activities, is described to be elevated following chemotherapy exposure of MSCs in a p53 dependent manner. Through the binding to LRP5/6 co-receptors, Dkk-1 sterically hinders aggregation of the Wnt surface receptor complex, resulting in inhibition of downstream signaling $^{32}$. Dkk-1 overexpression has been documented in several types of cancer such as prostate $^{33}$, esophagea $\left.\right|^{34}$, myeloma ${ }^{35}$, and non-small cell lung cancers ${ }^{36}$. Over expression of Dkk-1 has had negative consequences on tumor phenotype in these diseases. For example, Thudi et al. showed that overexpression of Dkk-1 in prostate tumor cells led to increased tumor mass and metastasis in a murine model of prostate cancer ${ }^{37}$, and Nagato et al. showed that anti-Dkk-1 antibody treatment reduced invasiveness in vitro and tumor growth in a murine model of lung cancer ${ }^{38}$. Given observations of MSCs homing to the tumor microenvironment (discussed in Chapter I of this dissertation), our finding that the exposure of MSCs to various chemotherapeutics increases the expression of Dkk-1 shows the potential for chemotherapy treatment to result in increased abundance of Dkk-1 protein in the tumor microenvironment. In cancers which have been shown to be more aggressive in the presence of elevated Dkk-1 (such as prostate and lung), Dkk-1 could potentially be pharmacologically regulated to prevent this outcome. BHQ880, an anti-Dkk-1 neutralizing antibody described in the Discussion section of 
Chapter IV, has been used in clinical trials ${ }^{39}$; however, the necessity of intravenous administration and the costs inherent to antibody therapies could limit clinical use as well as patient access to the drug. While clinical trials regarding the application of anti-Dkk-1 therapies should continue, investigations into the clinical use of chemical inhibitors of Dkk-1 should also be explored. Pelletier et al. have developed a small molecule (WAY-262611) which inhibits Dkk1 mediated inhibition of Wnt signaling in vitro as well as in mice ${ }^{40}$, and future work should focus on determining the safety and efficacy of this compound in humans as well as developing other structures that elicit similar effects. As mentioned above, Dkk-1 has only shown a pathological role in certain tumors. Some cancers do not respond in this manner to Dkk-1, such as colorectal cancers, which are promoted by Wnt signaling. For example, Qi et al. showed that overexpression of Dkk-1 by colon cancer cells reduced tumor growth in a nude mouse model of colon cancer ${ }^{41}$, suggesting that elevated Dkk-1 in the tumor microenvironment could have positive impacts for patients with certain malignancies. This observation highlights the necessity to better understand how different tumors respond to Dkk-1. A better understanding of which cancers elicit aggressive or invasive phenotypes in the presence of Dkk-1 would help guide the design of clinical trials to pharmacologically target MSC derived Dkk-1 following chemotherapy treatment, thereby preventing effects of MSC derived Dkk-1 on tumor phenotype. Given the known overexpression of Dkk-1 in various cancers, the novelty of our findings lies in the observation that MSCs can also express this protein, and to a greater extent in the context of chemotherapy treatment. Future studies will need to be performed to determine whether Dkk-1 is elevated by MSCs within the tumor microenvironment in vivo and whether chemotherapy elicits the expression of other molecules derived from MSCs that could have negative outcomes in the tumors of patients undergoing cytotoxic cancer therapies.

In summary, the findings discussed in Chapters II through IV illustrate the dynamic and responsive nature of stromal cells of the bone marrow microenvironment to physiologic stimuli, 
including chemotherapy induced stress. MSCs and osteoblasts react to cellular stress in ways that can impact the health and homeostasis of various tissues within our bodies which regulate necessary functions such as hematopoiesis and bone development. The supportive nature of MSCs to various processes in vivo have prompted their use in transplantation, with their inclusion needing to be further optimized prior to a broader implementation clinically.

Specifically, an increased mechanistic understanding of how the properties of MSCs are altered during in vitro expansion needs to be obtained, for the practical purpose of efficient cell generation without negatively altering supportive MSC properties. Furthermore, MSCs have been shown to regulate the activity of malignant cells in vivo, a process that could be targeted pharmacologically. This process requires further investigation in various contexts, such as during chemotherapy treatment. Such an understanding could lead to new approaches to treat tumors, initiated by a hypothesis regarding the contribution of stromal cells to regulating tumor phenotype following chemotherapy treatment. More studies need to be performed to understand how chemotherapy induced stress alters the ability of bone marrow stromal cells to perform their homeostatic functions, and how these events can be modulated in a clinical setting.

\section{$\underline{\text { References }}$}

1. Friedenstein AJ, Gorskaja JF, Kulagina NN. Fibroblast precursors in normal and irradiated mouse hematopoietic organs. Exp. Hematol. 1976;4(5):267-274.

2. Friedenstein AJ, Chailakhyan RK, Gerasimov UV. Bone marrow osteogenic stem cells: in vitro cultivation and transplantation in diffusion chambers. Cell Tissue Kinet. 1987;20(3):263-272.

3. Allen TD, Dexter TM. Cellular interrelationships during in vitro granulopoiesis. Differ. Res. Biol. Divers. 1976;6(3):191-194.

4. Dexter TM, Allen TD, Lajtha LG. Conditions controlling the proliferation of haemopoietic stem cells in vitro. J. Cell. Physiol. 1977;91(3):335-344. 
5. Pittenger MF, Mackay AM, Beck SC, et al. Multilineage Potential of Adult Human Mesenchymal Stem Cells. Science. 1999;284(5411):143-147.

6. Paget S. The distribution of secondary growths in cancer of the breast. 1889. Cancer Metastasis Rev. 1989;8(2):98-101.

7. Berger L, Shamai Y, Skorecki K, Tzukerman M. Tumor Specific Recruitment and Reprogramming of Mesenchymal Stem Cells in Tumorigenesis. Stem Cells Dayt. Ohio. 2015;

8. Iyer SS, Rojas M. Anti-inflammatory effects of mesenchymal stem cells: novel concept for future therapies. Expert Opin. Biol. Ther. 2008;8(5):569-581.

9. Horwitz EM, Prockop DJ, Fitzpatrick LA, et al. Transplantability and therapeutic effects of bone marrow-derived mesenchymal cells in children with osteogenesis imperfecta. Nat. Med. 1999;5(3):309-313.

10. Glenn JD. Mesenchymal stem cells: Emerging mechanisms of immunomodulation and therapy. World J. Stem Cells. 2014;6(5):526.

11. Rellick SL, O'Leary H, Piktel D, et al. Bone marrow osteoblast damage by chemotherapeutic agents. PloS One. 2012;7(2):e30758.

12. Wang L, Clutter S, Benincosa J, Fortney J, Gibson LF. Activation of Transforming Growth Factor- $\beta 1 / p 38 / S m a d 3$ Signaling in Stromal Cells Requires Reactive Oxygen SpeciesMediated MMP-2 Activity During Bone Marrow Damage. STEM CELLS. 2005;23(8):11221134.

13. Corre $\mathrm{E}$, Carmagnat $\mathrm{M}$, Busson $\mathrm{M}$, et al. Long-term immune deficiency after allogeneic stem cell transplantation: B-cell deficiency is associated with late infections. Haematologica. 2010;95(6):1025-1029.

14. Clutter SD, Fortney J, Gibson LF. MMP-2 is required for bone marrow stromal cell support of pro-B-cell chemotaxis. Exp. Hematol. 2005;33(10):1192-1200.

15. Rellick SL, Piktel D, Walton $\mathrm{C}$, et al. Melphalan exposure induces an interleukin-6 deficit in bone marrow stromal cells and osteoblasts. Cytokine. 2012;58(2):245-252.

16. Rezaee F, Rellick SL, Piedimonte G, et al. Neurotrophins regulate bone marrow stromal cell IL-6 expression through the MAPK pathway. PloS One. 2010;5(3):e9690.

17. Quarles LD, Yohay DA, Lever LW, Caton R, Wenstrup RJ. Distinct proliferative and differentiated stages of murine MC3T3-E1 cells in culture: an in vitro model of osteoblast development. J. Bone Miner. Res. Off. J. Am. Soc. Bone Miner. Res. 1992;7(6):683-692.

18. Thompson DL, Lum KD, Nygaard SC, et al. The derivation and characterization of stromal cell lines from the bone marrow of p53-/- mice: new insights into osteoblast and adipocyte differentiation. J. Bone Miner. Res. Off. J. Am. Soc. Bone Miner. Res. 1998;13(2):195-204.

19. Gencheva M, Hare I, Kurian S, et al. Bone marrow osteoblast vulnerability to chemotherapy. Eur. J. Haematol. 2013;90(6):469-478. 
20. Ding L, Morrison SJ. Haematopoietic stem cells and early lymphoid progenitors occupy distinct bone marrow niches. Nature. 2013;495(7440):231-235.

21. Raggatt LJ, Partridge NC. Cellular and molecular mechanisms of bone remodeling. J. Biol. Chem. 2010;285(33):25103-25108.

22. Wiser I, Orr N, Kaufman B, et al. Immunosuppressive Treatments Reduce Long-Term Immunity to Smallpox among Patients with Breast Cancer. J. Infect. Dis. 2010;201(10):1527-1534.

23. Tillmann V, Darlington ASE, Eiser C, Bishop NJ, Davies HA. Male sex and low physical activity are associated with reduced spine bone mineral density in survivors of childhood acute lymphoblastic leukemia. J. Bone Miner. Res. Off. J. Am. Soc. Bone Miner. Res. 2002;17(6):1073-1080.

24. Hui SK, Khalil A, Zhang Y, et al. Longitudinal assessment of bone loss from diagnostic computed tomography scans in gynecologic cancer patients treated with chemotherapy and radiation. Am. J. Obstet. Gynecol. 2010;203(4):353.e1-7.

25. Karpova D, Bonig H. Concise Review: CXCR4/CXCL12 Signaling in Immature Hematopoiesis--Lessons From Pharmacological and Genetic Models. Stem Cells Dayt. Ohio. 2015;33(8):2391-2399.

26. Liang $X$, Su Y-P, Kong P-Y, et al. Human bone marrow mesenchymal stem cells expressing SDF-1 promote hematopoietic stem cell function of human mobilised peripheral blood CD34+ cells in vivo and in vitro. Int. J. Radiat. Biol. 2010;86(3):230-237.

27. Götherström C, Westgren M, Shaw SWS, et al. Pre- and postnatal transplantation of fetal mesenchymal stem cells in osteogenesis imperfecta: a two-center experience. Stem Cells Transl. Med. 2014;3(2):255-264.

28. Hare I, Gencheva M, Evans R, et al. In Vitro Expansion of Bone Marrow Derived Mesenchymal Stem Cells Alters DNA Double Strand Break Repair of Etoposide Induced DNA Damage. Stem Cells Int. 2016;2016:8270464.

29. Doucet C, Ernou I, Zhang Y, et al. Platelet lysates promote mesenchymal stem cell expansion: a safety substitute for animal serum in cell-based therapy applications. J. Cell. Physiol. 2005;205(2):228-236.

30. Ikebe C, Suzuki K. Mesenchymal stem cells for regenerative therapy: optimization of cell preparation protocols. BioMed Res. Int. 2014;2014:951512.

31. Li C, Wu X, Tong J, et al. Comparative analysis of human mesenchymal stem cells from bone marrow and adipose tissue under xeno-free conditions for cell therapy. Stem Cell Res. Ther. 2015;6:55.

32. Cruciat C-M, Niehrs C. Secreted and Transmembrane Wnt Inhibitors and Activators. Cold Spring Harb. Perspect. Biol. 2013;5(3):a015081.

33. Robinson DR, Zylstra CR, Williams BO. Wnt signaling and prostate cancer. Curr. Drug Targets. 2008;9(7):571-580. 
34. Li S, Qin X, Guo X, et al. Dickkopf-1 Is Oncogenic and Involved in Invasive Growth in Non Small Cell Lung Cancer. PLoS ONE. 2013;8(12):e84944.

35. Zhou F, Meng S, Song H, Claret FX. Dickkopf-1 is a key regulator of myeloma bone disease: opportunities and challenges for therapeutic intervention. Blood Rev. 2013;27(6):261-267.

36. Sheng SL, Huang G, Yu B, Qin WX. Clinical significance and prognostic value of serum Dickkopf-1 concentrations in patients with lung cancer. Clin. Chem. 2009;55(9):16561664.

37. Thudi NK, Martin CK, Murahari S, et al. Dickkopf-1 (DKK-1) stimulated prostate cancer growth and metastasis and inhibited bone formation in osteoblastic bone metastases. The Prostate. 2011;71(6):615-625.

38. Sato N, Yamabuki T, Takano A, et al. Wnt inhibitor Dickkopf-1 as a target for passive cancer immunotherapy. Cancer Res. 2010;70(13):5326-5336.

39. lyer SP, Beck JT, Stewart AK, et al. A Phase IB multicentre dose-determination study of BHQ880 in combination with anti-myeloma therapy and zoledronic acid in patients with relapsed or refractory multiple myeloma and prior skeletal-related events. Br. J. Haematol. 2014;167(3):366-375.

40. Pelletier JC, Lundquist JT, Gilbert AM, et al. (1-(4-(Naphthalen-2-yl)pyrimidin-2-yl)piperidin4-yl)methanamine: A Wingless $\beta$-Catenin Agonist That Increases Bone Formation Rate. J. Med. Chem. 2009;52(22):6962-6965.

41. Qi L, Sun B, Liu Z, et al. Dickkopf-1 inhibits epithelial-mesenchymal transition of colon cancer cells and contributes to colon cancer suppression. Cancer Sci. 2012;103(4):828835. 